Florida International University

FIU Digital Commons

FIU Electronic Theses and Dissertations

University Graduate School

$11-21-2014$

\title{
Investigating the Outcomes of a Physical Activity Program offered to Older Adults in South Florida and Understanding the Correlates of Completion
}

Anamica Batra

Florida International University, abatr001@fiu.edu

DOI: $10.25148 /$ etd.FI15032107

Follow this and additional works at: https://digitalcommons.fiu.edu/etd

Part of the Community Health and Preventive Medicine Commons

\section{Recommended Citation}

Batra, Anamica, "Investigating the Outcomes of a Physical Activity Program offered to Older Adults in South Florida and Understanding the Correlates of Completion" (2014). FIU Electronic Theses and Dissertations. 1928.

https://digitalcommons.fiu.edu/etd/1928 


\section{FLORIDA INTERNATIONAL UNIVERSITY \\ Miami, Florida}

\section{INVESTIGATING THE OUTCOMES OF A PHYSICAL ACTIVITY PROGRAM OFFERED TO OLDER ADULTS IN SOUTH FLORIDA AND UNDERSTANDING THE CORRELATES OF COMPLETION}

A dissertation submitted in partial fulfillment of the requirements for the degree of DOCTOR OF PHILOSOPHY in

PUBLIC HEALTH

by

Anamica Batra

2015 
To: Dean Michelle Ciccazzo

Robert Stempel College of Public Health and Social Work

This dissertation, written by Anamica Batra, and entitled Investigating the Outcomes of a Physical Activity Program Offered to Older Adults in South Florida and Understanding the Correlates of Completion, having been approved in respect to style and intellectual content, is referred to you for judgment.

We have read this dissertation and recommend that it be approved

Elena Bastida

H. Virginia McCoy

Hafiz Khan

Richard C. Palmer, Major Professor

Date of Defense: November 21, 2014

The dissertation of Anamica Batra is approved.

Dean Michelle Ciccazzo

Robert Stempel College of Public Health and Social Work

Dean Lakshmi N. Reddi

University Graduate School

Florida International University, 2015 
(C) Copyright 2015 by Anamica Batra

All rights reserved. 


\section{DEDICATION}

I dedicate this degree to my parents. I want to thank my mother the most who stood by me through thick and thin and for bearing all the hardships, so that I could be allowed to pursue my dream. Mom you were always there for me during my difficult times and encouraged me to never give up. Thank you, for believing in me and inculcating the importance of education in me. A very special thanks to my father, who worked very hard to provide me with everything I needed to be where I am today, and supported me

all these years. You both believed in me more than I believed in myself. I am blessed to have you as my parents. 


\section{ACKNOWLEDGMENTS}

I would like to express my sincere gratitude to the members of my committee for their support, patience, time, and perseverance. This would not have been possible without their knowledge and guidance. I would like to thank the Health Foundation of South Florida also for allowing me use the data collected through the Healthy Aging Regional Collaborative. In addition, I would like to thank all HARC agencies that implemented EF. I would also like to thank the members of the Local Evaluation Team for their support and guidance. My final year of support as a Dissertation Year Fellow was received from the University Graduate School, Florida International University. My deepest thanks to the guidance of the University Graduate School staff throughout my studies. 


\begin{abstract}
OF THE DISSERTATION
INVESTIGATING THE OUTCOMES OF A PHYSICAL ACTIVITY PROGRAM OFFERED TO OLDER ADULTS IN SOUTH FLORIDA AND UNDERSTANDING THE CORRELATES OF COMPLETION
\end{abstract}

by

Anamica Batra

Florida International University, 2015

Miami, Florida

Professor Richard C. Palmer, Major Professor

Despite the well-known benefits of physical activity, in 2012 , only $37.5 \%$ of older adults aged 60 years or older met recommended physical activity levels. Effective exercise programs can help combat the problem of inactivity but $50 \%$ of those who start participating in an exercise program dropout within first few weeks, preventing them from gaining health benefits. Since fall 2008, Healthy Aging Regional Collaborative of South Florida has offered EnhanceFitness (EF), an evidence-based physical activity program to older adults. This dissertation compared EF effectiveness at 4-,8-, and 12months and examined factors associated with program completion.

Between October 1, 2008 and December 31, 2012, 4,531 older adults ( $>=60$ years) attended at-least one EF session. Repeated measures design revealed significant improvement in the number of chair stands performed in 30-seconds with mean change of $1.7,1.6$, and 2.0 at $4-, 8$-, and 12-months $(p<0.001)$. The number of arm curls performed in 30-seconds improved by 1.9, 2.0, and 2.4 at 4-,8-, and 12-months. Participants improved their eight-foot up-and-go time by decreasing, on average, by 0.5 -seconds at 4- 
and 8 -months, and by 0.4 -seconds at 12 -months $(p<0.001)$. Of the total 702 men $31.3 \%$ and $24.2 \%$ of 3,829 women attended recommended 32 -sessions within first 4-months. Results suggested Black, non-Haitian men were less likely to complete the program when compared to white, non-Hispanic men $(\mathrm{OR}=0.41, p=0.02)$. Men who self-reported having at least one risk factor were more likely to complete the program $(\mathrm{OR}=1.81, p=0.03)$. In addition, women who lived in Miami-Dade County $(\mathrm{OR}=2.13, p<0.001)$ and were 80 years or older $(\mathrm{OR}=1.46, p<0.05)$ were more likely to complete the program. When compared with non-Hispanic whites, Black women were less likely to complete the program $(\mathrm{OR}=0.613, p<0.01)$. Women who did not report depression were 1.6 times more likely to complete the program $(\mathrm{OR}=1.62, p<0.05)$. Absence of risk factors for chronic conditions increased completion rates among women $(\mathrm{OR}=1.63, p<0.01)$.

Effectiveness results revealed that all participants significantly improved on all outcome measures. However, improvement is more than double for those who completed recommended sessions $(p<0.01)$. Study findings reaffirm the successful translation of EF in community-based settings. Our findings suggest that participants should attend the minimum recommended sessions to attain greater health benefits. 


\section{TABLE OF CONTENTS}

CHAPTER

PAGE

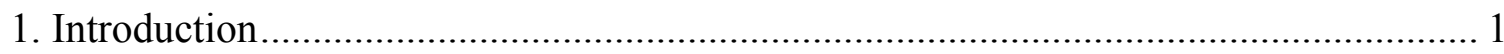

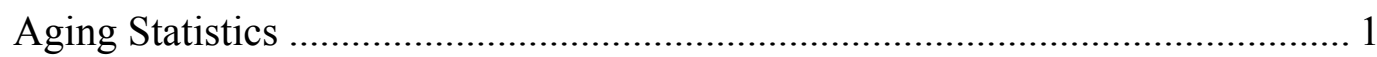

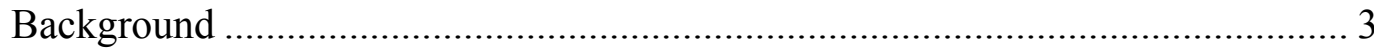

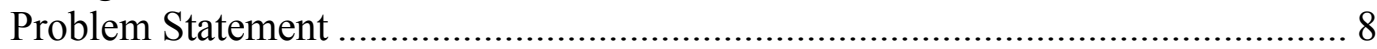

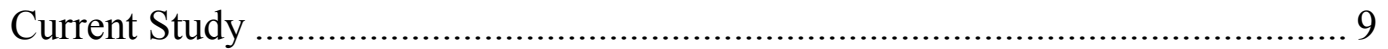

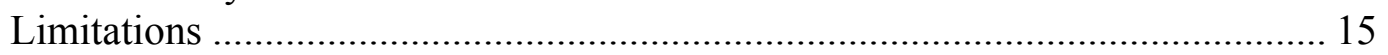

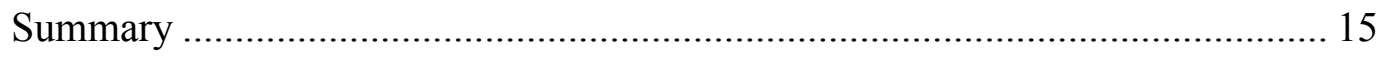

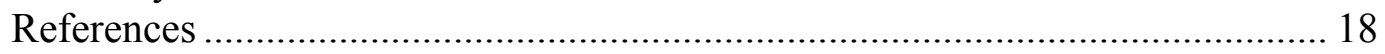

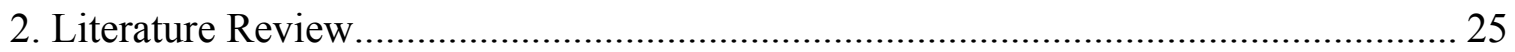

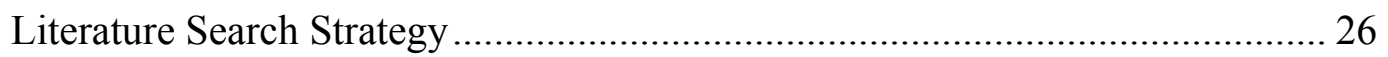

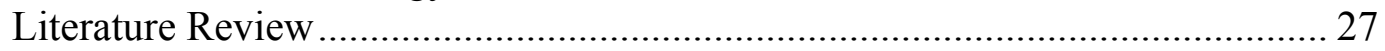

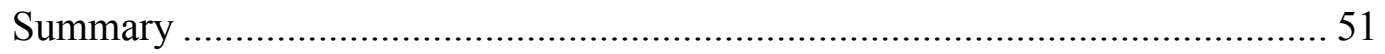

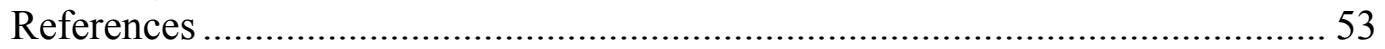

3. Manuscript Title: Are Group Exercise Programs Effective in Older Adults?

Determining the Effectiveness of a Community-Based Exercise Program

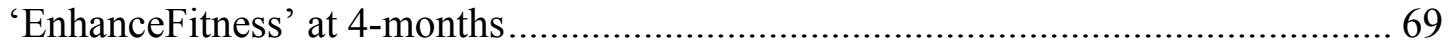

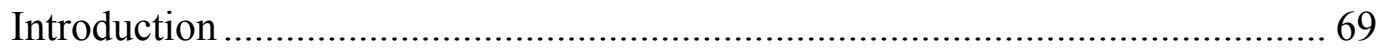

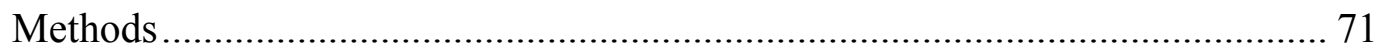

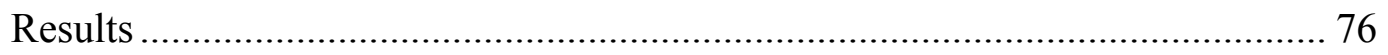

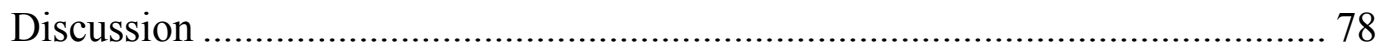

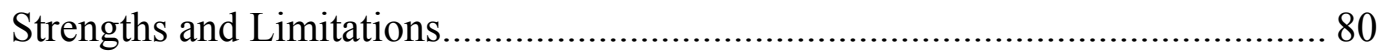

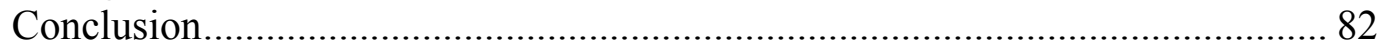

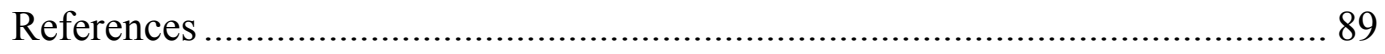

4. Manuscript Title: Determining the Long Term Effectiveness of a Group-Based

Exercise Program for Older Adults: EnhanceFitness …………………………........ 93

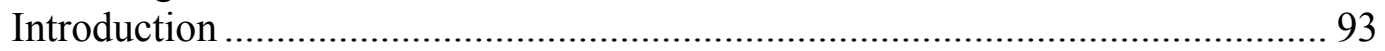

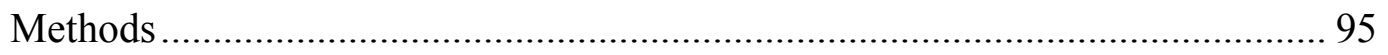

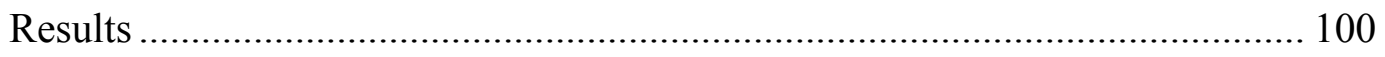

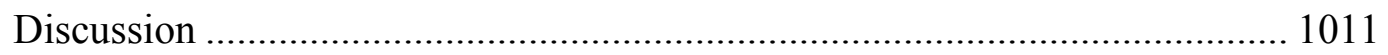

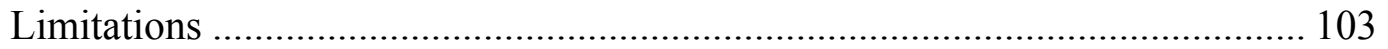

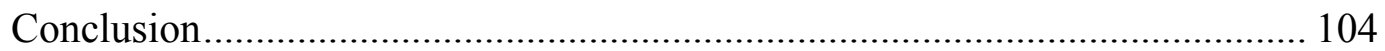

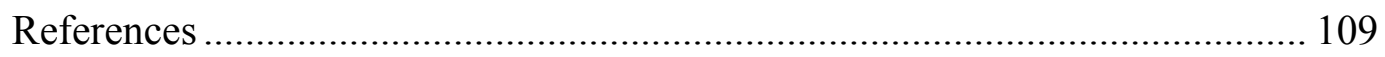

5. Manuscript Title: Physical Activity, Adherence, and Older Adults: Findings from a Community-Based Exercise Program in South Florida........................................... 113

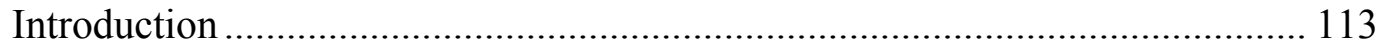

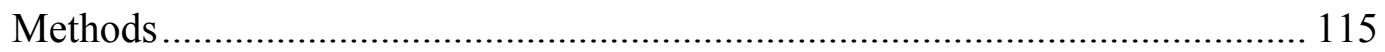

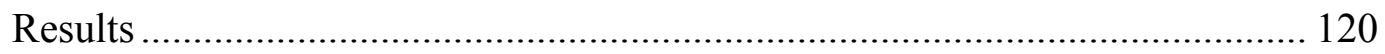




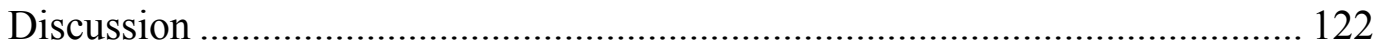

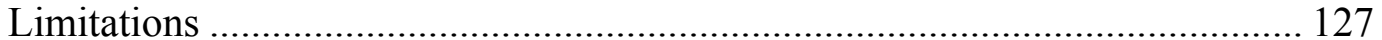

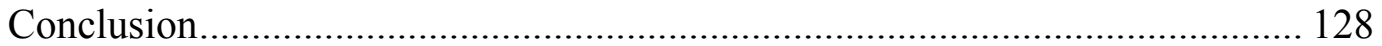

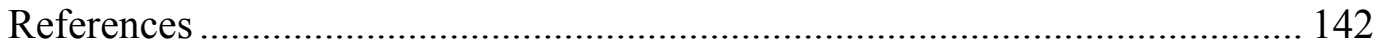

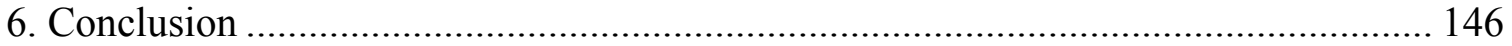

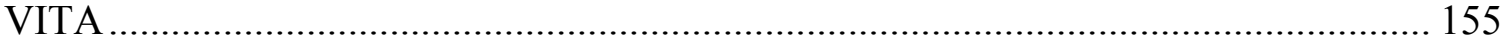




\section{LIST OF TABLES}

TABLE

PAGE

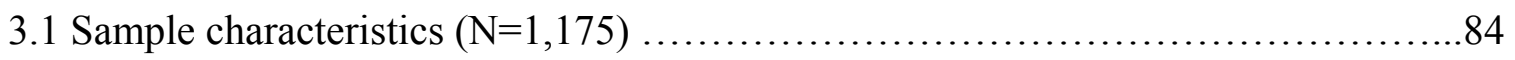

3.2 Independent $t$-test results to identify baseline group difference $(\mathrm{N}=1,175) \ldots \ldots \ldots . .86$

3.3 Change in Outcome Measures after Participating in EnhanceFitness for 4 months, Baseline to First Follow-up $(\bar{X} \pm \mathrm{SD})(\mathrm{N}=1,175)$.

3.4 Change in self-rated health status and reported number of falls after Participating in EnhanceFitness for 4 months, Baseline to First Follow-up (\%) 4.1 Sample

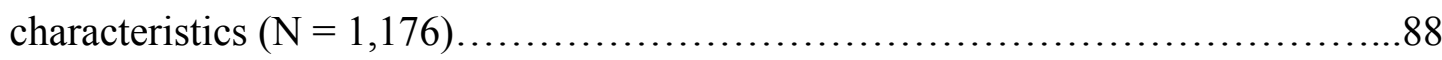

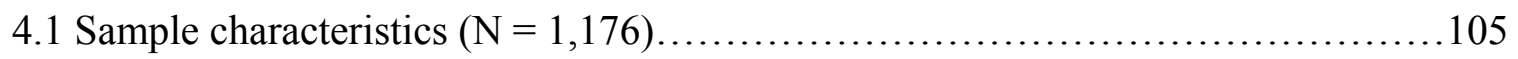

4.2 Change in Outcome Measures after Participating in EnhanceFitness for One Year: Baseline, 4-, 8-, 12-months $(\mathrm{N}=1,176)$.

4.3 Change in Health-Status and Number of Falls after Participating in EnhanceFitness for One Year: Baseline, 4-, 8-, 12-months ( $\mathrm{N}=1,176)$

5.1 Sample characteristics and Comparison of Older Men who attended $\geq 32$ sessions with those who attended $<32$ sessions within 4-months following their start date, $(\mathrm{n}=702)$.

5.2 Sample characteristics and Comparison of Older Women who attended $\geq 32$ sessions with those who attended $<32$ sessions within 4-months following their start date, $(n=3,829)$.

5.3 Logistic Regression model predicting factors influencing completion of older men, $(\mathrm{n}=534)$.

5.4 Logistic regression model predicting factors influencing completion of older women, $(\mathrm{n}=1,578)$. 


\section{CHAPTER1}

\section{Introduction}

\section{Aging Statistics}

Aging is an issue of utmost importance to public health professionals and policy makers (AARP Public Policy Institute, 2009; Garrett \& Martini, 2007; Joyce, Keeler, Shang, \& Goldman, 2005; Martini, Garrett, Lindquist, \& Isham, 2007; USDHHS:

Healthy People, 2014). According to U.S. Census Bureau, in 2012, the number of people over the age of 65 in the United States (U.S.) was 43.1 million and accounted for approximately $14 \%$ of total U.S. population (USDHHS, 2014a). This is an increase of $21 \%$ since 2002 (USDHHS, 2014a). Further, the number of people 65 years of age and older is expected to be 54.8 million in 2020 , an increase of $36 \%$ for the decade, and by 2040, it is expected to reach 81.2 million (Figure 1.1) (USDHHS, 2014b). According to Florida Department of Health, from 1970 to 2000 Florida's population has increased by $134.6 \%$ (Florida Department of Health, 2014b). In comparison to $14 \%$ of national estimates of 2012, the population over the age of 65 years in Florida is 3.5 million, representing $18 \%$ of Florida's total population, which is the highest concentration of older adults in the U.S. (Florida Department of Health, 2014b; U.S. Census Bureau, 2014; USDHHS, 2014a). Older adults are the fastest growing segment of this state due to aging baby boomers and migration (Florida Department of Health, 2014b). 
Figure 1.1 Number of older adults in United States, 65 years \& above, 1900-2060

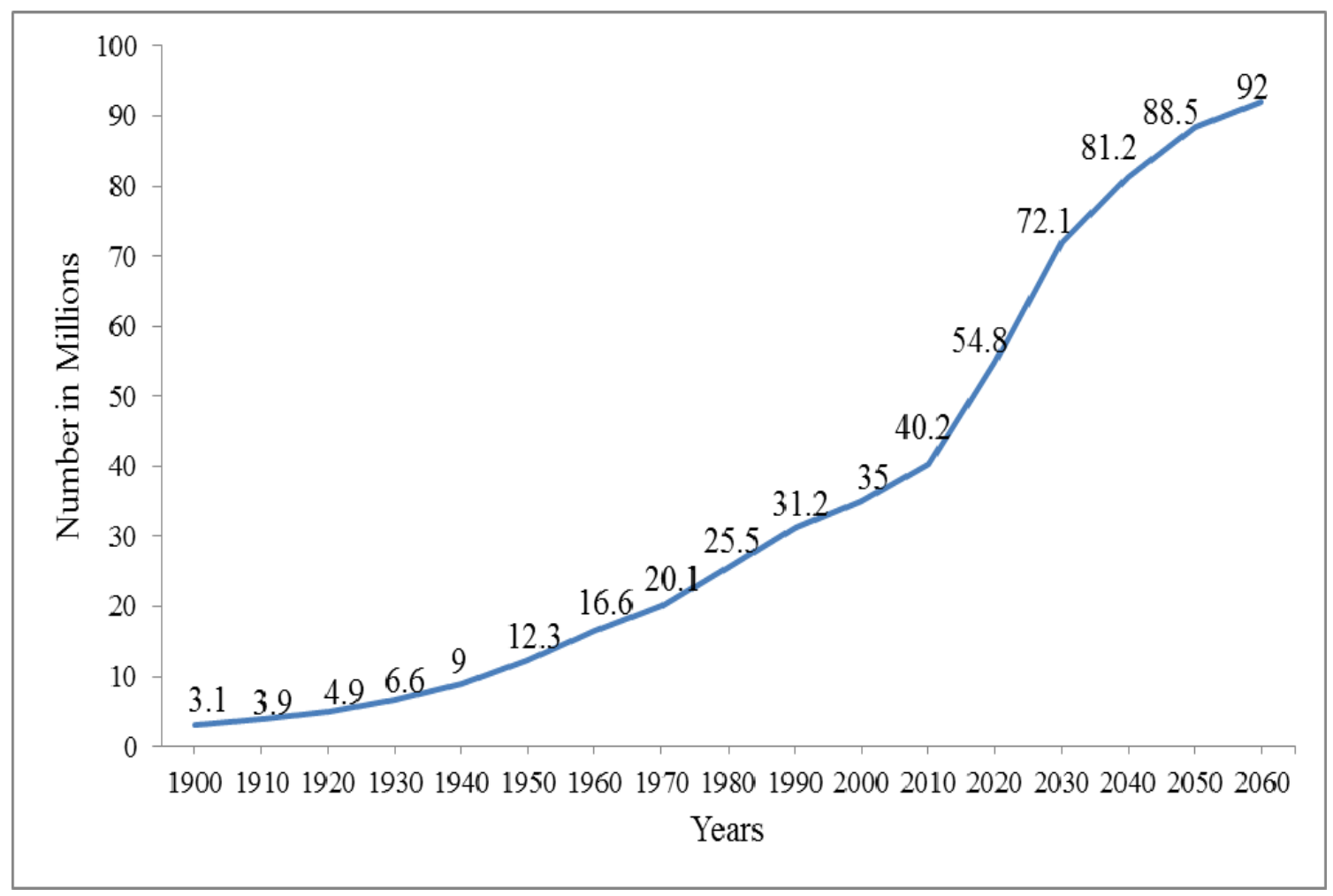

Source: Administration on Aging, U.S. Department of Health and Human Services (USDHHS, 2014b)

Not only is the U.S. aging, but it is also aging differently. Between 2012 and 2030, the 65 years and older non-Hispanic whites are expected to increase by $54 \%$ (USDHHS, 2014a). Hispanic older adults are expected to increase by $155 \%$ and nonHispanic African-Americans by 104\%. In 2012, the number of older women aged 65 years and above was 23.4 million in comparison to 18.8 million for older men, resulting in a sex ratio of 129 women for every 100 men. This ratio further increases to 200 women for every 100 men at ages 85 and older. Additionally, in comparison to men, women are expected to live approximately 3 years more (USDHHS, 2014a). 


\section{Background}

\section{Chronic Conditions and Aging: Prevalence, Morbidity, and Associated Cost}

Chronic conditions is an issue that is correlated with aging (AHRQ, 2002;

USDHHS: Healthy People, 2014). The prevalence of chronic conditions increases with age. Chronic conditions are the most common cause of death and disability among older adults (AHRQ, 2002; USDHHS: Healthy People, 2014). Approximately 92\% of older adults suffer from at least one chronic condition, and approximately $77 \%$ have at least two chronic conditions (National Council on Aging, 2014). Further, by 2049, the number of older adults suffering from disability due to chronic conditions such as arthritis, diabetes, coronary heart disease, cancer or cognitive impairment is expected to increase by at least $300 \%$ (AHRQ, 2002). Some of the common chronic conditions among older adults include diabetes, arthritis, cardiovascular disease, hypertension, chronic renal failure, osteoporosis, dementia, cancer, obesity, Alzheimer's, and macular degeneration (CDC, 2011d; USDHHS: Healthy People, 2014). Florida’s 2012 Behavioral Risk Factor Surveillance System (BRFSS) revealed that approximately 50\% of older adults suffer from some kind of arthritis, and 26\% have functional limitations due to it (Florida Department of Health, 2013a). In addition, approximately $20.5 \%$ of older adults reported some kind of cardiovascular disease, 58.2\% were diagnosed with high blood pressure, $21.2 \%$ reported diabetes, and $63.8 \%$ were either overweight or obese (Florida Department of Health, 2013a).

Chronic conditions affect overall quality of life of older adults and are associated with higher mortality, increased disability, and functional decline over time (CDC, 2013a; Maaten, Kephart, Kirkland, \& Andreou, 2008; National Council on Aging, 2014). 
Between 1999-2009, the top three causes of death among U.S. older adults were heart disease (30\%), cancer (24\%), and stroke (8\%) (Christ \& Diwan, 2008; National Center for Health Statistics, 2011). Together, these three causes accounted for $62 \%$ of all deaths in this age group (Christ \& Diwan, 2008; National Center for Health Statistics, 2011). Results from the Medicare Current Beneficiary Survey revealed that in both noninstitutionalized and institutionalized settings, in 2010, approximately $13 \%$ of older adults needed help bathing/showering, about $14 \%$ needed assistance in getting in and out of a chair/bed, and approximately $25 \%$ required assistance walking (CDC, 2013a). Research also suggests that if these needs of daily activities of older adults are left unmet, it may result in additional adverse effects such as depression or increased utilization of health care services (Choi \& McDougall, 2009; Desai, Lentzner, \& Weeks, 2001).

Chronic conditions not only place a burden on individual suffering, but also on an already fragmented health care system (Garrett \& Martini, 2007; Maaten et al., 2008). Utilization of medical services and associated cost is higher for older adults (Figure 1.2). The number of physician visits, hospital visits, and emergency room visits increases with the increase in the number of chronic conditions in older adults (Maaten et al., 2008; AARP Public Policy Institute, 2009). The costs associated with treating older adults with chronic conditions are high and continue to grow. This cost was projected to increase from $\$ 2,993$ in 2000 to $\$ 3,543$ in 2050, an approximate increase of $18 \%$ (Garrett \& Martini, 2007; Martini, Garrett, Lindquist, \& Isham, 2007). In addition, the total health care spending for an older adult with a chronic condition is about $\$ 1,000-\$ 2,000$ more per year in comparison to one without a condition (Joyce et al., 2005). Schneider, O'Donnell, and Dean (2009) reported that the annual Medicare payment amounts for a beneficiary 
with only one chronic condition is $\$ 7,172$. This amount increases to $\$ 14,931$ for those with two conditions and $\$ 32,498$ for those with three or more conditions (Schneider, O’Donnell, \& Dean, 2009). Further, as per AARP policy institute report, even after accounting for shorter life expectancy associated with multiple chronic conditions, the total spending for someone with three or more chronic conditions at age 65 is reported to be more than $\$ 41,000$ (AARP Public Policy Institute, 2009). The annual average expense of utilizing home health services under the age of 65 years is $\$ 3,342$ per person and increases to $\$ 6,041$ for 65 years and above. Approximately $60 \%$ of these costs are paid by Medicare (AHRQ, 2002).

Figure 1.2 Cost pattern for utilization of all medical services

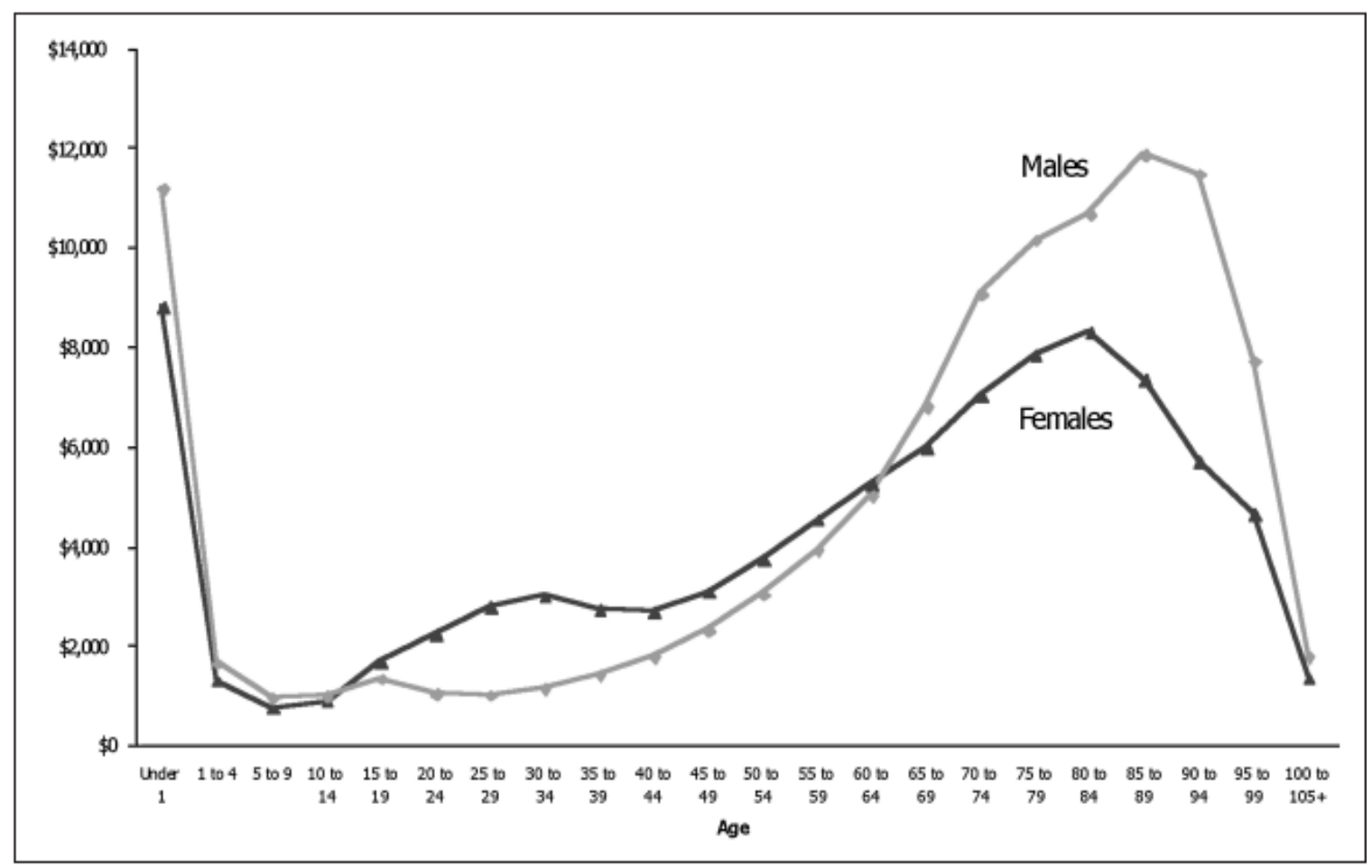

Source: HealthPartners medical and pharmacy claims 2002-2003 standardized to the U.S. 2001 Medical Expenditure Panel Survey per capita U.S. costs, in 2003 dollars (Garrett \& Martini, 2007). 


\section{Risk Factors for Chronic Conditions}

The most common identified risk factors for chronic conditions include unhealthy eating habits and lack of physical activity (Ford, Croft, Posner, Goodman, \& Giles, 2013). Consumption of diets rich in highly saturated fats and sugars and lack of physical activity result in obesity, which is a precursor for many other chronic conditions including diabetes mellitus (DM), hypertension, arthritis, stroke, cancer, respiratory problems, sleep apnea and many more (CDC, 2011d). In general, an adult with a Body Mass Index (BMI) between 25 and 29.9 is considered overweight and a BMI of 30 or higher is considered obese (CDC, 2012b). According to National Health and Nutrition Examination Survey (NHANES), during the period of 2007-2010 approximately $35 \%$ of older adults were obese (Fakhouri, Ogden, Carrol, Kit, \& Flegal, 2012). The major concern of health care providers is the increasing number of chronic conditions due to high prevalence of obesity among older adults. In the Nurses' Health Cohort Study, which followed a cohort of women for 14 years, BMI was found to be significant predictor of DM (Colditz, Willctt, Rotnitzky, \& Manson, 1995; Hu et al., 2001). Women with a BMI of 30 or higher had an age-adjusted relative risk of 40 to develop DM compared to women with a BMI lower than 22 (Colditz et al., 1995). In another prospective cohort study, men with a BMI of 30 or higher were seven times more likely to develop DM compared with men in normal weight range (Oguma, Sesso, Paffenbarger, \& Lee, 2005). Further, overweight individuals have 32\% and obese individuals have $81 \%$ higher risk of developing coronary heart disease (Bogers et 1., 
2007). The risk of ischemic stroke increases by $22 \%$ in overweight individuals and $64 \%$ in obese individuals (Strazzullo et al., 2010).

\section{Physical Activity Benefits and Recommendations}

Physical activity has been identified as one of three, key, modified health behaviors that can alter the course of many chronic diseases of aging (Dogra \& Stathokostas, 2012; Kravitz, 1996; Rogers \& Keller, 2009; USDHHS: Healthy People, 2014). The Centers for Disease Control and Prevention (CDC) recommends that older adults should engage in at least 150 minutes of moderate intensity exercise or 75 minutes of vigorous intensity exercise every week (CDC, 2011c). Following the guidelines reduces the risk of developing heart disease, stroke, DM, metabolic syndrome, and some cancers. It also improves the psychological state of individuals and reduces the risk of depression (CDC, 2011e). In addition, muscle strengthening exercises to work all major muscle groups including legs, hips, back, abdomen, chest, shoulders, and arms for two or more days a week helps preventing wasting of muscles and increases their strength (CDC, 2011c). It can also slow down the loss of bone density and prevents degeneration of joints (CDC, 2011f, 2011g; Barbara Resnick et al., 2014). In addition, balance and muscle strengthening exercises lowers the risk of falling in older adults and enhances their quality of life by allowing them to carry out their day-to-day activities easily and independently (CDC, 2011e). Following the guidelines also decreases chances of dependency on others later in life. To further lower the risk of developing chronic conditions, $\mathrm{CDC}$ recommends to increase physical activity. According to CDC, "older adults should increase their moderate-intensity aerobic physical activity to 300 minutes per week, or engage in 150 minutes of vigorous-intensity aerobic physical activity per 
week, or an equivalent combination of moderate-and vigorous-intensity activity " (CDC, 2011b; CDC, 2011c). In general, physical activity can help prevent or delay the onset of many physical and psychological conditions commonly occurring due to aging (Dogra \& Stathokostas, 2012; Kravitz, 1996; Rogers \& Keller, 2009; USDHHS: Healthy People, 2014). Additionally, physical activity allows effective management of stress, improves sleep and related disorders, enlightens mental outlook and therefore helps lowering depression and anxiety (Dogra \& Stathokostas, 2012; Kravitz, 1996; Rogers \& Keller, 2009; USDHHS: Healthy People, 2014).

\section{Problem Statement}

\section{Prevalence of Physical Inactivity and Morbidity due to Chronic Condition(s)}

Despite the known benefits of physical activity, $47 \%$ of older adults between 65 to 74 years old and $61 \%$ of those who are 75 years old and above reported not to engage in any kind of physical activity in 2005 (Rogers \& Keller, 2009; USDHHS: AHRQ, 2006). Fifty two percent of adults did not meet recommended physical activity levels in 2008 (CDC, 2012a). According to the BRFSS survey, in 2011, 45.6\% of older adults in Florida did not meet the recommended physical activity levels of 150 minutes or more (BRFSS: CDC, 2011a), and 78.1\% fail to meet the recommended guidelines for muscle strengthening exercises (BRFSS: CDC, 2011b). According to 2007 data from the Florida Department of Health, prevalence of sedentary behavior among older adults is highest in Miami-Dade County (44.6\%) in comparison to Florida as whole (30.9\%) and two neighboring counties: Broward (29.2\%) and Monroe (31.2\%) (Florida Department of Health, 2013c). Further, only 32.5\% of older adults in Florida met moderate physical activity recommendations in 2007 (Florida Department of Health, 2013d). This number is 
lowest for Miami-Dade County (19.8\%) followed by Broward County (28.2\%) and then Monroe County (34.0\%) (Florida Department of Health, 2013d). These percentages reduce further for older adults who met vigorous physical activity recommendations in 2007, Florida (14.0\%), Miami-Dade (11.2\%), Broward (8.3\%) and Monroe (21.6\%) (Florida Department of Health, 2013b).

\section{Current Study}

\section{Physical Activity Program for Older Adults in South Florida}

Florida has highest concentration of older adults, $18 \%$ (Florida Department of Health, 2014b; U.S. Census Bureau, 2014; USDHHS, 2014a). The changing demography, increased longevity, high prevalence rates of chronic conditions, and low levels of physical activity among older adults' in South Florida suggested the need for targeted physical activity interventions (AARP Public Policy Institute, 2009; Garrett \& Martini, 2007; Joyce et al., 2005; Martini et al., 2007; USDHHS: Healthy People, 2014). The Health Foundation of South Florida recognized the needs of this population and established the Healthy Aging Regional Collaborative (HARC) in 2008 to reduce/eliminate the burden of preventable diseases. HARC is a five-year initiative for delivering evidence-based health promotion programs in three southeast counties of South Florida: Miami-Dade, Broward, and Monroe. HARC offered four programs to older adults in year 1: EnhanceFitness (EF) (physical fitness program), Living Healthy/Tomando Control de su Salud/Diabetes Self-Management (LHP/TCDS/DSMP) (chronic disease self-management program), Matter of Balance/Asunto de Equilibrio (MOB/ADE) (fall prevention program), and Healthy Ideas (HI) (depression management program). 


\section{Nature and Purpose of the Study}

EnhanceFitness (EF) is a low-cost, multicomponent, evidence-based physical activity program for older adults (Belza, Susan, Meghan, \& James, 2010; Senior Services, 2013). EF, formerly known as 'Lifetime Fitness', was developed, tested, and found efficacious in 1998 (Belza et al., 2010; Moore-Harrison, Johnson, Quinn, \& Cress, 2009; Wallace et al., 1998). The original EF program was conducted for six months in a controlled environment (Wallace et al., 1998). It consists of a one-hour session held three times a week. EF focuses on stretching, flexibility, balance, low impact aerobics, and strength training exercises. This exercise program helps older adults at all levels of fitness become more active, energized, and empowered to sustain independent lives (Belza et al., 2010; Moore-Harrison et al., 2009; Wallace et al., 1998). HARC offered EF on an ongoing basis, with a class structure and material similar to the original EF program. However, program participation was voluntary and implemented by community-based agencies in real world settings of South Florida. The majority of agencies chose adult day care centers, senior centers, clinics, hospitals, skilled nursing facilities, assisted living facilities, community centers, or senior housings as sites for program delivery. Certified instructors trained by EF developers led classes.

Randomized controlled trials are commonly used to determine the efficacy of an intervention (Kelsey, Whitemore, Evans, \& Thompson, 1996; Shadish, Cook, \& Campbell, 2001; Stolberg, Norman, \& Trop, 2004), but effective strategies found to improve health of individuals are seldom disseminated to the broader community (Belza

et al., 2010; Kessler \& Glasgow, 2011). Although EF was found efficacious in controlled settings (Belza et al., 2010; Moore-Harrison et al., 2009; Wallace et al., 1998), there is a 
lack of literature that examines the impact of group exercise program in communitybased settings (Belza et al., 2006). This study aimed to fill an existing gap in literature by analyzing four-years of data $(10 / 01 / 2008-12 / 31 / 2012)$ collected from the EF program offered as part of the HARC in community-based settings. Analyzing the outcome data will establish evidence in support of a successful translation of EF in community-based settings. If found effective, the model used by the HARC could be replicated by other communities that identify a need for physical activity programs for older adults to improve their quality of life and to reduce the burden on the health care system.

An additional aim of this study was to identify factors that might provide insight into why certain individuals complete or do not complete physical activity programs. Program completion and adherence are important determinants of positive outcomes (Allen \& Morey, 2010; Hughes, Seymour, Campbell, Whitelaw, \& Bazzarre, 2009; Moore, Moore, \& Murphy, 2011; White, Ransdell, Vener, \& Flohr, 2005). Lack of literature available on predictors of attrition in physical activity programs provides an opportunity for this study to present findings that may provide insight on factors that affect completion and result in high program attrition rates. Identifying these factors may further help to identify strategies for motivating participants to complete the program (Allen \& Morey, 2010; Hughes et al., 2009; Moore et al., 2011; B Resnick \& Spellbring, 2000; White et al., 2005), resulting in lower program attrition rates, which would improve the effectiveness of the program and reduce its unit cost (Page, Batra, \& Palmer, 2012). In addition, this study also aimed to determine the demographic and health characteristics of participants who voluntarily participated in EF. The information gained can be utilized in making decisions about the need of additional promotional channels 
using instituting techniques or repositioning existing ones, and developing marketing strategies that allow for the engagement of more participants that could benefit from the available programs.

The following aims and hypothesis will be tested in this study:

Aim 1: To determine the short-term effectiveness of EF intervention: Baseline to first follow-up (4 months)

$\mathrm{H}_{\mathrm{o}}$ : As a result of EF program, there is no change in the physical activity levels of participants from baseline to first follow-up.

$\mathrm{H}_{\mathrm{A}}$ : As a result of EF program, there is an increase in the physical activity levels of participants from baseline to first follow-up.

Aim 2: To determine the long-term effectiveness of EF intervention: From Baseline to first (4-months), second (8-months) and third (12-months) follow-up

$\mathrm{H}_{\mathrm{o}}$ : As a result of continued attendance in EF program, there is no change in the physical activity levels of participants over time.

$\mathrm{H}_{\mathrm{A}}$ : As a result of continued attendance in EF program, there is an increase in physical activity levels of participants over time.

Aim 3: To determine factors that affect the program completion.

$\mathrm{H}_{\mathrm{o}}$ Socio-demographic factors, number of chronic conditions, risk factors, and other health indicators are not associated with program completion.

$\mathrm{H}_{\mathrm{A}}$ : Socio-demographic factors, number of chronic conditions, risk factors, and other health indicators are associated with program completion. 


\section{Theoretical Perspective}

Given the heuristic value of theoretical models in developing effective prevention procedures, the Health Belief Model (HBM) and Social Cognitive Theory (SCT) guided the design of this study. Hochbaum and Rosenstock developed HBM in the 1950s (Glanz, Rimer, \& Viswanath, 2008; USDHHS: National Cancer Institute, 2005). Constructs of HBM enable understanding failure of people to participate in readily available prevention programs such as EF in this study. HBM is based on value-expectancy. It also emphasizes the role of subjective hypotheses and expectations held by individuals. Perceived susceptibility, perceived severity, perceived benefits, perceived barriers, and cues to action are the key constructs of HBM (Glanz et al., 2008; USDHHS: National Cancer Institute, 2005). Perceived susceptibility refers to beliefs about the likelihood of getting a disease. Perceived severity is the belief about the seriousness of the disease. The combination of susceptibility and severity is labeled as perceived threat. Perceived benefit is the belief that taking an action will reduce susceptibility to the condition or its severity. Perceived barriers include potential negative aspects of a behavior and cues to action includes factors that activate readiness to change (Glanz et al., 2008; USDHHS: National Cancer Institute, 2005). According to HBM, for a behavior to change people must feel threatened by their current behavior (perceived threat) and believe that change of a specific kind will result in a valued outcome (perceived benefit) at an acceptable cost (perceived barrier) (Glanz et al., 2008; USDHHS: National Cancer Institute, 2005).

Social Cognitive Theory (SCT), proposed by Bandura, is based on the concept of reciprocal determinism and is often used to understand the behavior of individuals (Bandura, 1977; Bandura, 1997; Glanz et al., 2008; USDHHS: National Cancer Institute, 
2005). Concepts of SCT can be broadly grouped into 5 categories: (i) psychological determinants of behavior, (ii) observational learning, (iii) environmental determinants of behavior, (iv) self-regulation, and (v) moral disengagement (Bandura, 1977a, 1997; Glanz et al., 2008; USDHHS: National Cancer Institute, 2005). A number of individuallevel psychological determinants of behavior identified in SCT include outcome expectations, self-efficacy, and collective efficacy. SCT is most widely known for the concept of self-efficacy. It refers to a person's confidence in their ability to perform a certain behavior (Bandura, 1977a, 1997). Motivation is determined by outcome expectations and environmental determinants of behavior. According to SCT, human beings learn behavior by observing others (observational learning). Attention towards a behavior, cognitive retention of the behavior, performance of the modeled behavior, and motivation to reproduce the behavior are four processes that govern observational learning and hence influence behavior (Bandura, 1977a, 1997; Glanz et al., 2008; USDHHS: National Cancer Institute, 2005).

Figure 1.3 presents the conceptual framework for this study. The main aim of EF is to improve physical activity among older adults. Self-efficacy, perceived susceptibility, and perceived benefits serve as mediators for improved physical activity. The concepts of perceived susceptibility and perceived benefits are guided by HBM (Glanz et al., 2008; USDHHS: National Cancer Institute, 2005). Self-efficacy, defined as confidence in one's own ability to perform physical activity, is guided by SCT (Bandura, 1977a, 1997; Glanz et al., 2008; USDHHS: National Cancer Institute, 2005). Motivation, which is also based on SCT, is moderated by demographic factors and health conditions. Self-efficacy, perceived susceptibility, perceived benefits, demographic variables, and health status of 
individual directly influences one's ability to improve physical activity. In addition, they also influence one's ability to improve physical activity via motivation (E. Anderson, Wojcik, Winett, \& Williams, 2006; Kaiser, Brown, \& Baumann, 2010; McAuley \& Blissmer, 2000).

\section{Limitations}

There are certain limitations of this study that should be acknowledged. The study findings have limited generalizability since findings are for programs offered in South Florida. Further, since the evaluation design had no control group, the participant results may reflect other treatments or history events. However, this is unlikely since all the agencies that were offering physical activity program for study participants prior to the establishment of HARC collaborated with HARC. Therefore, study participants solely attended HARC programs only. Additionally, participants were not randomly selected but rather volunteered because they thought they might benefit from the program. Therefore, selection bias may create a positive skew in the results. Further, the use of convenience sampling limits the generalization of results. Moreover, all data collected were selfreported and therefore subject to response and social desirability biases.

\section{Summary}

The number of older adults in the United States and Florida is increasing (Florida Department of Health, 2014b; USDHHS, 2012, 2013a). Older adults are vulnerable and bear a greater burden of chronic conditions (AHRQ, 2002; CDC, 2011d; Florida Department of Health, 2014a; USDHHS: Healthy People, 2014). Physical activity produces multiple health benefits for older adults (CDC, 2011c, 2011e; Dogra \& Stathokostas, 2012; Kravitz, 1996; Rogers \& Keller, 2009; USDHHS: Healthy People, 
2014). However, the rates of older adults that follow CDC's recommended guidelines for physical activity and muscle strengthening exercises are very low (CDC, 2011c, 2011e). Programs aimed at increasing physical activity levels among older adults have been designed and evaluated to determine program efficacy/effectiveness (Barnett, 2003; Kolbe-Alexander, Lambert, \& Charlton, 2006; White et al., 2005). One physical activity program that has been found to be efficacious in older adults is EF (Belza et al., 2010; Moore-Harrison et al., 2009; Wallace et al., 1998). The increasing numbers of older adults, low rates of physical activity, chronic conditions, and associated comorbidity that increase with age demonstrate clear need for wider dissemination of evidence-based programs such as EF. HARC was established by the Health Foundation of South Florida in 2008 to make evidence-based programs such as EF, LHP, MOB, and HI available to older adults in three southeast counties of South Florida: Miami-Dade, Broward, and Monroe Counties. Little is known about the effectiveness of these programs (Batra, Melchior, Seff, Frederick, \& Palmer, 2012; Belza et al., 2006; Ory et al., 2013, 2014). This study focused on EF, one of the several programs offered by HARC. This study aimed to describe the demographic and health characteristics of study participants, and address the existing gap in literature regarding effectiveness of EF and identified factors associated with the completion of EF. 
Figure 1.3 Conceptual Framework

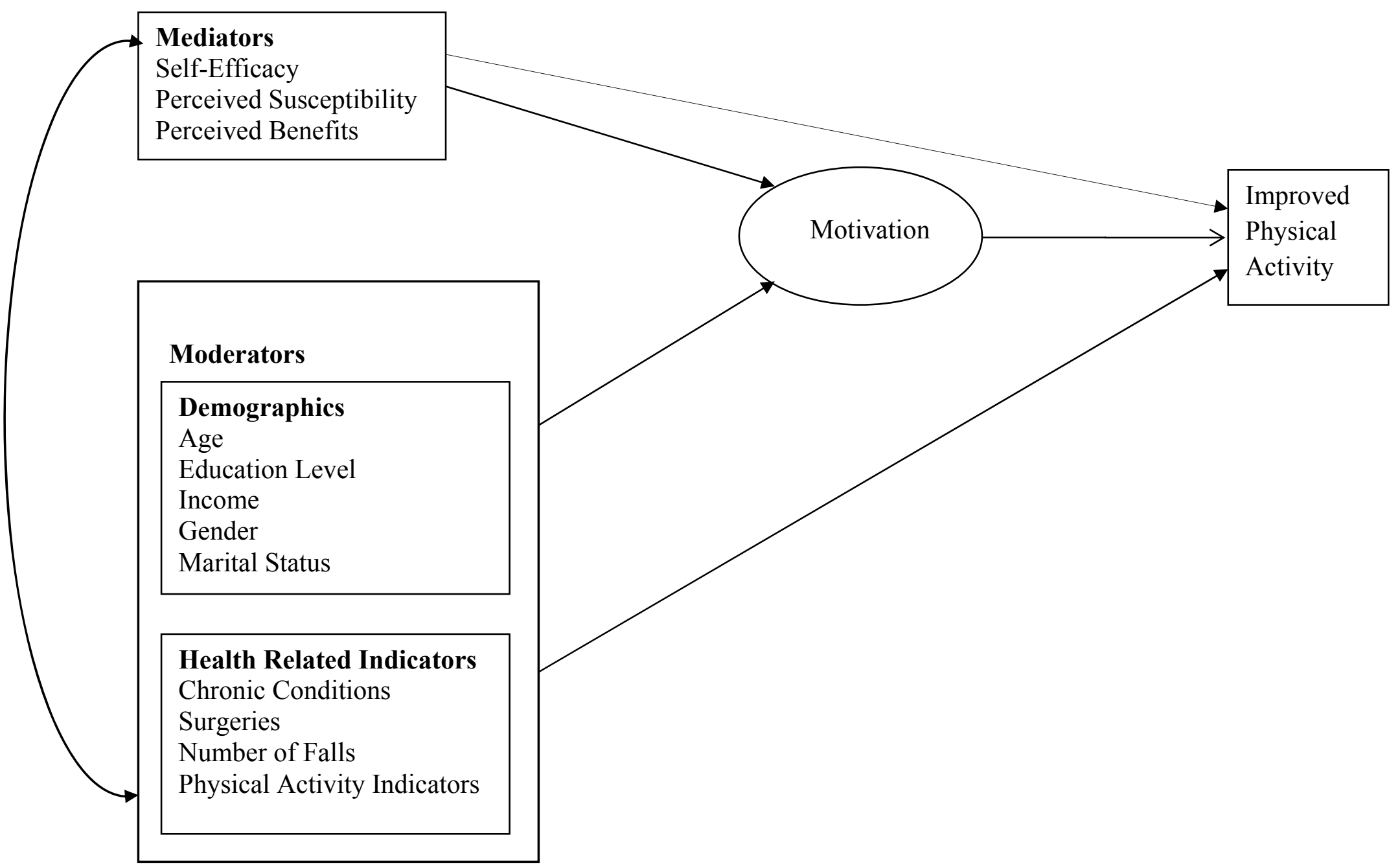




\section{References}

AARP Public Policy Institute. (2009). Chronic Care : A Call to Action for Health Reform (Vol. 9, pp. 1-116). Retrieved from http://assets.aarp.org/rgcenter/health/beyond_50_hcr.pdf

AHRQ. (2002). Preventing Disability in the Elderly With Chronic Disease. Retrieved September 06, 2014, from http://www.ahrq.gov/legacy/research/elderdis.htm

Allen, K., \& Morey, M. C. (2010). Physical Activity and Adherence. In Improving Patient Treatment Adherence. New York, NY: Springer.

Anderson, E., Wojcik, J., Winett, R., \& Williams, D. (2006). Social-cognitive determinants of physical activity: the influence of social support, self-efficacy, outcome expectations, and self-regulation among participants in a church-based health promotion study. Health Psychology, 25(4), 510-20.

Bandura, A. (1977). Self-efficacy: toward a unifying theory of behavioral change. Psychological Review, 84(2), 191-215.

Bandura, A. (1997). Self-Efficacy: The Exercise of Control (1st ed.). New York, NY: W.H. Freeman \& Company.

Barnett, A. (2003). Community-based group exercise improves balance and reduces falls in at-risk older people: a randomised controlled trial. Age and Ageing, 32(4), 407414.

Batra, A., Melchior, M., Seff, L., Frederick, N., \& Palmer, R. C. (2012). Evaluation of a community-based falls prevention program in South Florida, 2008-2009. Preventing Chronic Disease, 9, E13. Retrieved from http://www.cdc.gov/pcd/issues/2012/11_0057.htm

Belza, B., Shumway-Cook, A., Phelan, E., Williams, B., Snyder, S., \& LoGerfo, J. (2006). The Effects of a Community-Based Exercise Program on Function and Health in Older Adults: The EnhanceFitness Program. Journal of Applied Gerontology, 25(4), 291-306. doi:10.1177/0733464806290934

Belza, B., Susan, S., Meghan, T., \& James, L. (2010). From Research to Practice: EnhanceFitness, an Innovative Community-Based Senior Exercise Program. Topics in Geriatric Rehabilitation, 26(4), 299-309.

Bogers, R. P., Bemelmans, W. J., Hoogenveen, R. T., Boshuizen, H. C., Woodward, M., Knekt, P., ... Shipley, M. J. (2007). Association of overweight with increased risk of coronary heart disease partly independent of blood pressure and cholesterol levels: a 
meta-analysis of 21 cohort studies including more than 300000 persons. Archives of Internal Medicine, 167(16), 1720-8.

BRFSS: CDC. (2011a). BRFSS Prevalence Data Physical Activity "Participated in 150 minutes or more of Aerobic Physical Activity per week" : Florida 2011. Retrieved September 29, 2014, from http://apps.nccd.cdc.gov/BRFSS/age.asp?cat=PA\&yr=2011\&qkey=8271\&state=FL

BRFSS: CDC. (2011b). BRFSS Prevalence Data: Participated Muscle Strengthing exercises more than twice per week. Retrieved September 29, 2014, from http://apps.nccd.cdc.gov/BRFSS/age.asp?cat=PA\&yr=2011\&qkey=8281\&state=FL

CDC. (2011a). How much physical activity do older adults need? Retrieved September 09, 2014, from http://www.cdc.gov/physicalactivity/everyone/guidelines/olderadults.html

CDC. (2011b). Obesity: Halting the epidemic by making health easier. Retrieved from http://www.cdc.gov/chronicdisease/resources/publications/aag/pdf/2011/Obesity_A AG_WEB_508.pdf

CDC. (2011c). Physical Activity for Everyone: The Benefits of Physical Activity. Retrieved September 29, 2014, from http://www.cdc.gov/physicalactivity/everyone/health/index.html\#ReduceCardiovasc ularDisease

CDC. (2011d). Physical Activity for Everyone: The Benefits of Physical Activity | DNPAO $\mid$ CDC. Retrieved September 10, 2014, from http://www.cdc.gov/physicalactivity/everyone/health/

CDC. (2011e). Physical Activity: Strength Training for Older Adults: Why strength training? Retrieved October 02, 2014, from http://www.ncoa.org/improvehealth/center-for-healthy-aging/contentlibrary/PAPrograms_RecruitRetainInstructors.pdf

CDC. (2012a). CDC - Facts - Data - Physical Activity. Retrieved September 29, 2014, from http://www.cdc.gov/physicalactivity/data/facts.html

CDC. (2012b). Overweight and Obesity. Retrieved September 29, 2014, from http://www.cdc.gov/obesity/adult/defining.html

CDC. (2013). Difficulty performing activities of daily living among Medicare beneficiaries, ages 65+: US, 1992-2010 (Source: MCBS). Retrieved September 19, 2014, from http://205.207.175.93/HDI/TableViewer/tableView.aspx?ReportId=522 
Choi, N. G., \& McDougall, G. (2009). Unmet needs and depressive symptoms among low--income older adults. Journal of Gerontological Social Work, 52(6), 567-83. doi: $10.1080 / 01634370802609270$

Christ, G., \& Diwan, S. (2008). Chronic Illnesses and Aging. Council on Social Work Education, Section 1 (pp. 1-14). Retrieved from http://www.cswe.org/File.aspx?id=25462

Colditz, G. A., Willctt, W. C., Rotnitzky, A., \& Manson, J. E. (1995). Weight Gain as a Risk Factor for Clinical Diabetes Mellitus in Women. Annals of Internal Medicine, 122(7), 481-486.

Desai, M., Lentzner, H., \& Weeks, J. (2001). Unmet need for personal assistance with activities of daily living among older adults. The Gerontologist, 41(1), 82-8.

Dogra, S., \& Stathokostas, L. (2012). Sedentary behavior and physical activity are independent predictors of successful aging in middle-aged and older adults. Journal of Aging Research, 2012. Retrieved from http://www.hindawi.com/journals/jar/2012/190654/

Fakhouri, T. H., Ogden, C. L., Carrol, M. D., Kit, B. K., \& Flegal, K. M. (2012). Prevalence of Obesity Among Older Adults in the. CDC, NCHS Data Brief, 106(September 2012). Retrieved from http://www.cdc.gov/nchs/data/databriefs/db106.htm\#ref6

Florida Department of Health. (2013a). Florida Behavioral Risk Factor Surveillance System (BRFSS) 2012 Surveillance Data (p. 51). Retrieved from http://www.floridahealth.gov/statistics-and-data/survey-data/behavioral-risk-factorsurveillance-system/reports/_documents/2012-brfss.pdf

Florida Department of Health. (2013b). Florida CHARTS BRFSS Data: Adults who meet vigorous physical activity recommendation. Retrieved September 27, 2014, from http://www.floridacharts.com/charts/Brfss.aspx

Florida Department of Health. (2013c). Florida Charts BRFSS Indicators: Adults who are sedentary. Retrieved September 27, 2014, from http://www.floridacharts.com/charts/Brfss/DataViewer.aspx?bid=81

Florida Department of Health. (2013d). Florida Charts BRFSS Indicators: Adults who meet moderate physical activity recommendations. Retrieved September 27, 2014, from http://www.floridacharts.com/charts/Brfss/DataViewer.aspx?bid=3

Florida Department of Health. (2014a). 2010 Florida Behavioral Risk Factor Surveillance System (BRFSS) Data Report. Retrieved from http://www.doh.state.fl.us/Disease_ctrl/epi/brfss/2011databook.pdf 
Florida Department of Health. (2014b). Florida's Population. Retrieved October 02, 2014, from http://www.floridacharts.com/charts/AtlasIntro.aspx?ID=3

Ford, E. S., Croft, J. B., Posner, S. F., Goodman, R. a, \& Giles, W. H. (2013). Cooccurrence of leading lifestyle-related chronic conditions among adults in the United States, 2002-2009. Preventing Chronic Disease, 10(1), E60.

doi: $10.5888 / \mathrm{pcd} 10.120316$

Garrett, N., \& Martini, E. M. (2007). The boomers are coming: a total cost of care model of the impact of population aging on the cost of chronic conditions in the United States. Disease Management, 10(2), 51-60. doi:10.1089/dis.2006.630

Glanz, K., Rimer, B. K., \& Viswanath, K. (2008). Health Behavior and Health Education: Theory, Research, and Practice (4th ed.). San Francisco, CA: JosseyBass.

Hu, F. B., Manson, J. E., Stampfer, M. J., Colditz, G., Liu, S., Solomon, C. G., \& Willett, W. C. (2001). Diet, lifestyle, and the risk of type 2 diabetes mellitus in women. The New England Journal of Medicine, 345(11), 790-797.

Hughes, S. L., Seymour, R. B., Campbell, R. T., Whitelaw, N., \& Bazzarre, T. (2009). Best-practice physical activity programs for older adults: findings from the national impact study. American Journal of Public Health, 99(2), 362-8. doi:10.2105/AJPH.2007.131466

Joyce, G. F., Keeler, E. B., Shang, B., \& Goldman, D. P. (2005). The Lifetime BurdenOf Chronic Disease Among The Elderly. Health Affairs, 24(Suppl 2), W5R18-29. doi:10.1377/hlthaff.W5.R18

Kaiser, B. L., Brown, R. L., \& Baumann, L. C. (2010). Perceived influences on physical activity and diet in low-income adults from two rural counties. Nursing Research, 59(1), 67-75. doi:10.1097/NNR.0b013e3181c3bd55

Kelsey, J., Whitemore, A., Evans, A., \& Thompson, W. (1996). Methods in Observational Epidemiology (2nd ed.). New York, NY: Oxford University Press.

Kessler, R., \& Glasgow, R. (2011). A proposal to speed translation of healthcare research into practice: dramatic change is needed. American Journal of Preventive Medicine, 40(6), 637-44. doi:10.1016/j.amepre.2011.02.023

Kolbe-Alexander, T., Lambert, E., \& Charlton, K. (2006). Effectiveness of a community based low intensity exercise program for older adults. The Journal of Nutrition, Health \& Aging, 10(1), 21-9. 
Kravitz, L. (1996). Age and Exercise. IDEA Today, 14(2), 28-35. Retrieved from http://www.unm.edu/ lkravitz/Article folder/age.html

Maaten, S., Kephart, G., Kirkland, S., \& Andreou, P. (2008). Chronic disease risk factors associated with health service use in the elderly. BMC Health Services Research, 8 , 237-245. doi:10.1186/1472-6963-8-237

Martini, E. M., Garrett, N., Lindquist, T., \& Isham, G. J. (2007). The boomers are coming: a total cost of care model of the impact of population aging on health care costs in the United States by Major Practice Category. Health Services Research, 42(1), 201-18. doi:10.1111/j.1475-6773.2006.00607.x

McAuley, E., \& Blissmer, B. (2000). Self-efficacy determinants and consequences of physical activity. Exercise and Sport Sciences Reviews, 28(2), 85-8.

Moore, G. F., Moore, L., \& Murphy, S. (2011). Facilitating adherence to physical activity: exercise professionals' experiences of the National Exercise Referral Scheme in Wales: a qualitative study. BMC Public Health, 11, 935. doi:10.1186/1471-2458-11-935

Moore-Harrison, T. L., Johnson, M. A., Quinn, M. E., \& Cress, M. E. (2009). An evidence-based exercise program implemented in congregate-meal sites. Journal of Physical Activity \& Health, 6(2), 247-51.

National Center for Health Statistics. (2011). Health, United States, 2010. Retrieved October 03, 2014, from http://www.cdc.gov/nchs/data/hus/hus10.pdf

National Council on Aging. (2014). Chronic Disease Self-Management: Fact Sheet. Retrieved October 03, 2014, from http://www.ahrq.gov/legacy/research/elderdis.htm

Oguma, Y., Sesso, H., Paffenbarger, R., \& Lee, I. (2005). Weight Change and Risk of Developing Type 2 Diabetes. Obesity Research, 13(5), 945-951.

Ory, M. G., Ahn, S., Jiang, L., Smith, M. L., Ritter, P. L., Whitelaw, N., \& Lorig, K. R. (2013). Successes of a national study of the Chronic Disease Self-Management Program: meeting the triple aim of health care reform. Medical Care, 51(11), 992-8. doi:10.1097/MLR.0b013e3182a95dd1

Ory, M. G., Smith, M. L., Ahn, S., Jiang, L., Lorig, K., \& Whitelaw, N. (2014). National study of chronic disease self-management: age comparison of outcome findings. Health Education \& Behavior, 41(1 Suppl), 34S-42S.

doi: $10.1177 / 1090198114543008$ 
Page, T. F., Batra, A., \& Palmer, R. (2012). Cost analysis of a community-based fall prevention program being delivered in South Florida. Family \& Community Health, 35(3), 264-70. doi:10.1097/FCH.0b013e318250be2e

Resnick, B., Nahm, E. S., Zhu, S., Brown, C., An, M., Park, B., \& Brown, J. (2014). The impact of osteoporosis, falls, fear of falling, and efficacy expectations on exercise among community-dwelling older adults. Orthopaedic Nursing, 33(5), 277-86. doi:10.1097/NOR.0000000000000084

Resnick, B., \& Spellbring, A. M. (2000). Understanding what motivates older adults to exercise. Journal of Gerontological Nursing, 26(3), 34-42.

Rogers, C., \& Keller, C. (2009). Roy's Adaptation Model To Promote Physical Activity Among Sedentary Older Adults. Geriatric Nursing, 30(2 Suppl), 21-26.

doi:10.1016/j.gerinurse.2009.02.002.Roy

Schneider, K., O’Donnell, B., \& Dean, D. (2009). Prevalence of multiple chronic conditions in the United States' Medicare population. Health and Quality of Life Outcomes, 7, 82. doi:10.1186/1477-7525-7-82

Senior Services. (2013). Enhance Fitness. Retrieved October 02, 2014, from http://www.projectenhance.org/EnhanceFitness.aspx

Shadish, W. R., Cook, T. D., \& Campbell, D. T. (2001). Experimental and QuasiExperimental Designs for Generalized Causal Inference (2nd ed.). CENGAGE Learning.

Stolberg, H. O., Norman, G., \& Trop, I. (2004). Randomized controlled trials. American Journal of Roentgenology, 183(6), 1539-44. doi:10.2214/ajr.183.6.01831539

Strazzullo, P., D’Elia, L., Cairella, G., Garbagnati, F., Cappuccio, F. P., \& Scalfi, L. (2010). Excess body weight and incidence of stroke: meta-analysis of prospective studies with 2 million participants. Stroke: Journal of the American Heart Association, 41(5), e418-426. doi:10.1161/STROKEAHA.109.576967

U.S. Census Bureau. (2014). Sixty-Five Plus in the United States. Retrieved September 09, 2014, from https:/www.census.gov/population/socdemo/statbriefs/agebrief.html

USDHHS. (2012). A Profile of Older Americans: 2011. Retrieved from http://www.aoa.gov/Aging_Statistics/Profile/2011/docs/2011profile.pdf

USDHHS. (2013). A Profile of Older Americans : 2012. Retrieved from http://www.aoa.gov/Aging_Statistics/Profile/2012/docs/2012profile.pdf 
USDHHS. (2014a). Profile of Older Americans: 2013. Retrieved from http://www.aoa.gov/Aging_Statistics/Profile/Index.aspx

USDHHS. (2014b). Projected Future Growth of the Older Population. Retrieved October 28, 2014, from http://www.aoa.gov/Aging_Statistics/future_growth/future_growth.aspx\#age

USDHHS: AHRQ. (2006). Measure Summary: Physical activity in older adults. Retrieved from http://www.qualitymeasures.ahrq.gov/content. aspx?id=47219

USDHHS: Healthy People. (2014). Older Adults - Healthy People 2020. Washington DC. Retrieved from http://www.healthypeople.gov/2020/topicsobjectives2020/overview.aspx?topicid=3 1

USDHHS: National Cancer Institute. (2005). Theory at a Glance: A Guide For Health Promotion Practice (2nd ed.). Retrieved from $\mathrm{http}: / /$ www.cancer.gov/cancertopics/cancerlibrary/theory.pdf

Wallace, J. I., Buchner, D. M., Grothaus, L., Leveille, S., Tyll, L., LaCroix, A. Z., \& Wagner, E. H. (1998). Implementation and effectiveness of a community-based health promotion program for older adults. The Journals of Gerontology. Series A, Biological Sciences and Medical Sciences, 53(4), M301-6.

White, J. L., Ransdell, L. B., Vener, J., \& Flohr, J. A. (2005). Factors related to physical activity adherence in women: review and suggestions for future research. Women \& Health, 41(4), 123-48. doi:10.1300/J013v41n04_07 


\section{CHAPTER 2}

\section{Literature Review}

The demography of older adults in the U.S. and Florida is vastly changing (USDHHS, 2014a). Older adults defined as people 65 years of age or above accounted for approximately $14 \%$ of total U.S. population in $2012(\mathrm{n}=43.1$ million) (USDHHS, 2014a). By 2020, this number is expected to increase to 56 million, an increase of $36 \%$ for the decade (USDHHS, 2014a). According to Florida Department of Health, from 1970 to 2000 Florida's population has increased by $134.6 \%$ (Florida Department of Health, 2014b). In addition, percentage of older adults in Miami-Dade County has increased by $10 \%$ followed by Monroe County and then Broward County (7.9\%) (Florida Department of Health, 2014b). Older adults are the fastest growing segment of this state due to aging baby boomers and migration. In contrast to $14 \%$ of national average, older adults constitute 18\% of Florida's population (Florida Department of Health, 2014b).

Unhealthy life style habits such as physical inactivity, poor diet, smoking and physiological age-related changes put older adults at higher risk for developing chronic conditions (Fulop et al., 2010; Glei, Goldman, Lin, \& Weinstein, 2011; Kravitz, 1996). Approximately $92 \%$ of older adults suffer from at least one chronic condition, and approximately $77 \%$ of those 65 years and above have at least two chronic conditions (National Council on Aging, 2014). Hypertension, arthritis, osteoporosis, diabetes, coronary artery diseases, stroke, visual impairment, chronic obstructive pulmonary diseases, Alzheimer's, and kidney disorders are some of the most common age-related chronic conditions (AARP Public Policy Institute, 2009; Campbell et al., 2013; CDC, 2011b; Chou et al., 2013; Fulop et al., 2010; Glei et al., 2011; Lee et al., 2013; USDHHS: 
Healthy People, 2014; Ward \& Schiller, 2013). In addition, the fear of falls and number of falls increases with increased age (Batra et al., 2012; Chang, Lynm, \& Glass, 2010; Finlayson \& Peterson, 2010). High prevalence of chronic conditions, muscle loss, and balance impairment increases the chances of dependency on others later in life, anxiety, social isolation, and in advance cases depression (Almeida et al., 2012; El-Gabalawy, Mackenzie, Shooshtari, \& Sareen, 2011; Hersil, 2011). Therefore, if not managed they can impact overall quality of life of older adults (Rothrock et al., 2010; Schafer et al., 2010).

Physical activity, a modifiable factor, can alter the course of many chronic conditions (Dogra \& Stathokostas, 2012; USDHHS: Healthy People, 2014). Recognizing the benefits of physical activity such as improved management of chronic conditions, decreased incidence of chronic conditions and comorbidities, strengthening of muscles and bones; $\mathrm{CDC}$ recommended guidelines of physical activity for older adults (CDC, 2011c, 2011e). As per CDCs recommendations, older adults should engage in at least 150 minutes of moderate intensity exercise or 75 minutes of vigorous intensity exercise every week. In addition, muscle-strengthening exercises to work all major muscle groups should be performed for two or more days a week (CDC, 2011c; Nelson et al., 2007).

\section{Literature Search Strategy}

A literature search for this study was conducted using different strategies. Electronic databases such as 'PubMed' and 'CINAHL Plus' were searched by combining search terms using AND, OR, NOT and truncation (wildcard characters like *). In addition, more targeted PubMed search was conducted using MeSH Terms. Using MeSH terms, appropriate subheadings were chosen and added to PubMed search builder tool. 
This indexing process allowed automatically mapping the MeSH terms to relevant articles and displayed them in order of hierarchy. Further, the 'Cochrane library' was searched primarily to identify literature reviews of previous studies (meta-analysis) on the chosen topic. Search engine tool 'Google' was also used. Data for this study was also obtained using reliable online websites of agencies such as Agency for Healthcare Research and Quality's, CDC, Florida Department of Health, National Council on Aging, U.S. Census Bureau, and U.S. Department of Health and Human Services. Another search tool used includes checking through the reference lists of chosen studies to see if the references of other studies were eligible for review. Occasionally, tables of contents of journals were reviewed to identify any relevant study. The main key words used for search were older adults, aged, physical activity, inactivity, chronic conditions, comorbidities, and age-related disorders. Prior to starting an article search, key words and timeline for including articles was determined. Only those studies that were published in and after 2000 in peer-reviewed journals were included. Exceptions include books, and articles determining the reliability and validity of instruments used, and theories underlying the intervention.

\section{Literature Review}

\section{Chronic Conditions and Older Adults}

As mentioned before, data from National Council on Aging suggests that approximately $92 \%$ of older adults suffer from at least one chronic condition, and approximately $77 \%$ of those 65 years and above have at least two chronic conditions (National Council on Aging, 2014). The number of chronic conditions and associated comorbidity increases with age. Further, by 2049, the number of older adults suffering 
from disability due to chronic conditions is expected to increase by at least $300 \%$ (AHRQ, 2002). Some of the common chronic conditions among older adults include diabetes, arthritis, cardiovascular disease, hypertension, chronic renal failure, osteoporosis, dementia, cancer, obesity, Alzheimer's, macular degeneration, fractures, arthritis, frailty, and asthma (Biggs et al., 2010; Brookmeyer et al., 2011; CDC, 2011d; L. Chen, Nelson, Zhao, Cui, \& Johnston, 2013; Crews et al., 2010; Foster et al., 2013; Hebert, Scherr, Bienias, Bennett, \& Evans, 2003; Kirkman et al., 2012; Lawrence et al., 2008; Munshi et al., 2006; Park et al., 2006; Rothrock et al., 2010; Sue Kirkman et al., 2012; USDHHS: Healthy People, 2014). The Florida Behavioral Risk Factor Surveillance System (BRFSS) 2012 reveals that in Florida, approximately 50\% of older adults suffer from some kind of arthritis, approximately $20.5 \%$ have some kind of cardiovascular disease, $58.2 \%$ reported to have high blood pressure, $21.2 \%$ had diabetes, and $63.8 \%$ were either overweight or obese (Florida Department of Health, 2013a). Anderson and Horvath (2004) analyzed data from the Medical Expenditure Panel Survey. According to their study, approximately $85 \%$ of individuals aged 65 or above had one chronic condition and 62\% had multiple chronic conditions (Gerard Anderson \& Horvath, 2004). In comparison to men, women were more likely to suffer from chronic conditions. In addition, whites had highest rates of chronic conditions. The number of chronic conditions and their comorbidities further increased with age. They also reported on the economic burden of chronic conditions on the health care system. Individuals with chronic conditions have been accounted for more than $95 \%$ of home health, $88 \%$ of prescriptions, $72 \%$ of physician visits, and $76 \%$ of inpatient hospital stay costs (Gerard Anderson \& Horvath, 2004). Lenhert et al. (2011) also reported increased in the 
utilization of physician and hospital services with increased number of chronic conditions. According to a study by Wolff et al. an older adult with four or more conditions were 99 times more likely to be hospitalized for an ambulatory care sensitive condition than an individual without any chronic condition (Wolff, Starfield, \& Anderson, 2002). Similar results were reported by other researchers (Condelius, Edberg, Jakobsson, \& Hallberg, 2008; Lochner \& Cox, 2013; Schneider et al., 2009; Schoen, Osborn, How, Doty, \& Peugh, 2009; Schoenberg, Kim, Edwards, \& Fleming, 2007; Starfield, Lemke, Herbert, Pavlovich, \& Anderson, 2005; Thorpe, Ogden, \& Galactionova, 2010). Chronic conditions also pose a deleterious effect on the health of older adults by affecting their daily activities and perceived quality of life (Rothrock et al., 2010; Schafer et al., 2010).

The prevalence of comorbidity defined as the presence of two or more chronic conditions has also increased due to decrease in mortality rates and increased life expectancy (Salive, 2013). Study by Salive (2013) revealed that comorbidity increases with age. In $2008,81.5 \%$ of Medicare beneficiaries that aged 85 years or more had comorbidity in comparison to $62 \%$ of those between ages $65-74$. Comorbidity impacts the quality of life of older adults and poses a serious challenge for health care providers (Lehnert et al., 2011; Schoen et al., 2009; Thorpe et al., 2010). Patients having one chronic condition are more likely to develop other chronic conditions (R. Anderson, Freedland, Clouse, \& Lustman, 2001; Munshi et al., 2006; Tucker-Seeley, Li, Sorensen, \& Subramanian, 2011). According to U.S. Department of Health and Human Services, "patients who have metabolic syndrome are twice as likely to develop heart disease and five times as likely to develop diabetes as someone who doesn't have metabolic 
syndrome" (USDHHS: National Heart, Lung, 2011). Ward et al., in 2013 analyzed data from 2010 National Health Interview Survey to determine the prevalence of multiple chronic conditions by age and sex. Analyses of data revealed that overall the number of multiple chronic conditions had increased from $21.8 \%$ in 2001 to $26.0 \%$ in 2010.

Interestingly, when analyzed by age and gender, until 44 years of age, females are more likely to have four or more chronic conditions however, after 65 years, men were more likely to have multiple chronic conditions (Ward \& Schiller, 2013). Further, statistical significance among older adults was reported between comorbidity, and increased mortality, disability, decreased functional status, low quality of life, and increased utilization of health care services (Gijsen et al., 2001; Schafer et al., 2010).

\section{Role of physical activity in prevention of chronic conditions}

For older adults, the health benefits of physical activity outweigh the risks by far (CDC, 2010b, 2013c; NIH, 2012). Regular physical activity regimens could delay the aging process and help prevent or delay the onset of many chronic conditions (Neid \& Franklin, 2002a). Similar findings have been reported by other researchers (CDC, 2010, 2011e, 2013; Geller, Mendoza, Timbobolan, Montjoy, \& Nigg, 2012; National Institute on Aging and the National Library of Medicine, 2012). Maintaining a healthy life style helps better management of diabetes mellitus, improves sleep quality, lowers risk of fractures, reduces chances of obesity, and lowers risk of cancers (CDC, 2010b, 2011f, 2013; Colberg et al., 2010; Michaëlsson et al., 2007; Morseth et al., 2012; National Cancer Institute, 2009; Neid \& Franklin, 2002; Reid et al., 2010; Yang, Ho, Chen, \& Chien, 2012). In addition, physical activity has been found to alleviate the symptoms associated with inflammatory disorders of joints and associated conditions such as 
arthritis, gout, spondylitis, osteomyelitis and other inflammatory disorders of joints (CDC, 2010b, 2011a, 2013c; Hootman \& Helmick, 2006; NIAMS, 2012; Shih, Hootman, Kruger, \& Helmick, 2006; Stewart, 2005). Further, strength training exercises reduces bone loss in those with low bone density such as osteoporosis patients (Bosković et al., 2013; CDC, 2011f, 2013c; Korpelainen, Keinanen-Kiukaanniemi, Heikkinen, Vaananen, \& Korpelainen, 2006; NIH Osteoporosis and Related Bone Diseases National Resource Center, 2012).

Unintentional falls are a significant predictor of morbidity and mortality in the older population and are ranked first among all nonfatal causes of injuries in this population (Batra et al., 2012). Balance and strength training exercises through full range of motions in older adults allow improving flexibility, gait, and restores balance, which decreases the likelihood and severity of falls and related complications including fractures (Bosković et al., 2013; CDC, 2010b, 2011f, 2013c; Michaelsson et al., 2007; Morseth et al., 2012; Neid \& Franklin, 2002a). Further, physical activity promotes circulation that allows reducing complications of immobility and sedentary behaviors in older adults such as heart disease, deep vein thrombosis, edema, hypertension, contractures, pressure sores, and severe constipation (CDC, 2010b, 2011f; Conti, Russomanno, Corbi, \& Filippelli, 2012; Neid \& Franklin, 2002a; NIH, 2012). Physical activity also helps patients with depression and anxiety disorders by improving their mental health including perceptions of mental wellbeing, improved stress management skills, and self-esteem (CDC, 2011f, 2013c; Neid \& Franklin, 2002a; NIH, 2012).

Overall, strong evidence demonstrates that older adults who are physically active have lower rates of morbidity. They maintain positive well-being, live independently and have 
better quality of life (Bosković et al., 2013; CDC, 2010b, 2011f, 2013c; Neid \& Franklin, 2002a; Reid et al., 2010; Rothrock et al., 2010; Schafer et al., 2010; Ziden, HaggblomKronlof, Gustafsson, Lundin-Olsson, \& Dahlin-Ivanoff, 2013).

\section{Current trends of physical activity in older adults}

Although the health benefits of physical activity are well-known, data from the National Center for Health Statistics revealed that in 2012, only $37.5 \%$ of older adults aged 60 years and older met recommended aerobic physical activity levels (National Center for Health Statistics, 2014a). This number drops to $16.1 \%$ for those who met the muscle-strengthening guidelines (National Center for Health Statistics, 2014a). Further, in 2011, 45.6\% of older adults in Florida did not meet the recommended physical activity levels of 150 minutes or more (BRFSS: CDC, 2011a), and 78.1\% failed to meet the recommended guidelines for muscle strengthening exercises (BRFSS: CDC, 2011b). The prevailing problem of physical inactivity among older adults calls for action.

\section{Physical activity program for older adults in South Florida}

In order to combat the issue of physical inactivity in older adults in South Florida, the Health Foundation of South Florida initiated HARC in fall 2008' with an aim to implement evidence-based programs in South Florida. HARC offered four programs to older adults in year 1: EnhanceFitness (physical fitness program), Living Healthy/Tomando Control de su Salud/Diabetes Self-Management (chronic disease selfmanagement program), Matter of Balance/Asunto de Equilibrio (fall prevention program), and Healthy Ideas (depression management program). This study focused on the EF program. 
EF is an evidence-based physical activity program for older adults (Belza et al., 2006; Senior Services, 2013; Wallace et al., 1998). EF sessions were held three times a week for one hour by a trained master or lay leader. Recommended class size ranged from 10 to 25 participants having approximately the same level of fitness. The components of an EF class include warm-up, cardiovascular endurance, cool down, upper and lower body strength training and stretching. The recommended time guidelines are warm-up for about 5-8 minutes, cardiovascular endurance (aerobics) for 20 minutes, cool-down 3 to 5 minutes, strength training for 20 minutes and stretching for 8 to 10 minutes (Senior Services, 2013).

\section{Past EF studies}

EF formerly known as 'Lifetime Fitness' program was developed in 1998 (Belza et al., 2010; Moore-Harrison et al., 2009; Wallace et al., 1998). EF partnership consisted of Washington Health Promotion Research Center, Group Health Organization: Washington, and Senior Services: Seattle (Belza et al., 2010). Since 1999, Senior Services solely oversees EF because implementation and dissemination of EF was consistent with their mission (Belza et al., 2010). EF, a multicomponent intervention included domains of exercise, nutrition counseling, and home safety assessment (Wallace et al., 1998). Exercise is the central component of EF intervention. The original EF program was a 6-month randomized controlled trial and was conducted in a senior center. USDHHS reported that approximately $25 \%$ older adults use senior centers, therefore, 'Northshore Senior center' was chosen as the site to deliver the EF program in Washington (Wallace et al., 1998). Inclusion criteria required an individual to be 65 years or older and being able to walk. Individuals who were blind, cognitively impaired, frail, 
disabled, had a medical condition that precluded or contradicted exercise, and had a timed "Up and Go" test greater than 30 seconds were excluded. In addition, approval from participant's physician was required to participate. In total 100 participants were recruited and randomly assigned to either intervention or control group. Fifty-three participants were in the intervention and 47 were in the control group. Data was collected from participants at three time points: baseline, 2-months, and 6-months. Data variables included demographic information, history of tobacco and alcohol use, self-rated health status, and measures of activity and exercise. Four outcome measures were chosen to determine efficacy of EF trial. The first outcome was taken from the Medical Outcomes Study Short-Form (SF-36), which had 36 items under eight domains and measured individual's physical functioning, role limitations due to physical and emotional health, social activity limitations, body pain, mental health index, fatigue, and general perceptions about health. The other three outcome measures included a score of 60 on the CES-Depression scale, restricted activity days, and bed days. The exercise regimen was the main component of EF intervention. In addition, participants who reported consuming tobacco and alcohol received an additional intervention component based on their habits. A registered nurse evaluated and helped participants develop a nutrition plan and reduce tobacco and alcohol consumption. To increase compliance and motivate participants, barriers to participation were identified and addressed. In addition, the nurse called participants at 2-, 4-, and 16-weeks and motivated them to continue program participation. All the study participants who received intervention reported significant positive changes in all the outcome measures. Participants' in the intervention group reported a mean of 83.6 for physical functioning in comparison to 78.0 of control group 
at 2-months interval and at 6-months; intervention group had mean 83.3 and comparison group 76.7. For CES-Depression score, the control group had a mean of 8.2 in comparison to 6.0 of control group at 2-months. At 6-months follow-up, the control group had a mean of 8.2 in comparison to 4.7 of intervention group for CES-Depression score. For restricted-activity days, intervention group had mean of 6.2 versus 21.7 for comparison group at 6-months follow up. Overall, study participants showed significant improvement in all outcome measures at 2- and 6-months follow-up. Participants in the control group were allowed to join EF program after 6-months. After completion of the trial, Senior services decided to continue offering EF and participants were allowed to take EF classes for as long as they desired (Wallace et al., 1998).

After it was found efficacious, EF was offered in community-based settings (Belza et al., 2006). Belza et al., in 2006, studied the effectiveness of EF. Data for the study was collected through April 2002 to September 2005. In total 2,889 older adults with a mean age of 75.5 years participated in $116 \mathrm{EF}$ classes in nine states. The class structure was similar to the original EF program. The aim of the study was to improve the physical activity levels of older adults, improve their health status, and reduce the number of falls. Baseline data was collected on demographics, health history, and functional performance measures. Initially, a seven-item functional performance measure was chosen. The seven-items included: (1) number of arm curls performed in 30-seconds, (2) number of chair stands in 30-seconds, (3) time taken to get up from chair and complete an eight foot circuit, (4) chair sit and reach, which measured the distance between the extended fingers and tip of toe, (5) back scratch, which is the distance between the middle fingers when one arm is placed behind the back and other over the shoulder, (6) 
distance covered in six-minute walk, and (7) number of steps taken in two-minutes (Belza et al., 2006; Moore-Harrison et al., 2009; Rikli \& Jones, 1999a, 2013; Wallace et al., 1998). In addition, the health status of participants was determined using a shorter version of SF-36, SF-12 health status questionnaire. In order to determine the effectiveness of intervention, functional test and health status of participants was tested again at 4- and 8-months. In order to make the outcome measures test feasible, program implementers decided to use only three of seven-item original functional measure test items. The three measures kept included 30-seconds arm curls, 30 -seconds chair stands, and eight-foot-up and go circuit. The study results revealed that all participants significantly improved on their outcome measures at 4- and 8-months (Belza et al., 2006). This exercise program helped older adults at all levels of fitness become more active, energized, and empowered to sustain independent lives (Belza et al., 2006, 2010; MooreHarrison et al., 2009; Wallace et al., 1998).

In 2009, Moore-Harrison et al. evaluated effectiveness of EF offered to older adults in congregate-meal sites in Georgia (Moore-Harrison et al., 2009). Congregatemeal sites generally serve lower-income older adults and researchers aimed to evaluate the feasibility of implementing EF to the specific population. Intervention was 12-week long and class structure was similar to original EF program with focus only on exercise component. In order to be considered eligible for participation, physician clearance was required. Individuals who had any medical condition that contradicted their participation in a physical activity program such as heart failure, uncontrolled arrhythmias, and uncontrolled hypertension etcetera were excluded. Forty-one participants were enrolled and 31 completed the program. Blood pressure of chosen study participants was 
measured before every session and those who had blood pressure of more than $200 \mathrm{~mm}$ Hg were not allowed to exercise that day. Outcome measures were evaluated at baseline and 12-weeks using SF-36 form and six functional fitness tests. Data analyses revealed that after 12-weeks of participation, participants showed significant improvement in four fitness test scores and three health status measures. Participants showed significant improvement in mean number of chair stands (3.3), back scratch (5.4), chair sit-and-reach (2.1), and eight feet up and go (2.3). An improvement in mean of 25.0 was observed in bodily pains, 28.6 in social functioning, and 14.5 in mental health (Moore-Harrison et al., 2009).

EF was also implemented in Kaua 'i, a rural island in Hawaii with support from Healthy Aging Partnership (Tomioka, Sugihara, \& Braun, 2012). After reviewing the EF manual, researchers chose to make certain changes for better adaptation of EF in Kaua i. Proposed changes were discussed with senior services prior to implementation. Minor changes like renaming exercises, using local music during exercise session were allowed however; other changes related with content of EF such as eliminating certain phases of exercises were declined. Between July 2007 and December 2010, 223 Kaua i residents enrolled in EF classes. Physician clearance was taken for participation. To determine the effectiveness of intervention data was collected at two time points: baseline and 4months. Three fitness checks measures; number of arm curls in 30 seconds, number of chair stands in 30 seconds and time taken to complete eight-foot circuit were recorded. Participants were also asked to report on the number of falls in last 4-months. Data analysis revealed that participants significantly improved their physical performance at $p$ $<0.001$ (chair stands, $\mathrm{t}=-11.06$; arm curls, $\mathrm{t}=-6.66$; and up-and-go test, $\mathrm{t}=6.56$ ). 
Participants reported high satisfaction with the program. One hundred seventy eight participants completed the EF program (Tomioka et al., 2012).

Ackermann et al. conducted a retrospective cost-effective study of EF users (Ackermann et al., 2008). In total 3,650 participants were chosen: EF users $(n=1,188)$ and controls $(n=2,462)$. During the first year, EF participants had more primary care visits but lower hospitalization rates than non-users. Further, there was not much difference between total and specialty care cost among EF users and controls. EF was found to be cost-effective in the second year. Individuals who were enrolled in EF classes reported lower inpatient and total health care costs. EF users spent $\$ 1,186$ less than the participants in control group did (Ackermann et al., 2008). In another study by Sugihara et al., similar results were found. Annual health care costs of EF participants were compared to annual reports of health care costs for elderly. Cost-benefit analysis revealed that those who attended at least one EF session every week spent approximately $\$ 1,000$ less annually on health care (Sugihara, Watanabe, Tomioka, Braun, \& Pang, 2011). Similar results have been reported by other researchers also (Belza et al., 2010; Sugihara et al., 2011). Page et al. (2014) estimated the monthly cost of implementing EF in community settings to be $\$ 873$ per month for agencies who had been offering the program for at least one year (Page, Batra, Ghouse, \& Palmer, 2014). Assuming 15 completers in each 4-month time period yields a per completer cost of $\$ 232.80$, (Page et al., 2014) well below the cost-savings documented in Ackermann et al. (2008).

\section{Functional Fitness Test Measures}

In the proposed study and previous EF studies, functional fitness of participants was tested using Senior Fitness Test also known as Functional Fitness Test (FFT) battery 
(Ackermann et al., 2008; Belza et al., 2006, 2010; Moore-Harrison et al., 2009; Tomioka et al., 2012; Wallace et al., 1998). FFT battery was developed by Rikli and Jones to assess the parameters that support functional mobility in older adults (Rikli \& Jones, 1997, 1999a, 2013). FFT includes seven items to assess lower and upper body strength, lower and upper body flexibility, aerobic endurance, agility/balance, and body composition. Lower body strength is assessed by 30 -second chair stand. In this test, an instructor counts and record the number of full chair stands with arms folded across chest that a participant can perform in 30 seconds. To measure the upper body strength, a participant is asked to perform arm curls for 30 seconds by holding weights (female $5 \mathrm{lbs}$, male $8 \mathrm{lbs}$ ). Aerobic endurance of a participant is measured by recording the number of yards walked in 6-minutes. For those who have difficulty in walking an alternative ' 2 minute step test' can be used. In this test, an instructor counts and record number of full steps completed by a participant in 2-minutes. Chair sit-and-reach test, which measures the distance between the extended fingers and tip of toe, allows measuring the lower flexibility. Back scratch, which is the distance between the middle fingers when one arm is placed behind the back and other over the shoulder, allows measuring upper body flexibility. Agility/balance of participants was assessed by asking and recording the time taken to complete an eight-foot circuit. Body mass index of participant is measured to assess body composition (Rikli \& Jones, 1999a, 2013). After finalizing the items for FFT battery, Rikli and Jones tested each item in the tool for its reliability. Intraclass correlation coefficients were computed. Test-retest reliability for the items ranged from 0.80 to 0.98 (Rikli \& Jones, 1999a). In addition, every item in the FFT battery was analyzed for its content, criterion, and construct validity. Interclass correlation coefficient 
(r) was calculated to establish criterion validity for FFT battery. R-values ranged from 0.77 to 0.88 suggesting the tool has strong psychometric properties (Rikli \& Jones, 1999a). In addition to the development of FFT tool, Rikli and Jones conducted a nationwide study to develop normative scores for older adults (Rikli \& Jones, 1999b). FFT norms are reported by gender and ages for adults aged 60 to 94 years (Rikli \& Jones, 1999b, 2001). The scores serve as a benchmark and researchers use them to compare the physical activity level of their study participants.

Since its development, FFT tool has been used by several researchers aiming to measure physical activity levels in older adults (Ackermann et al., 2008; Belza et al., 2006, 2010; Moore-Harrison et al., 2009; Tomioka et al., 2012; Wallace et al., 1998). However, in EF study conducted by Belza et al. study participants and instructors found the seven items test difficult and time consuming (Belza et al., 2006, 2010). Therefore, they tested a subset of FFT and downsized it to three items including number of chair stands in 30 seconds, number of arm curls performed in 30 seconds, and time taken to complete a 8-foot circuit (Belza et al., 2010). For the purpose of this study, the three-item shorter version of FFT was made mandatory. The other four items from original sevenitem FFT were included in the questionnaire but were made optional to report. Functional performance of participants was measured at baseline and every four months thereafter. Participants absent on the day of the FFT were identified and FFT was conducted later at another time. In addition, participants completed an evaluation form after attending the workshop for four months. The evaluation form measured participant's levels of satisfaction with workshop, amount of individual attention given by instructor in class, challenge of the exercises, and the instructors' ability to make the class fun. The 
evaluation also included questions about participants' frequency and duration of exercise outside the workshop environment.

\section{Theories}

This study is guided by Health Belief Model and Social Cognitive Theory.

\section{Health Belief Model}

Health Belief Model (HBM) was developed by Hochbaum and

Rosenstock in the 1950s (Glanz et al., 2008; USDHHS: National Cancer Institute, 2005). HBM was developed to understand widespread failure of people to participate in available disease prevention and health promotion programs. Later, it was extended to understand adherence behavior especially to medical regimens. Perceived susceptibility, perceived severity, perceived benefits, perceived barriers, and cues to action are the key constructs of HBM (Glanz et al., 2008; USDHHS: National Cancer Institute, 2005). Later, in 1988, Rosenstock, Strecher, and Becker added the concept of self-efficacy (Glanz et al., 2008). Perceived susceptibility refers to beliefs about the likelihood of getting a disease. Perceived severity is the belief about the seriousness of the disease and its sequelae. The combination of susceptibility and severity is known as perceived threat. Perceived benefit is the belief that taking an action will reduce susceptibility to the condition or its severity. Perceived barriers include potential negative aspects of a behavior. Cues to action are triggering mechanisms that activate readiness to change or to take action. Cues could be as simple as a sneeze, or perception of poster or diagnosis of a serious illness. According to HBM, for a behavior to change people must feel threatened by their current behavior (perceived threat) and believe that change of a specific kind will result in a valued outcome (perceived benefit) at an acceptable cost (perceived barrier) 
(Glanz et al., 2008; USDHHS: National Cancer Institute, 2005). Concepts of HBM have been used to change wide variety of behaviors including cancer screening, attitudes towards risky sexual behavior, use of vaccinations, alcohol and drug education, injury prevention, and intention to comply with recommendations etcetera (Akey, Rintamaki, \& Kane, 2013; Carolyn, 2011; M. Chen et al., 2011; Davis, Buchanan, \& Green, 2013; Guvenc, Akyuz, \& Açikel, 2011; Sayegh \& Knight, 2013; Tenkorang, 2013; Wright, Randall, \& Hayes, 2012).

The concepts of perceived susceptibility and perceived benefits are incorporated in EF intervention. Older adults are vulnerable to chronic conditions and affect their quality of life. Approximately $92 \%$ of older adults suffer from at least one chronic condition (National Council on Aging, 2014). EF instructors bring awareness among older adults regarding their susceptibility to chronic conditions and their sequelae. This acts as a negative reinforcement agent. Individuals consider themselves to be susceptible for disease and therefore, initiate prevention behavior by participating in prevention workshops. Further, participants are made aware of all benefits that they can attain by initiating and maintaining healthy behavior such as physical activity in the case of EF intervention.

\section{Social Cognitive Theory}

Social Cognitive Theory (SCT) was proposed by Albert Bandura in 1962 and developed from the original Social Learning Theory (Bandura, 1977a, 1977b, 1997; Glanz et al., 2008; USDHHS: National Cancer Institute, 2005). It is an outcome expectancy theory that also recognizes the importance of factors outside the individual in shaping behavior. Social cognitive theory is based upon the principle of reciprocal 
determinism (or triadic reciprocity), which suggests that individuals act upon environment and are influenced by their environment. Three points of the reciprocal determinism triangle are behavior, personal characteristics, and environmental determinants. The theory also suggests, as an interpersonal theory, that humans act collectively and rarely are decisions made in a social vacuum (Bandura, 1977a, 1977b, 1997; Glanz et al., 2008; USDHHS: National Cancer Institute, 2005).

The primary constructs of SCT are psychological (cognitive) determinants, observational learning, environmental determinants, self-regulation, and moral disengagement (Bandura, 1977a, 1977b, 1997; Glanz et al., 2008; USDHHS: National Cancer Institute, 2005). Three main individual-level psychological determinants that have been identified in SCT are outcome expectancy, self-efficacy, and collective efficacy. Outcome expectations are beliefs about the likelihood of outcomes that result from performing a behavior and consequences of behavioral choices. Self-efficacy is defined as individuals' belief about her personal ability to perform behavior. A growing body of literature supports the role of self-efficacy in initiation and maintenance of behavior (AbuSabha \& Achterberg, 1997; Marlatt \& Gordon, 2005; O’Hea et al., 2009). Bandura extended the concept of perceived efficacy to collective efficacy, defined as the ability of a group to perform actions that bring desired outcomes (Bandura, 1977a, 1997; Glanz et al., 2008; USDHHS: National Cancer Institute, 2005).

Bandura and Walters challenged the long-standing operant learning theory by stating that it was possible to learn new behaviors simply through observation (Walters \& Bandura, 1963). Four processes govern observational learning: attention, retention, production, and motivation (Glanz et al., 2008; USDHHS: National Cancer Institute, 
2005). The concept of environmental determinants in SCT describes the influence of environment on individual's behavior. Environment plays role via incentive motivation and facilitation. Incentives work as reinforcements, which increases the likelihood of repeating the behavior. Facilitation depends on the factors that support the behavior and barriers that prevent someone from doing that behavior. Self-regulation, next construct of SCT emphasizes the human capacity to bear small negative hardships in anticipation of long-term benefits (Bandura, 1977a, 1997). Bandura proposed that self-regulation could be achieved through self-monitoring, goal setting, feedback, self-reward, self-instruction, and social support (Bandura, 1977a, 1997). Moral disengagement is related to moral standards of self-regulation. It can be achieved by euphemistic labeling (using lessoffensive words), placing the blames on others and having reason for that and justifying their action by considering them as beneficial or necessary (Glanz et al., 2008).

Since its development, concepts of SCT have been extensively used by researchers when designing interventions that aim to change behavior (AbuSabha \& Achterberg, 1997; Berlin, Norris, Kolodinsky, \& Nelson, 2013; Byom \& Turkstra, 2012; Marlatt \& Gordon, 2005; O’Hea et al., 2009; Puma et al., 2013). Puma et al. (2013) applied the concepts of SCT with Piaget's cognitive development theory to maximize likelihood of behavior change in designing an intervention that aims to improve nutritional intake and increase physical activity among students. SCT was chosen because of its ability to addresses both environmental and personal factors. Piaget's cognitive development theory allowed developing age-appropriate instructional approaches. Intervention addressed personal factors by having each child play an active role in food preparation and tasting, goal-setting, peer communication, self-regulation, and sharing 
thoughts with others. It addressed environmental factors through take-home messages and parent night events to influence the home environment. In addition, messages such as "Eat more fruits and vegetables", " Be more active" directly focused on behavior change (Puma et al., 2013).

Concepts of SCT guided EF. Self-efficacy is related with individual's capacity to perform a behavior (Bandura, 1977a, 1997). EF instructors motivated study participants helping them realize their ability to perform exercise. EF intervention addresses personal factors by having each participant play active role through goal setting, peer communication, self-regulation, and sharing thoughts. EF instructors also helped participants set reasonable goals for themselves. EF is a group based physical activity component. As proposed by Bandura, humans learn and feel motivated by observing (Bandura, 1997). Performing exercises in groups allowed study participants to observe each other and feel motivated. Further, since the class met thrice a week, it also allowed developing social networks. Prior starting the EF sessions, instructors discussed the aims of EF program. The aim of EF is to improve physical activity in older adults, which will improve their quality of life. Presenting the benefits of participation to study participants allows increasing their motivation as well as act as a reinforcing factor. Use of verbal cues during the EF session such as "Go at your own pace," "If it hurts, don't do it" allows participants to self-regulate their exercise pace. Advice was also given to study participants to make changes in the home-environment if required.

\section{Internal and External Barriers of Physical Activity}

Often physical activity interventions overlook the barriers. Understanding barriers to physical activity and creating strategies addressing these barriers will improve program 
participation rates. Barriers could be internal such as low self-efficacy, beliefs, norms or they could be external such as age, gender, race/ethnicity, socioeconomic status, insurance etcetera. Internal barriers are modifiable and several techniques have been suggested to address these barriers. Socio-demographic factors although cannot be modified through health promotion programs, are important in guiding the targeting of strategies and educational material, and identifying channels through which to reach target population.

\section{$\underline{\text { Review of internal and external barriers of physical activity }}$} Age

Inherent with aging, is a decline in general health most often due to multiple chronic diseases (Deimling, Bowman, \& Wagner, 2007; Thome, Esbensen, Dykes, \& Hallberg, 2004). Negative beliefs about aging prevent older adults form being physically active (Deimling et al., 2007; Thome et al., 2004). According to a study by Bouchard et al. (2012) increasing age is associated with lower expectations and reduced readiness with regard to lifestyle modifications. In comparison to younger age groups, older adults were reported to have low intentions to initiate and maintain physical activity (Barnes \& Schoenborn, 2003; Bouchard et al., 2012; A. C. King \& King, 2010; Martins, Assis, Nahas, Gauche, \& Moura, 2009). In another study, Aslan et al. (2008) found positive association between age and being physically inactive. Older adults defined as above 65 years of age were more likely to be inactive (Aslan et al., 2008). Increase in age is associated with less physical activity (E. Anderson et al., 2006; Aslan et al., 2008; Bongard, McDermott, Dallal, \& Schaefer, 2007; A. C. King \& King, 2010; Sjogren \& Stjernberg, 2010; Stathokostas, McDonald, Little, \& Paterson, 2013). Thus, age should be 
considered when planning a lifestyle modification program to improve physical activity levels among older adults (Bouchard et al., 2012).

\section{Gender}

High prevalence rates of physical inactivity among women haves been reported by many researchers (E. Anderson et al., 2006; Aslan et al., 2008; Barnes \& Schoenborn, 2003; Bongard et al., 2007; Crespo, Ainsworth, Keteyian, Heath, \& Smit, 1999; Crespo, Smit, Andersen, Carter-Pokras, \& Ainsworth, 2000; A. C. King \& King, 2010; Sjogren \& Stjernberg, 2010; Walter, Du Randt, \& Venter, 2011). Women are reported to participate in household activities (Marquez \& McAuley, 2006) but increasing age seems to affect physical activity level among women more negatively than men (Sjogren \& Stjernberg, 2010). Vrazel et al. (2008) reported that women are exposed to societal messages that indicate physical activity is not a priority and may be inappropriate. Further, cultural barriers, lack of social support, lack of past experience with exercise, and unavailability of safer places to exercise also result in low physical activity levels among women (El Ansari \& Lovell, 2009; Eyler et al., 2002; Gallagher et al., 2012; Sallis, King, Sirard, \& Albright, 2007; Vrazel, Saunders, \& Wilcox, 2008).

\section{Educational Status}

Inactivity is more common among individuals who are less educated (Boyette et al., 2002; Crespo et al., 1999; A. C. King \& King, 2010; A. King et al., 2000; Martins et al., 2009; Shaw \& Spokane, 2008). Level of education is found to influence perceptions of susceptibility, severity, benefits, and barriers (Glanz et al., 2008). Education takes into account an individual's capacity to obtain, process, and understand health information that is required to make health decisions (USDHHS, 2013b). Limited health literacy is a 
large barrier to health promotion programs (Sarkar, Fisher, \& Schillinger, 2006), and is more prevalent among older adults and minority groups (USDHHS, 2013b). In a study by Aslan et al. (2008), statistical significant differences among physically activity levels and number of years of schooling were found. Higher numbers of uneducated older adults were physically inactive (87.5\%) than educated older adults (48.9\%) (Aslan et al., 2008). Bungum and Morrow found in their study that individuals who had more than 11 years of education discussed about health benefits of physical activity with their physician and were more physically active (Bungum \& Morrow, 2000). Similar results have been reported by other researchers also (E. Anderson et al., 2006; Barnes \& Schoenborn, 2003).

\section{Marital Status}

Marital status has been found to be an important determinant of physical activity (Pettee et al., 2006). Married individuals when compared to single or widowed individuals are more likely to be physically active (Aslan et al., 2008; Pettee et al., 2006; Satariano, Haight, \& Tager, 2002). In a study by Pettee et al. (2006), when compared with their single counterparts, married men reported higher median levels of exercise participation $(\mathrm{p}<0.05)$ and married women reported higher levels of physical activity $(\mathrm{p}<0.05)$. Further, in spousal pairs, highly active men were almost three times as likely to have a similarly active spouse (Pettee et al., 2006).

\section{Race/Ethnicity}

Race and ethnicity may present their own set of barriers to physical activity. Physical inactivity is more prevalent among racial and ethnic minorities (E. Anderson et al., 2006; Barnes \& Schoenborn, 2003; Bongard et al., 2007; Crespo et al., 2000; A. C. 
King \& King, 2010; A. King et al., 2000; Marshall et al., 2007; Walter et al., 2011). In ethnic minorities, the removal of barriers such as unaffordable facilities and childcare, high crime rates, fear for personal safety and culturally inappropriate activities are reported to increase physical inactivity levels (Eyler et al., 2002; Seefeldt, Malina, \& Clark, 2002).

\section{Socioeconomic Status}

Socioeconomic status has been observed to play an important role in engagement in leisure time activities. Individuals living below poverty level are less likely to be physically active (Boyette et al., 2002; Crespo et al., 1999; Eyler et al., 2002; Kaiser et al., 2010; A. C. King \& King, 2010; Parks, Housemann, \& Brownson, 2003; Shaw \& Spokane, 2008). More income is related with higher education, access to better facilities and higher physical activity levels (E. Anderson et al., 2006; Barnes \& Schoenborn, 2003). Further in $2006,8.8 \%$ of adults over the age of 55 years reported not seeking medical care due to cost, and $13.4 \%$ reported delaying medical care due to cost (CDC, 2010a). Researchers identified lower income levels as being strongly associated with lower utilization of physician services, lower use of preventive services, non-adherence to recommendations for self-management, and lower health literacy (Zgibor \& Simmons, 2002; Zgibor \& Songer, 2001).

\section{Living Situation}

Living arrangement is an important determinant of leisure time physical activity (Satariano et al., 2002). In the study by Satariano et al. (2002), living arrangement was categorized based on the number of others individuals living with and relationship to participant. Data analysis indicated a significant difference for women and living 
arrangement. Women who lived with persons other than their spouse reported less engagement in brisk activity. Similarly, men who lived alone were less like to engage in brisk activity (Satariano et al., 2002). In addition, living alone is found to increase sedentary lifestyle (Pettee et al., 2006; Satariano, Haight, \& Tager, 2000) and low engagement in physical activities (Aslan et al., 2008; Hawkley, Thisted, \& Cacioppo, 2009).

Insurance Status

Low levels of physical activity are reported among those who do not have insurance (Aslan et al., 2008). Fear of injury, uncertainty about benefits and risks of physical activity, fear of cost, and lack of insurance prevents older adults from participating in programs aiming to increase physical activity levels (Dishman, Heath, \& Lee, 2012; O’Brien Cousins, 2000).

Older adults are covered through Medicare, a federal health insurance (Centers for Medicare \& Medicaid Services, 2013). Medicare covers costs associated with acute health care, requiring about $50 \%$ of total health expenditures to be covered by other means (Centers for Medicare \& Medicaid Services, 2013). Identifying ways to cover the expenses that Medicare does not cover is difficult for older adults (Jerant, von Friederichs-Fitzwater, \& Moore, 2005; Karter, Ferrara, Darbinian, Ackerson, \& Selby, 2000; Piette, Wagner, Potter, \& Schillinger, 2004; Rubin, 2005; Zgibor \& Simmons, 2002).

\section{Self-Efficacy}

Self-Efficacy is defined as individuals' ability to perform a behavior (Glanz et al., 2008). Higher Self-efficacy is found to be associated with higher levels of physical 
activity among older adults (E. Anderson et al., 2006; Kaiser et al., 2010; A. C. King \& King, 2010; McAuley \& Blissmer, 2000).

\section{Summary}

The number of older adults in the U.S. and Florida are increasing faster than ever (Florida Department of Health, 2014b; USDHHS, 2013a). In 2012, 43.1 million older adults aged 65 years and above accounted for approximately $14 \%$ of total U.S. population (USDHHS, 2014a). By 2020, this number is further expected to increase to 56 million, an increase of $36 \%$ for the decade (USDHHS, 2014a). In contrast to $14 \%$ national average, older adults constitute $18 \%$ of Florida's population (Florida Department of Health, 2014b). Unhealthy lifestyle habits like physical inactivity, poor dietary habits, smoking and physiological age-related changes put older adults at higher risk for developing chronic conditions (Fulop et al., 2010; Glei et al., 2011; Kravitz, 1996). According to the National Council on Aging, approximately 92\% of older adults have at least one chronic condition and about $77 \%$ at least two, highest percentage than any other age group (National Council on Aging, 2014). Hypertension, arthritis, osteoporosis, diabetes, coronary artery disease, stroke, visual impairment, chronic obstructive pulmonary diseases, Alzheimer's, and kidney disorders are some of the most common age-related conditions (AARP Public Policy Institute, 2009; Campbell et al., 2013; CDC, 2011b; Chou et al., 2013; Fulop et al., 2010; Glei et al., 2011; Lee et al., 2013; USDHHS: Healthy People, 2014; Ward \& Schiller, 2013). Physical activity, a modifiable factor, is found to alter the course of many chronic conditions (Dogra \& Stathokostas, 2012; USDHHS: Healthy People, 2014). Recognizing the benefits of physical activity, CDC recommends that older adults should engage in at least 150 minutes of moderate intensity 
exercise or 75 minutes of vigorous intensity exercise every week (CDC, 2011b). Despite the known benefits, few older adults follow the guidelines (BRFSS: CDC, 2011a, 2011b).

Socio-demographic factors, physical health, and psychological health are important determinants of health promotion behaviors such as physical activity (Glanz et al., 2008). Socio-demographic factors, although often non-modifiable, are important in guiding the strategies, and identify channels, which could allow reaching target population and design interventions that meet the specific needs of target population and improve adherence and completion rates. In addition, demographic factors may affect individual's perceptions and influence health-related behaviors indirectly. For example, educational attainment and knowledge impact behavior indirectly by influencing the perceptions of susceptibility, severity, benefits, and barriers; key constructs of HBM (Glanz et al., 2008). Perceived barriers, age, education, and income influence the likelihood of initiating/ maintaining a behavior (Guidry, Matthews-Juarez, \& Copeland, 2003; Skinner, Champion, Menon, \& Seshadri, 2002; Vadaparampil, Champion, Miller, Menon, \& Skinner, 2004). Identifying determinants of physical activity and designing interventions that improve physical activity levels would allow combating the problem of physical inactivity among older adults (Guidry et al., 2003; Skinner et al., 2002; Vadaparampil et al., 2004). 


\section{References}

AARP Public Policy Institute. (2009). Chronic Care : A Call to Action for Health Reform (Vol. 9, pp. 1-116). Retrieved from http://assets.aarp.org/rgcenter/health/beyond_50_hcr.pdf

AbuSabha, R., \& Achterberg, C. (1997). Review of self-efficacy and locus of control for nutrition- and health-related behavior. Journal of the American Dietetic Association, 97(10), 1122-1132.

Ackermann, R. T., Williams, B., Nguyen, H. Q., Berke, E. M., Maciejewski, M. L., \& LoGerfo, J. P. (2008). Healthcare cost differences with participation in a community-based group physical activity benefit for medicare managed care health plan members. Journal of the American Geriatrics Society, 56(8), 1459-65. doi:10.1111/j.1532-5415.2008.01804.x

AHRQ. (2002). Preventing Disability in the Elderly With Chronic Disease. Retrieved September 06, 2014, from http://www.ahrq.gov/legacy/research/elderdis.htm

Akey, J., Rintamaki, L., \& Kane, T. (2013). Health Belief Model deterrents of social support seeking among people coping with eating disorders. Journal of Affective Disorders, 145(2), 246-252. doi:10.1016/j.jad.2012.04.045.

Almeida, O. P., Draper, B., Pirkis, J., Snowdon, J., Lautenschlager, N. T., Byrne, G., ... Pfaff, J. J. (2012). Anxiety, depression, and comorbid anxiety and depression: risk factors and outcome over two years. International Psychogeriatrics, 24(10), 162232. doi:10.1017/S104161021200107X

Anderson, E., Wojcik, J., Winett, R., \& Williams, D. (2006). Social-cognitive determinants of physical activity: the influence of social support, self-efficacy, outcome expectations, and self-regulation among participants in a church-based health promotion study. Health Psychology, 25(4), 510-20.

Anderson, G., \& Horvath, J. (2004). The growing burden of chronic disease in America. Public Health Reports, 119(3), 263-70. doi:10.1016/j.phr.2004.04.005

Anderson, R., Freedland, K., Clouse, R., \& Lustman, P. (2001). The prevalence of comorbid depression in adults with diabetes: a meta-analysis. Diabetes Care, 24(6), 1069-78.

Aslan, D., Ozcebe, H., Temel, F., Takmaz, S., Topatan, S., Sahin, A., ... Tanriverdi, B. (2008). What influences physical activity among elders? A Turkish experience from Ankara, Turkey. Archives of Gerontology and Geriatrics, 46(1), 79-88. 
Bandura, A. (1977a). Self-efficacy: toward a unifying theory of behavioral change. Psychological Review, 84(2), 191-215.

Bandura, A. (1977b). Social Learning Theory (1st ed.). Englewood Cliffs: NJ: Prentice Hall.

Bandura, A. (1997). Self-Efficacy: The Exercise of Control (1st ed.). New York, NY: W.H. Freeman \& Company.

Barnes, P., \& Schoenborn, C. (2003). Advance Data From Vital and Health Statistics. $C D C, 333,1-23$. Retrieved from http://www.cdc.gov/nchs/data/ad/ad333.pdf

Batra, A., Melchior, M., Seff, L., Frederick, N., \& Palmer, R. C. (2012). Evaluation of a community-based falls prevention program in South Florida, 2008-2009. Preventing Chronic Disease, 9, E13. Retrieved from http://www.cdc.gov/pcd/issues/2012/11_0057.htm

Belza, B., Shumway-Cook, A., Phelan, E., Williams, B., Snyder, S., \& LoGerfo, J. (2006). The Effects of a Community-Based Exercise Program on Function and Health in Older Adults: The EnhanceFitness Program. Journal of Applied Gerontology, 25(4), 291-306. doi:10.1177/0733464806290934

Belza, B., Susan, S., Meghan, T., \& James, L. (2010). From Research to Practice: EnhanceFitness, an Innovative Community-Based Senior Exercise Program. Topics in Geriatric Rehabilitation, 26(4), 299-309.

Berlin, L., Norris, K., Kolodinsky, J., \& Nelson, A. (2013). The Role of Social Cognitive Theory in Farm-to-School-Related Activities: Implications for Child Nutrition The Role of Social Cognitive Theory in Farm-to-School-Related Activities: Implications for Child Nutrition. Journal of School Health, 83(8), 589-595. doi:10.1111/josh.12069

Biggs, M. L., Mukamal, K. J., Luchsinger, J. A., Ix, J. H., Carnethon, M. R., Newman, A. B., ... Siscovick, D. S. (2010). Association between adiposity in midlife and older age and risk of diabetes in older adults. JAMA : The Journal of the American Medical Association, 303(24), 2504-12. doi:10.1001/jama.2010.843

Bongard, V., McDermott, A. Y., Dallal, G. E., \& Schaefer, E. J. (2007). Effects of age and gender on physical performance. Age, 29(2-3), 77-85. doi:10.1007/s11357-0079034-z

Bosković, K., Gava, B. P., Grajić, M., Madić, D., Obradović, B., \& Todorović, S. T. (2013). [Adapted physical activity in the prevention and therapy of osteoporosis]. Medicinski Pregled, 66(5-6), 221-4. 
Bouchard, D., Langlois, M., Domingue, M., Brown, C., LeBrun, V., \& Baillargeon, J. (2012). Age differences in expectations and readiness regarding lifestyle modifications in individuals at high risk of diabetes. Archives of Physical Medicine and Rehabilitation, 93(6), 1059-64. doi:10.1016/j.apmr.2011.12.028

Boyette, L. W., Lloyd, A., Boyette, J. E., Watkins, E., Furbush, L., Dunbar, S. B., \& Brandon, J. (2002). Personal characteristics that influence exercise behavior of older adults. Journal of Rehabilitation Research and Development, 39(1), 95-103.

BRFSS: CDC. (2011a). BRFSS Prevalence Data Physical Activity "Participated in 150 minutes or more of Aerobic Physical Activity per week" : Florida 2011. Retrieved September 29, 2014, from http://apps.nccd.cdc.gov/BRFSS/age.asp?cat=PA\&yr=2011\&qkey=8271\&state=FL

BRFSS: CDC. (2011b). BRFSS Prevalence Data: Participated Muscle Strengthing exercises more than twice per week. Retrieved September 29, 2014, from http://apps.nccd.cdc.gov/BRFSS/age.asp?cat=PA\&yr=2011\&qkey=8281\&state=FL

Brookmeyer, R., Evans, D. A., Hebert, L., Langa, K. M., Heeringa, S. G., Plassman, B. L., \& Kukull, W. A. (2011). National estimates of the prevalence of Alzheimer's disease in the United States. Alzheimer's \& Dementia: The Journal of the Alzheimer's Association, 7(1), 61-73. doi:10.1016/j.jalz.2010.11.007

Bungum, T. J., \& Morrow, J. R. (2000). Differences in self-reported rationale for perceived increases in physical activity by ethnicity and gender. Research Quarterly for Exercise and Sport, 71(1), 55-60.

Byom, L. J., \& Turkstra, L. (2012). Effects of social cognitive demand on Theory of Mind in conversations of adults with traumatic brain injury. International Journal of Language \& Communication Disorders, 47(3), 310-21. doi:10.1111/j.14606984.2011.00102.x

Campbell, K. H., Huang, E. S., Dale, W., Parker, M. M., John, P. M., Young, B. A., ... Karter, A. J. (2013). Association Between Estimated GFR, Health-Related Quality of Life, and Depression Among Older Adults With Diabetes: The Diabetes and Aging Study. American Journal of Kidney Diseases, 62(3), 541-548. doi:10.1053/j.ajkd.2013.03.039

Carolyn, C. (2011). Post-thrombotic Syndrome Patient Education Based on the Health Belief Model: Self-reported Intention to Comply With Recommendations. Journal of Wound Ostomy \& Continence Nursing, 38(6), 648-654. doi:10.1097/WON.0b013e31822efc86 
CDC. (2010a). National Center for Health Statistics Health, United States, 2009: In Brief-Medical Technology. Retrieved September 29, 2014, from http://www.cdc.gov/nchs/data/hus/hus09_InBrief_MedicalTech.pdf

CDC. (2010b). The Power of Prevention: Chronic disease... the public health challenge of the 21 st century. Retrieved September 19, 2014, from http://www.cdc.gov/chronicdisease/overview/pop.htm

CDC. (2011a). Arthritis - Physical Activity for Arthritis - Overview. Retrieved September 29, 2014, from http://www.cdc.gov/arthritis/pa_overview.htm

CDC. (2011b). CDC - Chronic Disease - Healthy Aging - At A Glance. Retrieved September 29, 2014, from http://www.cdc.gov/chronicdisease/resources/publications/AAG/aging.htm

CDC. (2011c). How much physical activity do older adults need? Retrieved September 09, 2014, from http://www.cdc.gov/physicalactivity/everyone/guidelines/olderadults.html

CDC. (2011d). Obesity: Halting the epidemic by making health easier. Retrieved from http://www.cdc.gov/chronicdisease/resources/publications/aag/pdf/2011/Obesity_A AG_WEB_508.pdf

CDC. (2011e). Physical Activity for Everyone: The Benefits of Physical Activity. Retrieved September 29, 2014, from http://www.cdc.gov/physicalactivity/everyone/health/index.html\#ReduceCardiovasc ularDisease

CDC. (2011f). Physical Activity for Everyone: The Benefits of Physical Activity | DNPAO | CDC. Retrieved September 10, 2014, from http://www.cdc.gov/physicalactivity/everyone/health/

CDC. (2013). Physical Activity and Health, Older Adults. Retrieved June 26, 2014, from http://www.cdc.gov/nccdphp/sgr/olderad.htm

Centers for Medicare \& Medicaid Services. (2013). What Medicare covers. Retrieved September 29, 2014, from http://www.medicare.gov/what-medicarecovers/index.html

Chang, H. J., Lynm, C., \& Glass, R. M. (2010). Falls and older adults. JAMA : The Journal of the American Medical Association, 303(3), 288. doi:10.1001/jama.303.3.288

Chen, L., Nelson, D. R., Zhao, Y., Cui, Z., \& Johnston, J. A. (2013). Relationship between muscle mass and muscle strength, and the impact of comorbidities: a 
population-based, cross-sectional study of older adults in the United States. $B M C$ Geriatrics, 13(1), 74. doi:10.1186/1471-2318-13-74

Chen, M., Wang, R., Schneider, J., Tsai, C., Jiang, D., Hung, M., \& Lin, L. (2011). Using the Health Belief Model to understand caregiver factors influencing childhood influenza vaccinations. Journal of Community Health Nursing, 28(1), 29-40. doi:10.1080/07370016.2011.539087

Chou, C., Frances Cotch, M., Vitale, S., Zhang, X., Klein, R., Friedman, D., ... Saaddine, J. (2013). Age-related eye diseases and visual impairment among U.S. Adults. American Journal of Preventive Medicine, 45(1), 29-35. doi:10.1016/j.amepre.2013.02.018

Colberg, S. R., Sigal, R. J., Fernhall, B., Regensteiner, J. G., Blissmer, B. J., Rubin, R. R., ... Braun, B. (2010). Exercise and type 2 diabetes: the American College of Sports Medicine and the American Diabetes Association: joint position statement. Diabetes Care, 33(12), e147-67. doi:10.2337/dc10-9990

Condelius, A., Edberg, A., Jakobsson, U., \& Hallberg, I. (2008). Hospital admissions among people $65+$ related to multimorbidity, municipal and outpatient care. Archives of Gerontology and Geriatrics, 46(1), 41-55.

Conti, V., Russomanno, G., Corbi, G., \& Filippelli, A. (2012). Exercise training in aging and diseases. Translational Medicine UniSa, 3, 74-80.

Crespo, C. J., Ainsworth, B. E., Keteyian, S. J., Heath, G. W., \& Smit, E. (1999). Prevalence of physical inactivity and its relation to social class in U.S. adults: results from the Third National Health and Nutrition Examination Survey, 1988-1994. Medicine and Science in Sports and Exercise, 31(12), 1821-7.

Crespo, C. J., Smit, E., Andersen, R. E., Carter-Pokras, O., \& Ainsworth, B. E. (2000). Race/ethnicity, social class and their relation to physical inactivity during leisure time: results from the Third National Health and Nutrition Examination Survey, 1988-1994. American Journal of Preventive Medicine, 18(1), 46-53.

Crews, D. C., Plantinga, L. C., Miller, E. R., Saran, R., Hedgeman, E., Saydah, S. H., ... Powe, N. R. (2010). Prevalence of chronic kidney disease in persons with undiagnosed or prehypertension in the United States. Hypertension, 55(5), 1102-9. doi:10.1161/HYPERTENSIONAHA.110.150722

Davis, J., Buchanan, K., \& Green, B. (2013). Racial/Ethnic differences in cancer prevention beliefs: applying the health belief model framework. American Journal of Health Promotion, 27(6), 384-9. doi:10.4278/ajhp.120113-QUAN-15 
Deimling, G., Bowman, K., \& Wagner, L. (2007). The effects of cancer-related pain and fatigue on functioning of older adult, long-term cancer survivors. Cancer Nursing, $30(6), 421-33$.

Dishman, R., Heath, G., \& Lee, I. (2012). Physical Activity Epidemiology (2nd ed.). Champaign, IL: Human Kinetics.

Dogra, S., \& Stathokostas, L. (2012). Sedentary behavior and physical activity are independent predictors of successful aging in middle-aged and older adults. Journal of Aging Research, 2012. Retrieved from http://www.hindawi.com/journals/jar/2012/190654/

El Ansari, W., \& Lovell, G. (2009). Barriers to exercise in younger and older nonexercising adult women: a cross sectional study in London, United Kingdom. International Journal of Environmental Research and Public Health, 6(4), 1443-55. doi:10.3390/ijerph6041443

El-Gabalawy, R., Mackenzie, C., Shooshtari, S., \& Sareen, J. (2011). Comorbid physical health conditions and anxiety disorders: a population-based exploration of prevalence and health outcomes among older adults. General Hospital Psychiatry, 33(6), 556-64. doi:10.1016/j.genhosppsych.2011.07.005

Eyler, A. A., Matson-Koffman, D., Vest, J. R., Evenson, K. R., Sanderson, B., Thompson, J. L., ... Young, D. R. (2002). Environmental, policy, and cultural factors related to physical activity in a diverse sample of women: The Women's Cardiovascular Health Network Project--summary and discussion. Women \& Health, 36(2), 123-34.

Finlayson, M. L., \& Peterson, E. W. (2010). Falls, aging, and disability. Physical Medicine and Rehabilitation Clinics of North America, 21(2), 357-73. doi:10.1016/j.pmr.2009.12.003

Florida Department of Health. (2013a). Florida Behavioral Risk Factor Surveillance System (BRFSS) 2012 Surveillance Data (p. 51). Retrieved from http://www.floridahealth.gov/statistics-and-data/survey-data/behavioral-risk-factorsurveillance-system/reports/_documents/2012-brfss.pdf

Florida Department of Health. (2013b). Florida Population Estimates. Retrieved September 09, 2014, from http://www.floridacharts.com/FLQUERY/Population/PopulationRpt.aspx

Florida Department of Health. (2014). Florida's Population. Retrieved October 02, 2014, from http://www.floridacharts.com/charts/AtlasIntro.aspx?ID=3 
Foster, M. C., Rawlings, A. M., Marrett, E., Neff, D., Willis, K., Inker, L. A., ... Selvin, E. (2013). Cardiovascular risk factor burden, treatment, and control among adults with chronic kidney disease in the United States. American Heart Journal, 166(1), 150-156. doi:10.1016/j.ahj.2013.03.016

Fulop, T., Larbi, A., Witkowski, J., McElhaney, J., Loeb, M., Mitnitski, A., \& Pawelec, G. (2010). Aging, frailty and age-related diseases. Biogerontology, 11(5), 547-63. doi:10.1007/s10522-010-9287-2

Gallagher, P., Yancy, W., Swartout, K., Denissen, J., Kühnel, A., \& Voils, C. (2012). Age and sex differences in prospective effects of health goals and motivations on daily leisure-time physical activity. Preventive Medicine, 55(4), 322-4. doi:10.1016/j.ypmed.2012.07.017

Geller, K. S., Mendoza, I. D., Timbobolan, J., Montjoy, H. L., \& Nigg, C. R. (2012). The decisional balance sheet to promote healthy behavior among ethnically diverse older adults. Public Health Nursing, 29(3), 241-6. doi:10.1111/j.1525-1446.2011.00987.x

Gijsen, R., Hoeymans, N., Schellevis, F., Ruwaard, D., Satariano, W., \& van den Bos, G. (2001). Causes and consequences of comorbidity: a review. Journal of Cinical Epidemiology, 54(7), 661-74.

Glanz, K., Rimer, B. K., \& Viswanath, K. (2008). Health Behavior and Health Education: Theory, Research, and Practice (4th ed.). San Francisco, CA: JosseyBass.

Glei, D., Goldman, N., Lin, Y., \& Weinstein, M. (2011). Age-Related Changes in Biomarkers: Longitudinal Data from a Population-Based Sample. Research on Aging, 33(3), 312-326. doi:10.1177/0164027511399105

Guidry, J., Matthews-Juarez, P., \& Copeland, V. (2003). Barriers to breast cancer control for African-American women: the interdependence of culture and psychosocial issues. Cancer, 97(1 Suppl), 318-23.

Guvenc, G., Akyuz, A., \& Açikel, C. H. (2011). Health Belief Model Scale for Cervical Cancer and Pap Smear Test: psychometric testing. Journal of Advanced Nursing, 67(2), 428-37. doi:10.1111/j.1365-2648.2010.05450.x

Hawkley, L. C., Thisted, R. A., \& Cacioppo, J. T. (2009). Loneliness predicts reduced physical activity: cross-sectional \& longitudinal analyses. Health Psychology, 28(3), 354-63. doi:10.1037/a0014400

Hebert, L. E., Scherr, P. A., Bienias, J. L., Bennett, D. A., \& Evans, D. A. (2003). Alzheimer disease in the US population: prevalence estimates using the 2000 census. Archives of Neurology, 60(8), 1119-22. 
Hersil, S. (2011). Descriptive study of injuries and deaths due to falls among adults 65 and older in Lincoln County, Wisconsin. University of Wisconsin. Retrieved from http://digital.library.wisc.edu/1793/53280

Høidrup, S., Sørensen, T., Strøger, U., Lauritzen, J., Schroll, M., \& Grønbaek, M. (2001). Leisure-time physical activity levels and changes in relation to risk of hip fracture in men and women. American Journal of Epidemiology, 154(1), 60-8.

Hootman, J. M., \& Helmick, C. G. (2006). Projections of US prevalence of arthritis and associated activity limitations. Arthritis and Rheumatism, 54(1), 226-9. doi:10.1002/art.21562

Jerant, A., von Friederichs-Fitzwater, M., \& Moore, M. (2005). Patients' perceived barriers to active self-management of chronic conditions. Patient Education and Counseling, 57(3), 300-7. doi:10.1016/j.pec.2004.08.004

Kaiser, B. L., Brown, R. L., \& Baumann, L. C. (2010). Perceived influences on physical activity and diet in low-income adults from two rural counties. Nursing Research, 59(1), 67-75. doi:10.1097/NNR.0b013e3181c3bd55

Karter, A. J., Ferrara, A., Darbinian, J. A., Ackerson, L. M., \& Selby, J. V. (2000). Selfmonitoring of blood glucose: language and financial barriers in a managed care population with diabetes. Diabetes Care, 23(4), 477-83.

King, A. C., \& King, D. K. (2010). Physical Activity for an Aging Population. Public Health Reviews, 32, 401-426.

King, A., Castro, C., Wilcox, S., Eyler, A., Sallis, J., \& Brownson, R. C. (2000). Personal and environmental factors associated with physical inactivity among different racialethnic groups of U.S. middle-aged and older-aged women. Health Psychology, 19(4), 354-64.

Kirkman, M. S., Briscoe, V. J., Clark, N., Florez, H., Haas, L. B., Halter, J. B., ... Swift, C. S. (2012). Diabetes in older adults. Diabetes Care, 35(12), 2650-64. doi:10.2337/dc12-1801

Korpelainen, R., Keinanen-Kiukaanniemi, S., Heikkinen, J., Vaananen, K., \& Korpelainen, J. (2006). Effect of impact exercise on bone mineral density in elderly women with low BMD: a population-based randomized controlled 30-month intervention. Osteoporosis International, 17(1), 109-18. doi:10.1007/s00198-005$1924-2$

Kravitz, L. (1996). Age and Exercise. IDEA Today, 14(2), 28-35. Retrieved from http://www.unm.edu/ lkravitz/Article folder/age.html 
Lawrence, R. C., Felson, D. T., Helmick, C. G., Arnold, L. M., Choi, H., Deyo, R. A., ... Wolfe, F. (2008). Estimates of the prevalence of arthritis and other rheumatic conditions in the United States. Part II. Arthritis and Rheumatism, 58(1), 26-35. doi:10.1002/art.23176

Lee, P., Cigolle, C., Ha, J., Min, L., Murphy, S., Blaum, C., \& Herman, W. (2013). Physical Function Limitations Among Middle-aged and Older Adults With Prediabetes: One exercise prescription may not fit all. Diabetes Care, 36(10), 307683. doi:10.2337/dc13-0412

Lehnert, T., Heider, D., Leicht, H., Heinrich, S., Corrieri, S., Luppa, M., ... Konig, H. (2011). Review: health care utilization and costs of elderly persons with multiple chronic conditions. Medical Care Research and Review, 68(4), 387-420. doi: $10.1177 / 1077558711399580$

Lochner, K., \& Cox, C. (2013). Prevalence of multiple chronic conditions among Medicare beneficiaries, United States, 2010. Preventing Chronic Disease, 10. Retrieved from http://www.cdc.gov/pcd/issues/2013/12_0137.htm

Marlatt, G., \& Gordon, J. (2005). Relapse Prevention: Maintenance Strategies in the Treatment of Addictive Behaviors (2nd ed.). New York, NY: The Guilford Press.

Marquez, D. X., \& McAuley, E. (2006). Gender and acculturation influences on physical activity in Latino adults. Annals of Behavioral Medicine: A Publication of the Society of Behavioral Medicine, 31(2), 138-44. doi:10.1207/s15324796abm3102_5

Marshall, S. J., Jones, D. A., Ainsworth, B. E., Reis, J. P., Levy, S. S., \& Macera, C. A. (2007). Race/ethnicity, social class, and leisure-time physical inactivity. Medicine and Science in Sports and Exercise, 39(1), 44-51. doi:10.1249/01.mss.0000239401.16381.37

Martins, T., Assis, M. A., Nahas, M., Gauche, H., \& Moura, E. (2009). Leisure-time physical inactivity in adults and factors associated. Revista de Saúde Pública, 43(5), 814-24.

McAuley, E., \& Blissmer, B. (2000). Self-efficacy determinants and consequences of physical activity. Exercise and Sport Sciences Reviews, 28(2), 85-8.

Michaelsson, K., Olofsson, H., Jensevik, K., Larsson, S., Mallmin, H., Berglund, L., ... Melhus, H. (2007). Leisure physical activity and the risk of fracture in men. PLoS Medicine, 4(6), e199. doi:10.1371/journal.pmed.0040199

Moore-Harrison, T. L., Johnson, M. A., Quinn, M. E., \& Cress, M. E. (2009). An evidence-based exercise program implemented in congregate-meal sites. Journal of Physical Activity \& Health, 6(2), 247-51. 
Morseth, B., Ahmed, L. A., Bjørnerem, Å., Emaus, N., Jacobsen, B. K., Joakimsen, R., ... Jørgensen, L. (2012). Leisure time physical activity and risk of non-vertebral fracture in men and women aged 55 years and older: the Tromsø Study. European Journal of Epidemiology, 27(6), 463-71. doi:10.1007/s10654-012-9665-y

Munshi, M., Grande, L., Hayes, M., Ayres, D., Suhl, E., Capelson, R., ... Weinger, K. (2006). Cognitive dysfunction is associated with poor diabetes control in older adults. Diabetes Care, 29(8), 1794-9. doi:10.2337/dc06-0506

National Cancer Institute. (2009). Physical Activity and Cancer - National Cancer Institute. Retrieved September 27, 2014, from http://www.cancer.gov/cancertopics/factsheet/prevention/physicalactivity

National Center for Health Statistics. (2014). FastStats - Homepage. Retrieved September 24, 2014, from http://www.cdc.gov/nchs/fastats/

National Council on Aging. (2014). Chronic Disease Self-Management: Fact Sheet. Retrieved October 03, 2014, from http://www.ahrq.gov/legacy/research/elderdis.htm

Neid, R. J., \& Franklin, B. (2002). Promoting and Prescribing Exercise in the Elderly. American Family Physician, 65(3), 419-427.

Nelson, M. E., Rejeski, W. J., Blair, S. N., Duncan, P. W., Judge, J. O., King, A. C., ... Castaneda-Sceppa, C. (2007). Physical activity and public health in older adults: recommendation from the American College of Sports Medicine and the American Heart Association. Medicine and Science in Sports and Exercise, 39(8), 1435-45. doi:10.1249/mss.0b013e3180616aa2

NIAMS. (2012). Questions and Answers About Gout. Retrieved June 06, 2014, from http://www.niams.nih.gov/Health_Info/Gout/\#do

NIH. (2012). Exercise: Benefits of Exercise. Retrieved June 06, 2014, from http://nihseniorhealth.gov/exerciseforolderadults/healthbenefits/01.html

NIH Osteoporosis and Related Bone Diseases National Resource Center. (2012).

Exercise for your bone health. Retrieved June 06, 2014, from http://www.niams.nih.gov/Health_Info/Bone/Bone_Health/Exercise/

O'Brien Cousins, S. (2000). "My heart couldn't take it": older women's beliefs about exercise benefits and risks. The Journals of Gerontology. Series B, Psychological Sciences and Social Sciences, 55(5), P283-94.

O’Hea, E. L., Moon, S., Grothe, K. B., Boudreaux, E., Bodenlos, J. S., Wallston, K., \& Brantley, P. J. (2009). The interaction of locus of control, self-efficacy, and outcome expectancy in relation to $\mathrm{HbA} 1 \mathrm{c}$ in medically underserved individuals with type 2 
diabetes. Journal of Behavioral Medicine, 32(1), 106-17. doi:10.1007/s10865-0089188-x

Page, T. F., Batra, A., Ghouse, M. M., \& Palmer, R. C. (2014). Implementation Cost Analysis of a Community-Based Exercise Program for Seniors in South Florida. Health Promotion Practice, 15(4), 585-591. doi:10.1177/1524839913518221

Park, S. W., Goodpaster, B. H., Strotmeyer, E. S., de Rekeneire, N., Harris, T. B., Schwartz, A. V, ... Newman, A. B. (2006). Decreased muscle strength and quality in older adults with type 2 diabetes: the health, aging, and body composition study. Diabetes, 55(6), 1813-8. doi:10.2337/db05-1183

Parks, S. E., Housemann, R. A., \& Brownson, R. C. (2003). Differential correlates of physical activity in urban and rural adults of various socioeconomic backgrounds in the United States. Journal of Epidemiology and Community Health, 57(1), 29-35.

Pettee, K. K., Brach, J. S., Kriska, A. M., Boudreau, R., Richardson, C. R., Colbert, L. H., ... Newman, A. B. (2006). Influence of marital status on physical activity levels among older adults. Medicine and Science in Sports and Exercise, 38(3), 541-546. doi:10.1249/01.mss.0000191346.95244.f7

Piette, J. D., Wagner, T. H., Potter, M. B., \& Schillinger, D. (2004). Health insurance status, cost-related medication underuse, and outcomes among diabetes patients in three systems of care. Medical Care, 42(2), 102-109. doi:10.1097/01.mlr.0000108742.26446.17

Puma, J., Romaniello, C., Crane, L., Scarbro, S., Belansky, E., \& Marshall, J. A. (2013). Long-term Student Outcomes of the Integrated Nutrition and Physical Activity Program. Journal of Nutrition Education and Behavior, 45(6), 635-642. doi:10.1016/j.jneb.2013.05.006

Reid, K. J., Baron, K. G., Lu, B., Naylor, E., Wolfe, L., \& Zee, P. C. (2010). Aerobic exercise improves self-reported sleep and quality of life in older adults with insomnia. Sleep Medicine, 11(9), 934-40. doi:10.1016/j.sleep.2010.04.014

Rikli, R. E., \& Jones, C. J. (1997). Assessing physical performance in independent older adults: Issues and Guidelines. Journal of Aging and Physical Activity, 5, 244-261.

Rikli, R. E., \& Jones, C. J. (1999a). Development and Validation of a Functional Fitness Test for Community-Residing Older Adults. Journal of Aging and Physical Activity, 7, 129-161.

Rikli, R. E., \& Jones, C. J. (1999b). Functional Fitness Normative Scores for Community-Residing Older Adults, Ages 60-94. Journal of Aging and Physical Activity, 7, 162-181. 
Rikli, R. E., \& Jones, C. J. (2001). Senior Fitness Test Manual. (H. Kinetics, Ed.). Champaign, IL.

Rikli, R. E., \& Jones, C. J. (2013). Development and validation of criterion-referenced clinically relevant fitness standards for maintaining physical independence in later years. The Gerontologist, 53(2), 255-67. doi:10.1093/geront/gns071

Rothrock, N. E., Hays, R. D., Spritzer, K., Yount, S. E., Riley, W., \& Cella, D. (2010). Relative to the general US population, chronic diseases are associated with poorer health-related quality of life as measured by the Patient-Reported Outcomes Measurement Information System (PROMIS). Journal of Clinical Epidemiology, 63(11), 1195-204. doi:10.1016/j.jclinepi.2010.04.012

Rubin, R. R. (2005). Adherence to pharmacologic therapy in patients with type 2 diabetes mellitus. The American Journal of Medicine, 118(5A), 27S-34S. doi:10.1016/j.amjmed.2005.04.012

Salive, M. E. (2013). Multimorbidity in Older Adults. Epidemiologic Reviews, 35(1), 7583. doi:10.1093/epirev/mxs009

Sallis, J. F., King, A. C., Sirard, J. R., \& Albright, C. L. (2007). Perceived environmental predictors of physical activity over 6 months in adults: activity counseling trial. Health Psychology, 26(6), 701-709. doi:10.1037/0278-6133.26.6.701

Sarkar, U., Fisher, L., \& Schillinger, D. (2006). Is self-efficacy associated with diabetes self-management across race/ethnicity and health literacy? Diabetes Care, 29(4), 823-9.

Satariano, W., Haight, T., \& Tager, I. (2000). Reasons given by older people for limitation or avoidance of leisure time physical activity. Journal of the American Geriatrics Society, 48(5), 505-12.

Satariano, W., Haight, T., \& Tager, I. (2002). Living arrangements and participation in leisure-time physical activities in an older population. Journal of Aging and Health, 14(4), 427-51.

Sayegh, P., \& Knight, B. (2013). Cross-cultural differences in dementia: the Sociocultural Health Belief Model. International Psychogeriatrics, 25(4), 517-30. doi:10.1017/S104161021200213X

Schafer, I., von Leitner, E., Schon, G., Koller, D., Hansen, H., Kolonko, T., ... van den Bussche, H. (2010). Multimorbidity patterns in the elderly: a new approach of disease clustering identifies complex interrelations between chronic conditions. PloS One, 5(12), e15941. doi:10.1371/journal.pone.0015941 
Schneider, K., O'Donnell, B., \& Dean, D. (2009). Prevalence of multiple chronic conditions in the United States' Medicare population. Health and Quality of Life Outcomes, 7, 82. doi:10.1186/1477-7525-7-82

Schoen, C., Osborn, R., How, S., Doty, M., \& Peugh, J. (2009). In chronic condition: experiences of patients with complex health care needs, in eight countries, 2008. Health Affairs, 28(1), w1-w16. doi:10.1377/hlthaff.28.1.w1

Schoenberg, N. E., Kim, H., Edwards, W., \& Fleming, S. T. (2007). Burden of common multiple-morbidity constellations on out-of-pocket medical expenditures among older adults. The Gerontologist, 47(4), 423-37.

Seefeldt, V., Malina, R. M., \& Clark, M. A. (2002). Factors affecting levels of physical activity in adults. Sports Medicine, 32(3), 143-68.

Senior Services. (2013). Enhance Fitness. Retrieved October 02, 2014, from http://www.projectenhance.org/EnhanceFitness.aspx

Shaw, B. A., \& Spokane, L. S. (2008). Examining the association between education level and physical activity changes during early old age. Journal of Aging and Health, 20(7), 767-87. doi:10.1177/0898264308321081

Shih, M., Hootman, J. M., Kruger, J., \& Helmick, C. G. (2006). Physical activity in men and women with arthritis National Health Interview Survey, 2002. American Journal of Preventive Medicine, 30(5), 385-93. doi:10.1016/j.amepre.2005.12.005

Sjogren, K., \& Stjernberg, L. (2010). A gender perspective on factors that influence outdoor recreational physical activity among the elderly. BMC Geriatrics, 10, 34. doi:10.1186/1471-2318-10-34

Skinner, C. S., Champion, V., Menon, U., \& Seshadri, R. (2002). Racial and Educational Differences in Mammography-Related Perceptions Among 1,336 Nonadherent Women. Journal of Psychosocial Oncology, 20(3), 1-18. doi:10.1300/J077v20n03_01

Starfield, B., Lemke, K. W., Herbert, R., Pavlovich, W. D., \& Anderson, G. (2005). Comorbidity and the use of primary care and specialist care in the elderly. Annals of Family Medicine, 3(3), 215-22. doi:10.1370/afm.307

Stathokostas, L., McDonald, M., Little, R., \& Paterson, D. (2013). Flexibility of older adults aged 55-86 years and the influence of physical activity. Journal of Aging Research, 2013. Retrieved from http://www.hindawi.com/journals/jar/2013/743843/

Stewart, K. J. (2005). Physical activity and aging. Annals of the New York Academy of Sciences, 1055, 193-206. doi:10.1196/annals.1323.029 
Sue Kirkman, M., Briscoe, V. J., Clark, N., Florez, H., Haas, L. B., Halter, J. B., ... Swift, C. S. (2012). Diabetes in older adults: a consensus report. Journal of the American Geriatrics Society, 60(12), 2342-56. doi:10.1111/jgs.12035

Sugihara, N., Watanabe, M., Tomioka, M., Braun, K. L., \& Pang, L. (2011). Cost-benefit estimates of an elderly exercise program on Kaua'i. Hawaii Medical Journal, 70(6), $116-20$.

Tenkorang, E. (2013). A Multilevel Path Analysis of Risk Perception and Risky Sexual Behavior Under the Framework of the Health Belief Model. Journal of HIV/AIDS \& Social Services, 12(2), 125-145. doi:10.1080/15381501.2013.764489

Thome, B., Esbensen, B., Dykes, A., \& Hallberg, I. (2004). The meaning of having to live with cancer in old age. European Journal of Cancer Care, 13(5), 399-408. doi:10.1111/j.1365-2354.2004.00542.x

Thorpe, K. E., Ogden, L. L., \& Galactionova, K. (2010). Chronic conditions account for rise in Medicare spending from 1987 to 2006. Health Affairsffairs, 29(4), 718-724. doi:10.1377/hlthaff.2009.0474

Tomioka, M., Sugihara, N., \& Braun, K. L. (2012). Replicating the EnhanceFitness physical activity program in Hawai i's multicultural population, 2007-2010. Preventing Chronic Disease, 9, E74. Retrieved from http://www.cdc.gov/pcd/issues/2012/11_0155.htm

Tucker-Seeley, R. D., Li, Y., Sorensen, G., \& Subramanian, S. V. (2011). Lifecourse socioeconomic circumstances and multimorbidity among older adults. BMC Public Health, 11, 313. doi:10.1186/1471-2458-11-313

USDHHS. (2013a). A Profile of Older Americans : 2012. Retrieved from http://www.aoa.gov/Aging_Statistics/Profile/2012/docs/2012profile.pdf

USDHHS. (2013b). Improving Health Literacy | Health.gov (ODPHP). Retrieved July 09, 2014, from http://www.health.gov/communication/literacy/

USDHHS. (2014). Profile of Older Americans: 2013. Retrieved from http://www.aoa.gov/Aging_Statistics/Profile/Index.aspx

USDHHS: Healthy People. (2014). Older Adults - Healthy People 2020. Washington DC. Retrieved from http://www.healthypeople.gov/2020/topicsobjectives2020/overview.aspx?topicid=3 1 
USDHHS: National Cancer Institute. (2005). Theory at a Glance: A Guide For Health Promotion Practice (2nd ed.). Retrieved from http://www.cancer.gov/cancertopics/cancerlibrary/theory.pdf

USDHHS: National Heart, Lung, and B. I. (2011). What Is Metabolic Syndrome? Retrieved from http://www.nhlbi.nih.gov/health/health-topics/topics/ms/

Vadaparampil, S. T., Champion, V. L., Miller, T. K., Menon, U., \& Skinner, C. S. (2004). Using the Health Belief Model to Examine Differences in Adherence to Mammography Among African-American and Caucasian Women. Journal of Psychosocial Oncology, 21(4), 59-79. doi:10.1300/J077v21n04_04

Vrazel, J., Saunders, R. P., \& Wilcox, S. (2008). An overview and proposed framework of social-environmental influences on the physical-activity behavior of women. American Journal of Health Promotion, 23(1), 2-12. doi:10.4278/ajhp.06070999

Wallace, J. I., Buchner, D. M., Grothaus, L., Leveille, S., Tyll, L., LaCroix, A. Z., \& Wagner, E. H. (1998). Implementation and effectiveness of a community-based health promotion program for older adults. The Journals of Gerontology. Series A, Biological Sciences and Medical Sciences, 53(4), M301-6.

Walter, C. M., Du Randt, R., \& Venter, D. J. L. (2011). The physical activity and health status of two generations of Black South African professional women. Health SA Gesondheid, 16(1), 9. doi:10.4102/hsag.v16i1.538

Walters, A., \& Bandura, R. H. (1963). Social Learning and Personality Development. New York, NY: Holt, Rinehart and Winston, Inc.

Ward, B., \& Schiller, J. (2013). Prevalence of multiple chronic conditions among US adults: estimates from the National Health Interview Survey, 2010. Preventing Chronic Disease, 10, E65. Retrieved from http://www.cdc.gov/pcd/issues/2013/12_0203.htm

Wolff, J. L., Starfield, B., \& Anderson, G. (2002). Prevalence, expenditures, and complications of multiple chronic conditions in the elderly. Archives of Internal Medicine, 162(20), 2269-76.

Wright, P., Randall, A., \& Hayes, J. (2012). Predicting the Condom Assertiveness of Collegiate Females in the United States From the Expanded Health Belief Model. International Journal of Sexual Health, 24(2), 137-153. doi:10.1080/19317611.2012.661396

Yang, P., Ho, K., Chen, H., \& Chien, M. (2012). Exercise training improves sleep quality in middle-aged and older adults with sleep problems: a systematic review. Journal of Physiotherapy, 58(3), 157-63. doi:10.1016/S1836-9553(12)70106-6 
Zgibor, J., \& Simmons, D. (2002). Barriers to blood glucose monitoring in a multiethnic community. Diabetes Care, 25(10), 1772-7.

Zgibor, J., \& Songer, T. (2001). External Barriers to Diabetes Care: Addressing Personal and Health Systems Issues. Diabetes Spectrum, 14(1), 23-28. doi:10.2337/diaspect.14.1.23

Ziden, L., Haggblom-Kronlof, G., Gustafsson, S., Lundin-Olsson, L., \& Dahlin-Ivanoff, S. (2013). Physical Function and Fear of Falling 2 Years After the Health-Promoting Randomized Controlled Trial: Elderly Persons in the Risk Zone. The Gerontologist, 54(3), 387-397. doi:10.1093/geront/gnt078 


\section{CHAPTER 3}

\section{Manuscript Title: Are Group Exercise Programs Effective in Older Adults? Determining the Effectiveness of a Community-Based Exercise Program 'EnhanceFitness' at 4-months}

\section{Introduction}

The role of physical activity in combating obesity, chronic conditions, and associated comorbidities is well known (Dogra \& Stathokostas, 2012; USDHHS: Healthy People, 2014). The Centers for Disease Control and Prevention (CDC) recommends that older adults aged 60 and above should engage in at least 150 minutes of moderate intensity or 75 minutes of vigorous intensity aerobic exercise every week (CDC, 2011c), along with muscle strengthening exercises on two or more days every week. Following the guidelines reduces the risk of many chronic conditions including heart diseases, stroke, diabetes mellitus, arthritis, some cancers, and osteoporosis etcetera (CDC, 2011c). This level of exercise also reduces the risk of depression and improves the overall psychological state of individuals (CDC, 2014c).

Despite the evidence of benefits from physical activity, over half of Americans were reported to be inactive in 2012 (CDC, 2014a; USDHHS: Healthy People, 2014). The rates of inactivity are highest among older adults (A. C. King \& King, 2010; White et al., 2005). Data from the National Center for Health Statistics revealed that in 2012, only $37.5 \%$ of older adults aged 60 years and older met recommended aerobic physical activity levels (National Center for Health Statistics, 2014a). This number drops to $16.1 \%$ for those who met the muscle-strengthening guidelines to work all major muscle groups for two or more days a week (National Center for Health Statistics, 2014a). 
Older adults are likely to benefit from participation in structured exercise programs (Belza et al., 2006). Group exercise programs led by trained instructors provide a safe and structured environment for participants, including for those who are frail or disabled (National Council on Aging, 2005; Neid \& Franklin, 2002b). These programs are known to improve aerobic capacity of older adults, including those who suffer from mild to moderate cardiovascular diseases and other chronic conditions including arthritis (Pang, Eng, Dawson, \& Gylfadóttir, 2006). Improved physical activity levels can help prevent or delay the onset of many physical and psychological conditions that commonly occur with aging (Dogra \& Stathokostas, 2012; Kravitz, 1996; Rogers \& Keller, 2009; USDHHS: Healthy People, 2014). In addition, following the guidelines also promotes effective management of stress, improves sleep and related disorders, and enhances mental outlook thereby lowering risk of depression and anxiety (Dogra \& Stathokostas, 2012; Kravitz, 1996; Rogers \& Keller, 2009; USDHHS: Healthy People, 2014).

EF is a group exercise program designed specifically to increase strength, flexibility, and balance of older adults (Belza et al., 2006; Senior Services, 2012; Wallace et al., 1998). EF was developed, tested, and found efficacious in 1998 (Wallace et al., 1998). As of today, EF is offered in 26 states at approximately 141 sites (Senior Services, 2013); however, we could find only three studies reporting on the effectiveness of EF (Belza et al., 2006; Moore-Harrison et al., 2009; Tomioka et al., 2012). We aim to fill this gap by analyzing data from an ongoing EF program offered to older adults in South Florida. The purpose of the current study is to assess the effectiveness of EF at 4-months, and to evaluate the impact of program completion on health outcomes. 


\section{Methods}

\section{Setting}

The Health Foundation of South Florida established Healthy Aging Regional Collaborative (HARC) in fall 2008 to offer EF to older adults. As part of HARC, Health Foundation of South Florida funded 14 area-agencies between October 1, 2008 and December 31, 2012 to implement EF in Broward, Miami-Dade, and Monroe counties in South Florida. A total of 160 workshops, lasting at least 4-months, were offered. Sites chosen by the agencies included adult day care centers, senior centers, clinics, hospitals, skilled nursing facilities, assisted living facilities, community centers, or senior housing.

\section{Study Participants and Recruitment}

EF was offered to older adults, at least 60 years old, who were cognitively able to follow instructions. Individuals who had serious medical conditions, such as end-stage renal or heart disease that prohibited exercise, were excluded. Agencies offering the workshops recruited participants using a variety of methods including flyers, posters, and word of mouth.

\section{EF Overview}

$\mathrm{EF}$ is an evidence-based, low-cost, group exercise program for older adults (Belza et al., 2006, 2010; Page et al., 2014; Senior Services, 2013; Wallace et al., 1998). EF, formerly known as 'Lifetime Fitness Program', was developed, tested, and found efficacious in improving physical and psychosocial functioning of participants in 1998 (Wallace et al., 1998). The original evaluation of EF was conducted for six months in a controlled environment and consisted of a one-hour session held three times a week (Wallace et al., 1998). EF focuses on stretching, flexibility, balance, low impact aerobics, 
and strength training exercises. EF is designed to help older adults at all levels of fitness become more active, energized, and empowered to sustain independent lives (Belza et al., 2006, 2010; Moore-Harrison et al., 2009; Tomioka et al., 2012; Wallace et al., 1998). While the developers of EF define a complete course as three sessions per week for 4months (Belza et al., 2006, 2010), HARC offered EF on an ongoing basis. The class structure and material was similar to the original EF program; however, program participation was voluntary and was implemented by community-based agencies in real world settings in South Florida.

\section{Instructor Training and Fidelity Monitoring}

An EF Master Trainer from Senior Services, an organization that oversees the management of EF, trained EF instructors. In addition, all instructors were required to have a fitness certification from a nationally recognized certifying organization.

To ensure consistency in the delivery of the program as intended, $30 \%$ of offered EF workshops were monitored randomly using a fidelity instrument. The fidelity instrument was reflective of core components of interventions. Observations focused on (1) workshop environment, (2) instructor performance, (3) suitability of site, and (4) session content based on developers' instructor manual.

\section{Data Collection}

On the first day of the workshop, participants were asked to complete a consent form, participant information, and health history form. In addition, the functional performance of participants was tested using the FFT battery at baseline (T1) and every 4-months thereafter $(\mathrm{T} 2, \mathrm{~T} 3, \mathrm{~T} 4, \ldots)$ for those who continued in the program. 


\section{Measures}

Demographics

A participant information form was used to collect demographic information including gender, date of birth, address, marital status, disability, primary language, race/ethnicity, income, living situation, and insurance (Table 3.1).

\section{Health History Form}

In the health history form, participants were asked about their known medical condition(s), medication(s), and allergies. In addition, participants were asked to do a self-assessment of their physical fitness level and report on their weekly exercise schedule.

\section{Functional Performance Measures}

Outcome measures for the current study were collected using a fitness check form. Participants' functional performance was assessed by instructors using the FFT battery developed by Rikli and Jones (Belza et al., 2006; Jones, Rikli, \& Beam, 1999; Rikli \& Jones, 1999a). The original FFT was composed of seven fitness activity measures with intraclass reliability ranging from 0.79 to 0.95 (Belza et al., 2006; Jones et al., 1999; Rikli \& Jones, 1999a). In addition, Jones et al. (1999) assessed the reliability, criterionrelated and construct validity of a 30 -second chair stand as a measure of lower body strength. The item was reported to have test-retest intraclass correlations of 0.84 for men and 0.92 for women (Jones et al., 1999). After receiving feedback from instructors regarding difficulties in collecting the seven activity measures in community-based settings, Senior Services who oversees the management, dissemination, and licensing of EF since 1999, tested and decided to retain three FFT activities (Belza et al., 2006). 
These three items include (1) number of chair stands performed in 30 seconds, (2) number of arm curls performed in 30 seconds, and (3) time taken to complete an eightfoot up-and-go activity (Belza et al., 2006). This study used the same three activities. Lower body strength of participants was assessed by counting the number of full chair stands performed in 30 seconds with arms folded across the chest (Belza et al., 2006; Rikli \& Jones, 1999a; Senior Services, 2012). To measure upper body strength, participants were asked to perform arm curls for 30 seconds holding $5 \mathrm{lbs}$. weight for females and $8 \mathrm{lbs}$. for males. Agility and balance were assessed by recording the time taken to complete an eight foot circuit in which participants were asked to stand up, walk for a distance of eight feet quickly and safely, return, and get seated in their chair (Belza et al., 2006; Rikli \& Jones, 1999a; Senior Services, 2012).

\section{Health Status}

Participants rated their health status using a single-item scale $(1=$ poor and $5=$ excellent) adopted from National Health Interview Survey. This item has a test-retest reliability of 0.92 . It has been used in several studies of programs other than EF and has been reported to be a reliable predictor of health (Lorig et al., 1996; Stanford Patient Education Research Center, 2007).

\section{Data Extraction}

Data were extracted from an online database for the period October 1, 2008 through December 31, 2012, imported into Statistical Package for the Social Sciences (SPSS) version 21.0 (IBM Corp, 2012), cleaned, and reverse coded as required. 


\section{Data Synthesis}

The chronic conditions from the health history form were consolidated into a chronic conditions variable. The chronic conditions identified by participants were enumerated into four categories: none, one, two, and three or more (Table 3.1). Program completion in this study was defined as attending $66 \%$ of offered EF sessions or 32 of 48 sessions in 4-months ( $\sim 16$ weeks) as suggested by Bazia et al. (2010) as a minimum number of sessions required in order to attain program benefits. The number of sessions attended was dichotomized such that participants who attended at least 32 sessions within first 4-months following their start date were coded as "completers" and those who attended fewer than 32 sessions were coded as "non-completers."

\section{Statistical Analyses}

Participants who had a follow-up fitness check performed between 12 to 20 weeks from the first date of attendance were included in the current study. Outliers were identified using P-P plots. Overall participant characteristics and participant characteristics based on the completion status were described (Table 3.1).

\section{Effectiveness of the EF Program}

The effectiveness of EF was evaluated by comparing outcome measures between completers and non-completers, from baseline to 4-months follow-up. Both groups were also evaluated for baseline differences on outcome measures using independent samples $t$-test (Table 3.2). There were no significant differences among completers and noncompleters at baseline in the number of chairs stands performed in 30 seconds $(t=-$ 1.141, $d f=1,148, p=.254$ ) (Table 3.2). Similarly, no significant differences among completers and non-completers were found in the number of arm curls performed in 30 
seconds and time taken to complete eight-foot up-and-go activity at baseline $(\mathrm{t}=0.777, d f$ $=1,149, p=.437$ and $\mathrm{t}=1.856, d f=1,135, p=.064$, respectively) (Table 3.2$)$. Change in outcome measures were compared using paired-samples $t$-test for continuous variable and McNemar's Bowker test for categorical variables.

\section{Results}

\section{Participant Characteristics}

Based on inclusion criterion, 1,175 participants who attended an EF workshop between October 1, 2008 and December 31, 2012 and had follow-up fitness check performed between 12 to 20 weeks from the first date of attendance were included in the current study were included in this study (Table 3.1). Approximately 41\% were 70-79 years old with mean age of $76.9( \pm 8.9)$ years. More women $(82.3 \%)$ than men $(14.6 \%)$ participated in EF program. Half of the participants lived in Miami-Dade County. Approximately $44 \%$ of participants identified themselves as non-Hispanic whites. Nearly two-thirds of participants identified English as their primary language. Approximately $60 \%$ of participants identified themselves as single/not partnered and $47.7 \%$ lived alone.

Almost one-third of participants were college graduates and reported an annual income of more than $\$ 15,000$. Most of the participants $(73 \%)$ were enrolled in either Medicare or Medicaid. Few participants (11.4\%) identified themselves as frail/disabled and $8.8 \%$ reported to suffer from depression. Approximately $82 \%$ of study participants suffered from one or more chronic conditions and 53\% had at least two chronic conditions. About $40 \%$ rated their health status as either very good or excellent (Table 3.1). 
Change in Outcome Measures: Effectiveness Results

Of 1,175 eligible participants who had their follow-up fitness check done between 12 to 20 weeks, $586(49.9 \%)$ completed the program by attending 32 or more of 48 given sessions within 4-monthss from their first date of attendance. The number of participants with data at both baseline (T1) and T2 varied for each performance measure (Table 3.3).

Tables 3.3 and 3.4 compare baseline and follow-up scores on functional performance measures, health status, and number of falls, for participants who participated in the EF program for at least 4-months. A paired sample t-test revealed a significant mean increase of 3.4 in the number of chair stands performed in 30 -seconds for completers $(p<0.001)$ (Table 3.3). For non-completers, the mean improved by 1.5 $(p<0.001)$. The change in mean number of arm curls performed in 30 -seconds was 4.1 for completers, and for non-completers it was $2.1(p<0.001)$. After participation in EF, completers took an average of 1.0 second less time to complete an eight-foot up-and-go activity while non-completers took 0.6 seconds less. This change was significant at $p<0.001$ (Table 3.3).

Overall, more participants reported to feel "Good", "Very good", or "Excellent" about their health after participating in EF for 4-months $(84.5 \%$ to $89.9 \%, p<0.001)$. Further, at 4-months, higher number of completers reported a significant improvement in their self-rated health $(86.4 \%$ to $94.3 \%, p<0.001)$. Non-completers also reported an improvement in their self-rated health; however, the change was insignificant $(82.5 \%$ to $85.4 \%, p=0.102$ ). A significant decrease in the number of falls from 15.2 to 11.4 was reported among completers $(p=0.05)$ at 4-months. The number of falls increased in noncompleters by 0.2 however, this increase was insignificant at $p=1.0$ (Table 3.4). 


\section{Discussion}

Since fall 2008, HARC has been offering EF on an ongoing basis to older adults in the community-based settings of South Florida. Participants were enrolled for at least 4-months; however, if interested, they were allowed to continue participation for as long as the program was offered. As mentioned above, although, presently EF is offered in 26 states at approximately 141 sites with approximately 25,000 older adults participating (Senior Services, 2013), we could find only three studies reporting on the effectiveness of EF (Belza et al., 2006; Moore-Harrison et al., 2009; Tomioka et al., 2012). The objective of the current study was to assess the effectiveness of EF at 4-months and add to the existing body of EF effectiveness literature. In addition, we evaluated the impact of program completion, defined as attending 32 of 48 given sessions within 4-months from their first date of attendance, on outcome measures.

Results suggest that EF improved physical activity levels of participants. Participants, regardless of completion status, showed significant improvement in all performance measures upper body strength, lower body strength, agility/balance, selfreported health status, and number of falls at 4-months. These findings are consistent with the earlier randomized EF trial that reported significant improvement in the participants' physical functioning levels, mental health and social functioning, and reduction in their bodily pain (Belza et al., 2010; Wallace et al., 1998).

Belza et al. (2006) evaluated the 4- and 8- month's effectiveness of EF participation. Similar to their study findings where participants showed a significant mean increase of 1.6 in the number of chair stands performed in 30 seconds (Belza et al., 2006), our study participants reported an increase of 2.4. In addition, participants in the 
study by Belza et al. (2006) improved the number of arm curls performed in 30 seconds by 2.5 after 4-months of EF participation. The number of arm curls performed in our study improved by 3.1. In both the studies, participants took less time to complete an eight-foot circuit after attending EF classes for 4-months. A higher number of participants, in both the studies, reported feeling "Good," "Very good," or "Excellent" after participating in EF for 4-months. In contrast, to the Belza et al. study where an insignificant increase in the number of falls was reported at 4-months (Belza et al., 2006), a significant decrease in falls was observed in our study. Similar findings were reported in the other two EF studies (Moore-Harrison et al., 2009; Tomioka et al., 2012).

Belza et al. suggested attending at least $66 \%$ of offered sessions, which is 32 of 48 offered sessions within 4-months ( 16-weeks) to gain maximum health benefits (Belza et al., 2010). This study is the first to evaluate the impact of attending the recommended 32 or more sessions on participant's outcomes. Analyses of outcome measures demonstrated that participation in EF for 4-months improved the physical performance of all study participants, regardless of how many sessions they actually attended; however, participants who completed at least 32 recommended sessions within 4-months showed double the improvement of non-completers. These findings highlight the importance of attending minimum recommended sessions to attain greater health benefits.

Several fitness programs aiming to increase physical activity levels among older adults have been designed, evaluated, and found effective (Barnett, 2003; KolbeAlexander et al., 2006). One of the salient features of EF is that it is designed specifically for older adults, and its components recognize and address the needs and challenges of this specific population. For instance, loss of muscle mass, a common but often 
preventable result of aging, is linked to osteoporosis, immobility, falls, and even premature death (Berger \& Doherty, 2010; Doherty, 2003; Iannuzzi-Sucich, Prestwood, \& Kenny, 2002; Janssen, Heymsfield, \& Ross, 2002; von Haehling, Morley, \& Anker, 2010). The components of EF sessions include warm-up, cardiovascular endurance, upper and lower body muscle strength training and stretching (Senior Services, 2012). EF exercises target all muscle groups and report to improve upper and lower extremity muscle integrity (Belza et al., 2006; Moore-Harrison et al., 2009; Wallace et al., 1998), and thus could help prevent the onset or improve management of conditions that result from muscle loss (Belza et al., 2006, 2010; Moore-Harrison et al., 2009; Tomioka et al., 2012). Further, EF classes met three times per week, one hour per session, allowing the participants to meet CDC's recommended guidelines of engaging in least 150 minutes of moderate intensity or 75 minutes of vigorous intensity aerobic exercise every week, along with muscle strengthening exercises on two or more days every week (CDC, 2011c).

\section{Strengths and Limitations}

$\mathrm{EF}$, an evidence-based group exercise program, includes all three essential components required to gain health benefits aerobic exercise, strength training, and balance and flexibility. Further, it provides older adults the ability to track their performance using validated measures. Training of all EF instructors' prior teaching classes ensured that all instructors gained required specialized skills essential for understanding the specific needs of this population. EF participants showed significant improvement on all outcome measures, confirming EF effectiveness. In addition, EF participants indicated high levels of satisfaction with program content and instructors. In addition, for successful translation of efficacy trials, interventions must be delivered as 
developed. Therefore, EF workshops were monitored for any fidelity concerns. Results of fidelity monitoring found a high adherence rate for program content affirming that programs were delivered as intended. Literature suggests that adherence to programs and recommended guidelines is more likely to be accomplished when fitness programs are accessible in community-based settings (Allen \& Morey, 2010). EF is offered at an ongoing basis at several locations making it accessible to older adults.

Although evaluation findings suggest that EF was successfully implemented and achieved desired results there are certain limitations that warrant attention. The study findings have limited generalizability since participants are from South Florida only. In addition, absence of data on outcome measures at both time points resulted in exclusion of participants from analysis. However, no differences were identified when comparing participants with no missing data and those for whom we were missing data on one or more included variables. Further, since the evaluation design had no control group, the participant results may reflect other treatments. All the agencies that were offering physical activity programs for study participants prior to the establishment of HARC collaborated with HARC, so we find it unlikely that study participants attended other physical fitness programs. In addition, the change in outcome measures could be attributed as a maturation effect. However, evidence suggests that there is inverse relationship between an increase in age and physical activity, thus suggesting that the improvement in outcome measures seen in this study was because of participation in the program. Finally, selection bias should be considered; participants were not randomly selected but rather volunteered because they thought they might benefit from the program. 


\section{Conclusion}

The current study provides evidence in support of effective translation of EF into community-based settings. Analysis of outcome measures demonstrated that participation in EF for 4-months improved physical performance measures of participants. These findings are consistent with previous EF studies, where participants showed significant improvement in physical and psychosocial functioning after 4-months of EF participation (Belza et al., 2006; Tomioka et al., 2012). Lack of regular physical activity is the leading cause for developing chronic conditions among older adults and greatly impacts healthy aging (Allen \& Morey, 2010; CDC, 2014b; A. C. King \& King, 2010; White et al., 2005). An increase in the number of chronic conditions results in an increase in utilization of health care services and health care spending (Ackermann et al., 2008; G Anderson, 2010; Gerard Anderson \& Horvath, 2004; CDC, 2014b; Garrett \& Martini, 2007; Schneider et al., 2009). In $2010,84 \%$ of all health care spending was for the $50 \%$ of the population who had one or more chronic medical conditions (G Anderson, 2010; CDC, 2014b). Regular physical activity helps to increase metabolic rates that reduces the chances for developing obesity, a risk factor for many chronic conditions including hypertension, diabetes, and heart disease (Allen \& Morey, 2010; CDC, 2011f; A. C. King \& King, 2010; White et al., 2005). Further, regular physical activity and muscle strengthening exercises lowers the risk of falling in older adults and enhances their quality of life by allowing them to carry out their day-to-day activities easily and independently (CDC, 2011e). Ackermann et al. (2008) found that EF users spent \$1,929 less on health care annually substantiating that EF has the potential to reduce healthcare costs. Therefore, participation in effective programs like EF can be valuable in increasing 
independence among older adults, reducing chances of developing chronic conditions, and consequently health care cost. In addition, findings from the current study reaffirm the importance of participating in minimum recommended EF sessions and the successful implementation of EF into community-based settings. 
Table 3.1 Sample characteristics $(\mathrm{N}=\mathbf{1 , 1 7 5})$

\begin{tabular}{|c|c|c|c|}
\hline Variable & $\begin{array}{c}\text { All eligible } \\
\text { participants } \\
\mathrm{N}=\mathbf{1 , 1 7 5}^{\mathrm{a}} \\
\end{array}$ & $\begin{array}{c}\text { Completers } \\
(\geq 32 \text { sessions }) \\
n=586\end{array}$ & $\begin{array}{c}\text { Non-Completers } \\
\begin{array}{c}<\mathbf{3 2} \text { sessions }) \\
n=\mathbf{5 8 9}\end{array} \\
\end{array}$ \\
\hline & n $(\%)$ & n (\%) & $\mathrm{n}(\%)$ \\
\hline \multicolumn{4}{|l|}{ Age } \\
\hline $60-69$ years & $266(22.6 \%)$ & $124(21.2 \%)^{b}$ & $142(24.1 \%)$ \\
\hline $70-79$ years & $486(41.4 \%)$ & $251(42.8 \%)^{\mathrm{c}}$ & $235(39.9 \%)$ \\
\hline $80-89$ years & $314(26.7 \%)$ & $149(25.4 \%)^{d}$ & $165(28.0 \%)$ \\
\hline$\geq 90$ years & $109(9.3 \%)$ & $62(10.6 \%)^{\mathrm{e}}$ & $47(8.0 \%)$ \\
\hline \multicolumn{4}{|l|}{ Gender } \\
\hline Male & $172(14.6 \%)$ & $105(17.9 \%)$ & $67(11.4 \%)$ \\
\hline Female & $967(82.3 \%)$ & $465(79.4 \%)$ & $502(85.2 \%)$ \\
\hline \multicolumn{4}{|l|}{ County of Residence } \\
\hline Miami-Dade & $592(50.4 \%)$ & $298(50.9 \%)$ & $294(49.9 \%)$ \\
\hline Broward & $438(37.3 \%)$ & $213(36.3 \%)$ & $225(38.2 \%)$ \\
\hline Monroe & $139(11.8 \%)$ & $72(12.3 \%)$ & $67(11.4 \%)$ \\
\hline \multicolumn{4}{|l|}{ Race/Ethnicity } \\
\hline Hispanic/ Latino & $381(32.4 \%)$ & $194(33.1 \%)$ & $187(31.7 \%)$ \\
\hline $\begin{array}{l}\text { Haitian/ Other Non- } \\
\text { Hispanic Caribbean }\end{array}$ & $53(4.5 \%)$ & $18(3.1 \%)$ & $35(5.9 \%)$ \\
\hline $\begin{array}{r}\text { White, non-Hispanic } \\
\text { Black/African }\end{array}$ & $518(44.1 \%)$ & $286(48.8 \%)$ & $232(39.4 \%)$ \\
\hline American, non- & $143(12.2 \%)$ & $50(8.5 \%)$ & $93(15.8 \%)$ \\
\hline \multicolumn{4}{|l|}{ Hispanic, non-Haitian } \\
\hline Other & $41(3.5 \%)$ & $26(4.4 \%)$ & $15(2.5 \%)$ \\
\hline \multicolumn{4}{|l|}{ Primary Language } \\
\hline English & $798(67.9 \%)$ & $395(67.4 \%)$ & $403(68.4 \%)$ \\
\hline Spanish & $338(28.8 \%)$ & $175(29.9 \%)$ & $163(27.7 \%)$ \\
\hline Other & $39(3.3 \%)$ & $16(2.7 \%)$ & $23(3.9 \%)$ \\
\hline \multicolumn{4}{|l|}{ Marital Status } \\
\hline Single/not partnered & $714(60.8 \%)$ & $343(58.5 \%)$ & $371(63.0 \%)$ \\
\hline Married/partnered & $437(37.2 \%)$ & $237(40.4 \%)$ & $200(34.0 \%)$ \\
\hline \multicolumn{4}{|l|}{ Number in Household } \\
\hline Living alone & $561(47.7 \%)$ & $273(46.6 \%)$ & $288(48.9 \%)$ \\
\hline $\begin{array}{l}\text { Living with one or } \\
\text { more other people }\end{array}$ & $611(52.0 \%)$ & $311(53.1 \%)$ & $300(50.9 \%)$ \\
\hline \multicolumn{4}{|l|}{ Annual Income } \\
\hline$<\$ 15,000$ & $371(31.6 \%)$ & $164(28.0 \%)$ & $207(35.1 \%)$ \\
\hline$\geq \$ 15,000$ & $362(30.8 \%)$ & $213(36.3 \%)$ & $149(25.3 \%)$ \\
\hline \multicolumn{4}{|l|}{ Education } \\
\hline Less than High School & $180(15.3 \%)$ & $73(12.5 \%)$ & $107(18.2 \%)$ \\
\hline High School & $282(24.0 \%)$ & $130(22.2 \%)$ & $152(25.8 \%)$ \\
\hline Some college & $296(25.2 \%)$ & $156(26.6 \%)$ & $140(23.8 \%)$ \\
\hline
\end{tabular}




\begin{tabular}{|c|c|c|c|}
\hline Variable & $\begin{array}{c}\text { All eligible } \\
\text { participants } \\
\mathrm{N}=1,175^{\mathrm{a}} \\
\end{array}$ & $\begin{array}{c}\text { Completers } \\
(\geq 32 \text { sessions }) \\
n=586 \\
\end{array}$ & $\begin{array}{c}\text { Non-Completers } \\
\begin{array}{c}(<\mathbf{3 2} \text { sessions }) \\
n=\mathbf{5 8 9}\end{array} \\
\end{array}$ \\
\hline College Graduate & $376(32.0 \%)$ & $212(36.2 \%)$ & $164(27.8 \%)$ \\
\hline \multicolumn{4}{|l|}{ Frail/Disabled } \\
\hline Yes & $134(11.4 \%)$ & $46(7.8 \%)$ & $88(14.9 \%)$ \\
\hline No & $923(78.6 \%)$ & $491(83.8 \%)$ & $432(73.3 \%)$ \\
\hline \multicolumn{4}{|l|}{ Have Medicaid } \\
\hline Yes & $258(22.0 \%)$ & $114(19.5 \%)$ & $144(24.4 \%)$ \\
\hline No & $440(37.4 \%)$ & $242(41.3 \%)$ & $198(33.6 \%)$ \\
\hline \multicolumn{4}{|l|}{ Have Medicare } \\
\hline Yes & $858(73.0 \%)$ & $437(74.6 \%)$ & $421(71.5 \%)$ \\
\hline No & $152(12.9 \%)$ & $77(13.1 \%)$ & $75(12.7 \%)$ \\
\hline \multicolumn{4}{|l|}{ History of Depression } \\
\hline Yes & $103(8.8 \%)$ & $41(7.0 \%)$ & $62(10.5 \%)$ \\
\hline No & $1,040(88.5 \%)$ & $533(91.0 \%)$ & $507(86.1 \%)$ \\
\hline \multicolumn{4}{|l|}{$\begin{array}{l}\text { Number of Chronic } \\
\text { Conditions }\end{array}$} \\
\hline None & $208(17.7 \%)$ & $111(18.9 \%)$ & $97(16.5 \%)$ \\
\hline One Condition & $314(26.7 \%)$ & $167(28.5 \%)$ & $147(25.0 \%)$ \\
\hline Two Conditions & $279(23.7 \%)$ & $136(23.2 \%)$ & $143(24.3 \%)$ \\
\hline $\begin{array}{r}\text { Three or more } \\
\text { Conditions }\end{array}$ & $342(29.1 \%)$ & $160(27.3 \%)$ & $182(30.9 \%)$ \\
\hline \multicolumn{4}{|l|}{$\begin{array}{l}\text { Self-Rated Health } \\
\text { Status }\end{array}$} \\
\hline Poor & $14(1.2 \%)$ & $3(0.5 \%)$ & $11(1.9 \%)$ \\
\hline Fair & $163(13.9 \%)$ & $75(12.8 \%)$ & $88(14.9 \%)$ \\
\hline Good & $492(41.9 \%)$ & $247(42.2 \%)$ & $245(41.6 \%)$ \\
\hline Very Good & $352(30.0 \%)$ & $195(33.3 \%)$ & $157(26.7 \%)$ \\
\hline Excellent & $127(10.8 \%)$ & $58(9.9 \%)$ & $6911.7 \%)$ \\
\hline
\end{tabular}

${ }^{\text {a }}$ Percentage do not add up to $100 \%$ because of missing data

${ }^{\mathrm{b}}$ Within age group percentage is $46.6 \%$

${ }^{\mathrm{c}}$ Within age group percentage is $51.6 \%$

${ }^{\mathrm{d}}$ Within age group percentage is $47.5 \%$

${ }^{\mathrm{e}}$ Within age group percentage is $56.9 \%$

Completer: HARC participant who attended 32 or more sessions within first 4-months following their start date 
Table 3.2 Independent $t$-test results to identify baseline group difference $(N=1,175)$

\begin{tabular}{|c|c|c|c|c|c|}
\hline $\begin{array}{l}\text { Functional Performance } \\
\text { Measures }\end{array}$ & $\mathbf{n}$ & $\overline{\boldsymbol{X}} \pm \mathrm{SD}$ & $\mathbf{t}$ & $\mathrm{d} f$ & $p$-value ${ }^{a}$ \\
\hline \multicolumn{6}{|l|}{ Chair Stands in 30 seconds } \\
\hline Completer & 576 & $12.2 \pm 4.9$ & \multirow{2}{*}{-1.141} & \multirow{2}{*}{1,148} & \multirow{2}{*}{0.254} \\
\hline Non-Completer & 574 & $11.9 \pm 4.6$ & & & \\
\hline \multicolumn{6}{|l|}{ Arm Curls in 30 seconds } \\
\hline Completer & 582 & $15.7 \pm 5.8$ & \multirow{2}{*}{0.777} & \multirow{2}{*}{1,149} & \multirow{2}{*}{0.437} \\
\hline Non-Completer & 569 & $15.9 \pm 5.5$ & & & \\
\hline \multicolumn{6}{|l|}{ Eight-Foot Up-and-Go } \\
\hline Completer & 574 & $8.8 \pm 5.2$ & \multirow{2}{*}{1.856} & \multirow{2}{*}{1,135} & \multirow{2}{*}{0.064} \\
\hline Non-Completer & 563 & $9.4 \pm 5.6$ & & & \\
\hline
\end{tabular}

${ }^{a}$ Significance was calculated using independent samples $t$-test

$\overline{\boldsymbol{X}}$ : Mean

SD: Standard Deviation

Completer: HARC participant who attended 32 or more sessions within 4-months following their start date

Non-Completer: HARC participant who did not attend 32 or more sessions within 4months following their start date 
Table 3.3 Change in Outcome Measures after Participating in EnhanceFitness for 4months, Baseline to First Follow-up $(\bar{X} \pm \mathrm{SD})(\mathrm{N}=1,175)$

\begin{tabular}{|c|c|c|c|c|c|}
\hline $\begin{array}{c}\text { Functional } \\
\text { Performance } \\
\text { Measures } \\
\end{array}$ & $\mathbf{n}$ & $\begin{array}{c}\text { Baseline } \\
\bar{X} \pm \text { SD }\end{array}$ & $\begin{array}{c}\text { Follow-Up } \\
\bar{X} \pm \text { SD }\end{array}$ & $\Delta$ & $p$-value ${ }^{a}$ \\
\hline \multicolumn{6}{|c|}{ Chair Stands in 30 seconds } \\
\hline Total & 1,129 & $12.1 \pm 4.8$ & $14.5 \pm 5.8$ & 2.4 & $<.001$ \\
\hline Completer & 569 & $12.2 \pm 4.9$ & $15.6 \pm 6.1$ & 3.4 & $<.001$ \\
\hline Non-Completer & 560 & $11.9 \pm 4.6$ & $13.4 \pm 5.3$ & 1.5 & $<.001$ \\
\hline \multicolumn{6}{|c|}{ Arm Curls in 30 seconds } \\
\hline Total & 1,134 & $15.8 \pm 5.6$ & $18.9 \pm 6.3$ & 3.1 & $<.001$ \\
\hline Completer & 580 & $15.7 \pm 5.8$ & $19.8 \pm 6.4$ & 4.1 & $<.001$ \\
\hline $\begin{array}{l}\text { Non-Completer } \\
\text { 8-foot Up-Go }\end{array}$ & 554 & $16.0 \pm 5.5$ & $18.1 \pm 6.2$ & 2.1 & $<.001$ \\
\hline Total & 1,124 & $9.5 \pm 5.4$ & $8.3 \pm 5.5$ & $-0.8^{\mathrm{b}}$ & $<.001$ \\
\hline Completer & 571 & $8.8 \pm 5.2$ & $7.8 \pm 5.4$ & $-1.0^{b}$ & $<.001$ \\
\hline Non-Completer & 553 & $9.4 \pm 5.5$ & $8.8 \pm 5.4$ & $-0.6^{b}$ & $<.001$ \\
\hline
\end{tabular}

${ }^{a}$ Significance was calculated using paired t-test (continuous variables)

${ }^{\mathrm{b}}$ Improvement indicated by a reduction in time, resulting in a negative change

$\bar{X}$ : Mean

SD: Standard Deviation

$\Delta$ : Change in mean from baseline to 4-months follow-up

Completer: HARC participant who attended 32 or more sessions within 4-months following their start date

Non-Completer: HARC participant who did not attend 32 or more sessions within 4months following their start date 
Table 3.4 Change in self-rated health status and reported number of falls after Participating in EnhanceFitness for 4-months, Baseline to First Follow-up (\%) $(\mathrm{N}=\mathbf{1 , 1 7 5})$

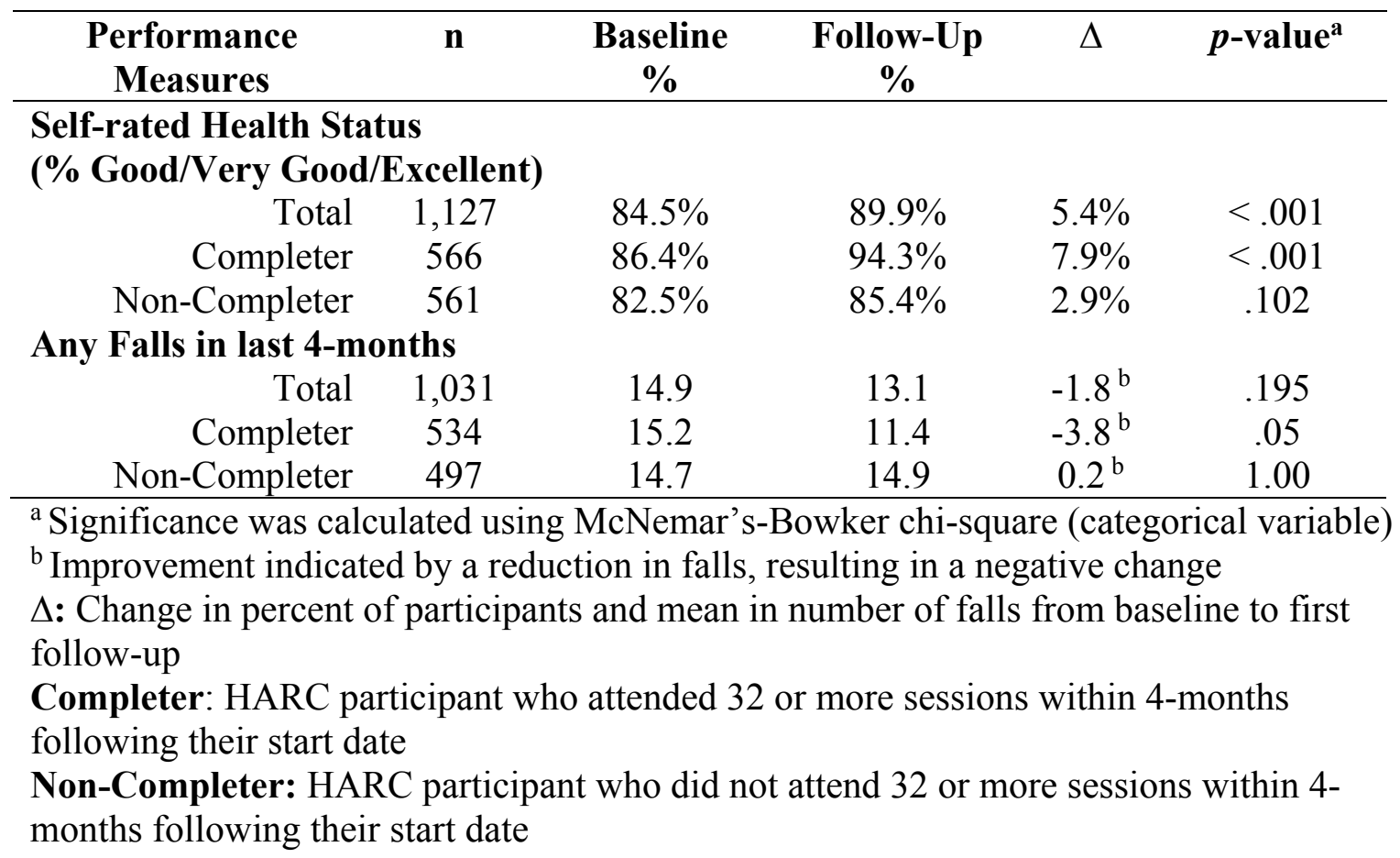




\section{References}

Ackermann, R. T., Williams, B., Nguyen, H. Q., Berke, E. M., Maciejewski, M. L., \& LoGerfo, J. P. (2008). Healthcare cost differences with participation in a community-based group physical activity benefit for medicare managed care health plan members. Journal of the American Geriatrics Society, 56(8), 1459-65. doi:10.1111/j.1532-5415.2008.01804.x

Allen, K., \& Morey, M. C. (2010). Physical Activity and Adherence. In Improving Patient Treatment Adherence. New York, NY: Springer.

Anderson, G. (2010). Chronic Care: Making the Case for Ongoing Care. Retrieved from http://www.rwjf.org/en/research-publications/find-rwjf-research/2010/01/chroniccare.html

Anderson, G., \& Horvath, J. (2004). The growing burden of chronic disease in America. Public Health Reports, 119(3), 263-70. doi:10.1016/j.phr.2004.04.005

Barnett, A. (2003). Community-based group exercise improves balance and reduces falls in at-risk older people: a randomised controlled trial. Age and Ageing, 32(4), 407414.

Belza, B., Shumway-Cook, A., Phelan, E., Williams, B., Snyder, S., \& LoGerfo, J. (2006). The Effects of a Community-Based Exercise Program on Function and Health in Older Adults: The EnhanceFitness Program. Journal of Applied Gerontology, 25(4), 291-306. doi:10.1177/0733464806290934

Belza, B., Susan, S., Meghan, T., \& James, L. (2010). From Research to Practice: EnhanceFitness, an Innovative Community-Based Senior Exercise Program. Topics in Geriatric Rehabilitation, 26(4), 299-309.

Berger, M. J., \& Doherty, T. J. (2010). Sarcopenia: prevalence, mechanisms, and functional consequences. Interdisciplinary Topics in Gerontology, 37, 94-114. doi: $10.1159 / 000319997$

CDC. (2011a). How much physical activity do older adults need? Retrieved September 09, 2014, from http://www.cdc.gov/physicalactivity/everyone/guidelines/olderadults.html

CDC. (2011b). Physical Activity for Everyone: The Benefits of Physical Activity. Retrieved September 29, 2014, from http://www.cdc.gov/physicalactivity/everyone/health/index.html\#ReduceCardiovasc ularDisease 
CDC. (2011c). Physical Activity for Everyone: The Benefits of Physical Activity | DNPAO | CDC. Retrieved September 10, 2014, from http://www.cdc.gov/physicalactivity/everyone/health/

CDC. (2014a). CDC - BRFSS - Behavioral Risk Factor Surveillance System. Retrieved February 10, 2014, from http://www.cdc.gov/brfss/index.htm

CDC. (2014b). CDC - Chronic Disease - Overview. Retrieved February 10, 2014, from http://www.cdc.gov/chronicdisease/overview/index.htm?s_cid=ostltsdyk_govd_203

CDC. (2014c). Physical Activity. Retrieved June 10, 2014, from http://www.cdc.gov/physicalactivity/index.html

Dogra, S., \& Stathokostas, L. (2012). Sedentary behavior and physical activity are independent predictors of successful aging in middle-aged and older adults. Journal of Aging Research, 2012. Retrieved from http://www.hindawi.com/journals/jar/2012/190654/

Doherty, T. J. (2003). Invited review: Aging and sarcopenia. Journal of Applied Physiology, 95(4), 1717-27. doi:10.1152/japplphysiol.00347.2003

Garrett, N., \& Martini, E. M. (2007). The boomers are coming: a total cost of care model of the impact of population aging on the cost of chronic conditions in the United States. Disease Management, 10(2), 51-60. doi:10.1089/dis.2006.630

Iannuzzi-Sucich, M., Prestwood, K. M., \& Kenny, A. M. (2002). Prevalence of sarcopenia and predictors of skeletal muscle mass in healthy, older men and women. The Journals of Gerontology. Series A, Biological Sciences and Medical Sciences, 57(12), M772-7.

IBM Corp. (2012). IBM SPSS Statistics for Windows. Armonk, NY: IBM Corp.

Janssen, I., Heymsfield, S., \& Ross, R. (2002). Low relative skeletal muscle mass (sarcopenia) in older persons is associated with functional impairment and physical disability. Journal of the American Geriatrics Society, 50(5), 889-96.

Jones, C. J., Rikli, R. E., \& Beam, W. C. (1999). A 30-s chair-stand test as a measure of lower body strength in community-residing older adults. Research Quarterly for Exercise and Sport, 70(2), 113-9. doi:10.1080/02701367.1999.10608028

King, A. C., \& King, D. K. (2010). Physical Activity for an Aging Population. Public Health Reviews, 32, 401-426. 
Kolbe-Alexander, T., Lambert, E., \& Charlton, K. (2006). Effectiveness of a community based low intensity exercise program for older adults. The Journal of Nutrition, Health \& Aging, 10(1), 21-9.

Kravitz, L. (1996). Age and Exercise. IDEA Today, 14(2), 28-35. Retrieved from http://www.unm.edu/ lkravitz/Article folder/age.html

Lorig, K., Stewart, A., Ritter, P., Gonzalez, V., Laurent, D., \& Lynch, J. (1996). Outcome Measures for Health Education and Other Health Care Interventions: Kate Lorig: 9780761900672 (1st ed.). Thousand Oaks, CA: SAGE Publications.

Moore-Harrison, T. L., Johnson, M. A., Quinn, M. E., \& Cress, M. E. (2009). An evidence-based exercise program implemented in congregate-meal sites. Journal of Physical Activity \& Health, 6(2), 247-51.

National Center for Health Statistics. (2014). FastStats - Homepage. Retrieved September 24, 2014, from http://www.cdc.gov/nchs/fastats/

National Council on Aging. (2005). Recruiting and Retaining Effective Instructors for Physical Activity Programs (p. 6). Retrieved from http://www.ncoa.org/improvehealth/center-for-healthy-aging/contentlibrary/PAPrograms_RecruitRetainInstructors.pdf

Neid, R. J., \& Franklin, B. (2002). Promoting and Prescribing Exercise in the Elderly. American Family Physician, 65(3), 419-427.

Page, T. F., Batra, A., Ghouse, M. M., \& Palmer, R. C. (2014). Implementation Cost Analysis of a Community-Based Exercise Program for Seniors in South Florida. Health Promotion Practice, 15(4), 585-591. doi:10.1177/1524839913518221

Pang, M., Eng, J., Dawson, A., \& Gylfadóttir, S. (2006). The use of aerobic exercise training in improving aerobic capacity in individuals with stroke: a meta-analysis. Clinical Rehabilitation, 20(2), 97-111.

Rikli, R. E., \& Jones, C. J. (1999). Development and Validation of a Functional Fitness Test for Community-Residing Older Adults. Journal of Aging and Physical Activity, 7, 129-161.

Rogers, C., \& Keller, C. (2009). Roy's Adaptation Model To Promote Physical Activity Among Sedentary Older Adults. Geriatric Nursing, 30(2 Suppl), 21-26. doi:10.1016/j.gerinurse.2009.02.002.Roy

Schneider, K., O'Donnell, B., \& Dean, D. (2009). Prevalence of multiple chronic conditions in the United States' Medicare population. Health and Quality of Life Outcomes, 7, 82. doi:10.1186/1477-7525-7-82 
Senior Services. (2012). EnhanceFitness. Retrieved from http://www.ncoa.org/improvehealth/center-for-healthy-aging/content-library/EnhanceFitness-6-30-2011.pdf

Senior Services. (2013). Enhance Fitness. Retrieved October 02, 2014, from http://www.projectenhance.org/EnhanceFitness.aspx

Stanford Patient Education Research Center. (2007). Chronic Disease Self-Management Program Codebook. Retrieved September 30, 2014, from http://patienteducation.stanford.edu/research/cdCodeBook.pdf

Tomioka, M., Sugihara, N., \& Braun, K. L. (2012). Replicating the EnhanceFitness physical activity program in Hawai'i's multicultural population, 2007-2010. Preventing Chronic Disease, 9, E74. Retrieved from http://www.cdc.gov/pcd/issues/2012/11_0155.htm

USDHHS: Healthy People. (2014). Older Adults - Healthy People 2020. Washington DC. Retrieved from http://www.healthypeople.gov/2020/topicsobjectives2020/overview.aspx?topicid=3 1

Von Haehling, S., Morley, J. E., \& Anker, S. D. (2010). An overview of sarcopenia: facts and numbers on prevalence and clinical impact. Journal of Cachexia, Sarcopenia and Muscle, 1(2), 129-133. doi:10.1007/s13539-010-0014-2

Wallace, J. I., Buchner, D. M., Grothaus, L., Leveille, S., Tyll, L., LaCroix, A. Z., \& Wagner, E. H. (1998). Implementation and effectiveness of a community-based health promotion program for older adults. The Journals of Gerontology. Series A, Biological Sciences and Medical Sciences, 53(4), M301-6.

White, J. L., Ransdell, L. B., Vener, J., \& Flohr, J. A. (2005). Factors related to physical activity adherence in women: review and suggestions for future research. Women \& Health, 41(4), 123-48. doi:10.1300/J013v41n04_07 


\section{CHAPTER 4}

\section{Manuscript Title: Determining the Long Term Effectiveness of a Group-Based Exercise Program for Older Adults: EnhanceFitness}

\section{Introduction}

Physical activity has been identified as one of three key modifiable health behaviors that can alter the course of chronic diseases (Dogra \& Stathokostas, 2012; Kravitz, 1996; Rogers \& Keller, 2009; USDHHS: Healthy People, 2014). Physiological age-related changes and unhealthy habits, including lack of physical activity and poor dietary habits, put older adults at higher risk for developing chronic conditions (Fulop et al., 2010; Glei et al., 2011; Kravitz, 1996). Recognizing the benefits of physical activity, such as improved management of chronic conditions, decreased incidence of chronic conditions and comorbidities, strengthening of muscles and bones, Centers for Disease Control and Prevention guidelines recommend physical activity for older adults (CDC, 2011c, 2011e).

For older adults, the health benefits of physical activity outweigh the risks by far (CDC, 2010b, 2013c; NIH, 2012). Regular physical activity regimens could delay the aging process and help prevent or delay the onset of many chronic conditions (CDC, 2013c; Geller et al., 2012; A. C. King \& King, 2010; NIH, 2012). Physical activity reduces chances of obesity, helps better management of diabetes mellitus, improved sleep quality, lower risk of falls, and many cancers (CDC, 2013b; Colberg et al., 2010; National Cancer Institute, 2009; Reid et al., 2010; Yang et al., 2012). In addition, physical activity has been found to alleviate the symptoms associated with inflammatory disorders of joints and associated structures such as arthritis, gout, spondylitis, 
osteomyelitis etcetera (CDC, 2013c; Hootman \& Helmick, 2006; NIAMS, 2012; Shih et al., 2006). Strength training exercises allow increasing bone turnover and reduce bone loss in those with low bone density such as osteoporosis patients (Bosković et al., 2013; CDC, 2013c; NIH Osteoporosis and Related Bone Diseases National Resource Center, 2012).

A comprehensive review of existing literature concluded that a number of interventions have been developed and found efficacious in randomized controlled trials for increasing physical activity levels among older adults (Allen \& Morey, 2010; Hughes et al., 2009; A. C. King \& King, 2010). Very few studies have examined the impact of evidence-based programs that are adopted in community-based settings (Hughes et al., 2009). EnhanceFitness (EF), an evidence-based physical activity program was found to be efficacious in improving physical and psychological states of study participants in 1998. Since then, EF has been widely disseminated. As of today, there are approximately 141 active EF sites offering EF to older adults in 26 U.S. states (Senior Services, 2013). Effectiveness measures the public health impact of an intervention (Glanz et al., 2008). Therefore, determining the long-term effectiveness of a program is essential (Belza et al., 2010). For EF, only one study reported 4- and 8- month's effectiveness (Belza et al., 2006). In addition, two studies reported on short-term (12 weeks and 4months) benefits of EF participation (Moore-Harrison et al., 2009; Tomioka et al., 2012). The lack of literature on long-term (4-, 8-, and 12-months) impacts of EF participation makes this study valuable. The purpose of this study is to assess the extended effectiveness of EF participation from baseline to 12-months. 


\section{Methods}

\section{Setting}

In the fall of 2008, the Health Foundation of South Florida formed Healthy Aging Regional Collaborative (HARC) with the aim to provide health promotion programs readily available to older adults of South Florida. Fourteen local agencies implemented 160 EF classes, lasting at least 4-months between October 1, 2008 and December 31, 2012 as part of HARC. The programs were made available in adult day care centers, senior centers, clinics, hospitals, skilled nursing facilities, assisted living facilities, community centers, or senior housing in three southeast counties of South Florida: Broward, Miami-Dade, and Monroe.

\section{Study Participants and Recruitment}

Older adults aged 60 years or above, who were cognitively able to follow instructions could enroll for EF classes. Only those individuals who had serious medical conditions, such as end-stage renal or heart disease that prohibited exercise, were refused from participation. To recruit participants, agencies used a variety of methods including identifying potential participants from their existing client database, flyers, posters, and word of mouth.

\section{EF Overview}

$\mathrm{EF}$ is a low-cost group exercise program for older adults that was developed, tested, and found efficacious in improving physical and psychosocial functioning of participants in 1998 (Belza et al., 2006, 2010; Page et al., 2014; Senior Services, 2013; Wallace et al., 1998). EF, was formerly known as 'Lifetime Fitness Program' (Wallace et al., 1998). EF classes focuses on stretching, flexibility, balance, low impact aerobics, and 
strength training exercises and consisted of a one-hour session held three times a week (Wallace et al., 1998). The aim of the program is to improve fitness levels of older adults, which would help them become more active, energized, and empowered to sustain independent lives (Belza et al., 2006, 2010; Moore-Harrison et al., 2009; Tomioka et al., 2012; Wallace et al., 1998). HARC offered EF on an ongoing basis. The class structure and material was similar to the original EF program; however, program participation was voluntary and was implemented by community-based agencies in real world settings of South Florida.

\section{Instructor Training and Fidelity Monitoring}

Potential instructors were recruited from within partner agencies or were identified using a variety of external methods, including word of mouth, flyers, and advertisements. In order to be considered eligible for instructor, an individual was required to have certain qualities such as good communication and interpersonal skills, enthusiasm and readiness to lead a small group of older adults, ability to carry up to 20 lbs weight and perform range of motion and low-level endurance exercises. An EF master trainer from Senior Services, an organization that oversees the management of EF, trained all EF instructors. In addition, all instructors were required to have a fitness certification from a nationally recognized certifying organization.

To ensure consistency in the delivery of EF as intended, $30 \%$ of offered EF workshops were randomly selected and monitored by a trained evaluator using a fidelity instrument. The fidelity instrument was reflective of core components of the interventions: (1) workshop environment, (2) instructor performance, (3) suitability of site, and (4) session content based on developers' instructor manual. 


\section{Data Collection}

A self-administered paper and pencil survey was chosen as the mode of data collection. On the first day of the workshop, participants completed a consent form, demographics, and health history form. Instructors and agency staff were available to assist participants in completing the surveys if necessary. Additionally, instructors collected data on functional performance of participants using the Functional Fitness Test (FFT) battery. Functional performance of participants was measured at baseline (T1) and every 4-months thereafter $(\mathrm{T} 2, \mathrm{~T} 3, \mathrm{~T} 4, \ldots)$ for those who continued in the program.

\section{Measures}

\section{Demographics}

Demographic data on gender, date of birth, address, marital status, disability, primary language, race/ethnicity, income, living situation, and insurance was collected using a self-administered participant information form (Table 4.1).

\section{Health History Form}

In addition, to reporting on weekly exercise schedules, participants provided information regarding known medical condition(s), medication(s), and allergies in the health history form. In addition, participants completed a self-assessment of their physical fitness level by responding to seven dichotomous questions: (1) do you believe you are physically fit (2) are you happy with your current weight (3) can you stand up from chair without using arm (4) can you get up from floor without assistance (5) can you stand on one leg without support (6) can you walk up and down steps without using the handrail (7) can you walk around the city without being short of breath. 


\section{Functional Performance Measures}

In 1999, Rikli and Jones developed and validated FFT for older adults (Rikli \& Jones, 1999a). FFT assesses the physiologic parameters that support physical mobility in older adults. FFT was composed of seven fitness activity measures and was reported to have intraclass reliability ranging from 0.79 to 0.95 (Belza et al., 2006; Jones et al., 1999; Rikli \& Jones, 1999a). Later, Jones et al. (1999) further assessed the reliability, criterionrelated and construct validity of a 30-s chair stand, one of seven FFT measures. The item was reported to have test-retest intraclass correlations of 0.84 for men and 0.92 for women (Jones et al., 1999). Agencies that implemented EF in community-settings reported difficulty in collecting data on seven FFT measures to Senior Services who oversees the management, dissemination, and licensing of EF. After receiving feedback, Senior Services decided to retain three FFT activities (Belza et al., 2006). These three items include (1) number of chair stands performed in 30 seconds, (2) number of arm curls performed in 30 seconds, and (3) time taken to complete an eight-foot up-and-go activity (Belza et al., 2006). This study used the same three activities. Number of full chair stands performed in 30 seconds with arms folded across the chest assessed lower body strength of participants (Belza et al., 2006; Rikli \& Jones, 1999a; Senior Services, 2012). To measure upper body strength, participants were asked to perform arm curls for 30 seconds holding $5 \mathrm{lbs}$. weight for females and $8 \mathrm{lbs}$. for males. Agility and balance of participants were assessed by recording the time taken to complete an eight foot circuit in which participants were asked to stand up, walk for a distance of eight feet quickly and safely, return, and get seated in their chair (Belza et al., 2006; Rikli \& Jones, 1999a; Senior Services, 2012). 


\section{Health Status}

Participants rated their health status using a single-item, "In general, what would you say your health is $(1=$ poor and $5=$ excellent $)$ ". This item is adopted from National Health Interview Survey and has a test-retest reliability of 0.92 . Same item has been used in several other programs as well and has been reported to be a reliable predictor of health (Lorig et al., 1996; Stanford Patient Education Research Center, 2007).

\section{Data Extraction}

Data were extracted from an online database for the period October 1, 2008 through December 31, 2012. It was then imported into Statistical Package for the Social Sciences (SPSS) version 21.0 (IBM Corp, 2012), cleaned, and reverse coded as required.

\section{Data Synthesis}

For the purpose of this study, chronic conditions from the health history form were consolidated into a chronic conditions variable. Based on number of self-reported chronic conditions, each participant received a score of 0 to 3 in the new consolidated variable $(0=$ none, $1=$ one chronic condition, $2=$ two chronic conditions, and $3=$ three or more chronic conditions) (Table 4.1).

\section{Statistical Analyses}

Participants who had a follow-up fitness check for three time points: baseline (T1), 4-months follow-up (T2), 8-months follow-up (T3) and 12-months follow-up (T4) were included in the current study. Prior to any analysis outliers were identified using P-P plots. Descriptive statistics were used to analyze the demographics of the study sample (Table 4.1). Participant characteristics based on amount of dose attained are also described (Table 4.1). 
The long-term effectiveness of EF was evaluated by comparing outcome measures from baseline to 4-, 8-, and 12-months follow-up. Change in outcome measures at four time points were compared using repeated measures design for continuous variable and McNemar's Bowker test for categorical variables.

\section{Results}

\section{Participant Characteristics}

Based on inclusion criterion, 1,176 participants who attended an EF workshop between October 1, 2008 and December 31, 2012 were included in this study (Table 4.1). Approximately $45 \%$ were $70-79$ years old with mean age of $76.8( \pm 8.9)$ years. More women (81.8\%) than men (14.7\%) participated in EF program. Nearly $46 \%$ of the participants lived in Miami-Dade County. Approximately 47\% of participants identified themselves as non-Hispanic whites. Three-fourths of participants identified English as their primary language. Sixty percent of participants identified themselves as single/not partnered and $45.7 \%$ lived alone. Almost one-third of participants were college graduates and 30\% reported an annual income of more than $\$ 15,000$. Most of the participants (73\%) were enrolled in Medicare. Few participants (9.9\%) identified themselves as frail/disabled and $7.6 \%$ reported to suffer from depression. Approximately $82 \%$ of study participants suffered from one or more chronic conditions. About $42 \%$ rated their health status as either very good or excellent (Table 4.1).

\section{Change in FFT measures}

A total of 1,176 participants had follow-up data at 4-,8-, and 12-months. The number of participants with data at T1, T2, T3, and T4 varied for each performance measure (Tables 4.2 and 4.3). 
Table 4.2 compares outcome data of continuous variables at four time points. All participants showed significant improvement in number of chair stands performed in 30 seconds from baseline to 4-, 8-, and 12-months. A mean change of 1.7, 1.6, and 2.0 respectively from baseline was reported at 4-, 8-, and 12-months $(p<0.001)$. The number of arm curls performed in 30 seconds improved from $16.8(S D=5.5)$ at baseline to 18.7 $(S D=5.9)$ at 4-months, $18.8(S D=6.1)$ at 8 -months, and $19.2(S D=5.9)$ at 12 -months $(p<0.001)$. At 4-months, participants improved their eight-foot up-and-go time by decreasing, on average, from $9.0(S D=4.9)$ to $8.5(S D=5.3)(p<0.001)$. Same amount of change was reported at 8-months. At 12-months, participants improved their eight-foot up-and-go time by decreasing, on average, from $9.0(S D=4.9)$ at baseline to $8.6(S D=$ 5.8) $(p<0.001)$.

Change in self-reported health status and number of falls

Overall, more participants reported to feel "Good", "Very good", or "Excellent" about their health after participating in EF for 4-, 8-, and 12-months (84.5\% (T1) to $86.8 \%$ (T2), to $87.8 \%$ (T3), to $89.3 \%$ (T4). Further, fewer number of participants reported to fall after participating in EF: $(15.1 \%$ (T1) to $9.7 \%$ (T2) to $8.0 \%$ (T3) to $6.7 \%$ (T4).

\section{Discussion}

Older adults are the most sedentary segment of our population. A number of randomized control trials have tested and been reported to be effective in improving physical activity levels among older adults yet, few have been adopted in communitybased settings. EF, formerly known as 'Lifetime Fitness Program' is an evidence-based, low-cost, community-based group exercise program for older adults (Belza et al., 2006, 2010; Page et al., 2014; Senior Services, 2013; Wallace et al., 1998). EF was developed, 
tested, and found efficacious in 1998 (Belza et al., 2006, 2010; Moore-Harrison et al., 2009; Wallace et al., 1998). Despite the fact that EF have been widely-disseminated with 141 active EF sites located in 26 U.S. states (Senior Services, 2013), we could find only one study that reported on 8-months effectiveness of EF participation. The purpose of this study is to fill this gap by assessing the long-term effectiveness of EF participation, baseline to 4-, 8-, and 12-months.

Despite the wide range availability of many interventions that have shown to improve physical activity levels among older adults in the controlled settings, few programs have been adopted in the community-based settings (Wilcox et al., 2006). High prevalence rates of physical inactivity among older adults and higher chances of developing chronic conditions demonstrate the need for wider-dissemination of these efficacious interventions. Efforts by HARC in implementing projects like EF are responsive to this call.

Outcome data on three continuous variables, number of chair stands performed in 30 seconds, number of arm curls performed in 30 seconds, and time taken to complete eight-foot up-go circuit when compared at baseline, 4-, 8-, and 12-months showed significant improvement among EF study participants. These findings are consistent with other EF studies (Belza et al., 2006; Moore-Harrison et al., 2009; Tomioka et al., 2012; Wallace et al., 1998). In the study by Wallace et al. (1998) EF participation in a controlled research setting for 6-months improved physical and psychosocial health of participants (Wallace et al., 1998). Further, Belza et al. (2006) reported significant gains in physical performance achieved through 4 to 8 months of EF participation offered in community-based settings (Belza et al., 2006). In addition, the number of participants that 
reported their health status to be good, very good, and excellent increased continuously with EF participation (Table 4.3). Continuous EF participation also resulted in decrease in number of falls (Table 4.3).

A class evaluation survey that assessed satisfaction with the program was administered at 4-months as well. Analysis of evaluation surveys revealed that all respondents either "strongly agreed" or "agreed" that overall the program was effective, beneficial, and well organized. Overall, the majority (88\%) of respondents agreed that the instructors were well prepared for the class and the participant workbook helped them better understand the classes. Furthermore, almost all the participants (91\%) agreed that they would recommend this program to a friend or relative.

\section{Limitations}

To combat the widespread problem of physical inactivity, it is essential to extend evidence-based findings from clinical trials into community-based settings and to population that is more representative however, majority $(82 \%)$ of our study participants

were females participants were from South Florida only, which limit the generalization of our findings. In addition, the change in outcome measures could be attributed as a maturation effect. However, evidence suggests that there is an inverse relationship between an increase in age and physical activity, thus suggesting that the improvement in outcome measures seen in this study was because of participation in the program. Finally, selection bias should be considered; participants were not randomly selected but rather volunteered because they thought they might benefit from the program. 


\section{Conclusion}

The current study is the first to our knowledge to determine the long-term effectiveness of EF. It adds to the science base by examining outcome measures for four time points: baseline, 4-, 8-, and 12-months follow-up. All the study participants improved their lower and upper body strength, after participating in program for 4-, 8-, and 12-months. However, those who attended EF sessions continuously improved the most on all measures. This establishes evidence in support that continuous participation results in tremendous health benefits. These findings are consistent with previous research and CDC's recommendations suggesting that any activity is beneficial however; individuals need to meet the recommended guidelines to gain maximum health benefits (Allen \& Morey, 2010; CDC, 2011f). Further, this higher improvement among those who continued participating in the program suggests the importance of implementing strategies that improve adherence rates. Findings from this investigation have the potential to inform policy makers and program implementers regarding the importance of attending EF sessions for about 12-months. 
Table 4.1 Sample characteristics $(N=1,176)$

\begin{tabular}{|c|c|}
\hline Variable & $\begin{array}{c}\text { All eligible participants } \\
\text { n (\%) }\end{array}$ \\
\hline \multicolumn{2}{|r|}{ 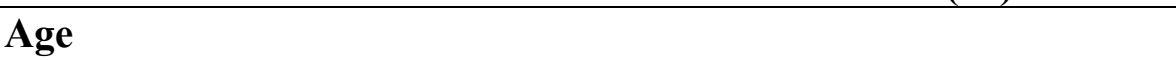 } \\
\hline $60-69$ years & $244(20.7 \%)$ \\
\hline $70-79$ years & $523(44.5 \%)$ \\
\hline $80-89$ years & $303(25.8 \%)$ \\
\hline$\geq 90$ years & $106(9.0 \%)$ \\
\hline \multicolumn{2}{|l|}{ Gender } \\
\hline Male & $173(14.7 \%)$ \\
\hline Female & $962(81.8 \%)$ \\
\hline \multicolumn{2}{|l|}{ County of Residence } \\
\hline Miami-Dade & $542(46.1 \%)$ \\
\hline Broward & $462(39.3 \%)$ \\
\hline Monroe & $162(13.8 \%)$ \\
\hline \multicolumn{2}{|l|}{ Race/Ethnicity } \\
\hline Hispanic/ Latino & $254(21.6 \%)$ \\
\hline $\begin{array}{r}\text { Haitian/ Other Non-Hispanic } \\
\text { Caribbean }\end{array}$ & $68(5.8 \%)$ \\
\hline White, non-Hispanic & $548(46.6 \%)$ \\
\hline $\begin{array}{l}\text { Black/African American, non- } \\
\text { Hispanic, non-Haitian }\end{array}$ & $218(18.5 \%)$ \\
\hline Other & $35(3.0 \%)$ \\
\hline \multicolumn{2}{|l|}{ Primary Language } \\
\hline English & $892(75.9 \%)$ \\
\hline Spanish & $231(19.6 \%)$ \\
\hline Other & $53(4.5 \%)$ \\
\hline \multicolumn{2}{|l|}{ Marital Status } \\
\hline Single/not partnered & $707(60.1 \%)$ \\
\hline Married/ partnered & $442(37.6 \%)$ \\
\hline \multicolumn{2}{|l|}{ Number in Household } \\
\hline Living alone & $537(45.7 \%)$ \\
\hline $\begin{array}{r}\text { Living with one or more } \\
\text { other people }\end{array}$ & $625(53.1 \%)$ \\
\hline \multicolumn{2}{|l|}{ Annual Income } \\
\hline$<\$ 15,000$ & $363(30.9 \%)$ \\
\hline$\geq \$ 15,000$ & $346(29.4 \%)$ \\
\hline \multicolumn{2}{|l|}{ Education } \\
\hline Less than High School & $232(19.7 \%)$ \\
\hline High School & $270(23.0 \%)$ \\
\hline Some college & $253(19.7 \%)$ \\
\hline College Graduate & $381(32.4 \%)$ \\
\hline
\end{tabular}




\begin{tabular}{|c|c|}
\hline Variable & $\begin{array}{c}\text { All eligible participants } \\
\text { n }(\%)^{\mathrm{a}}\end{array}$ \\
\hline \multicolumn{2}{|l|}{ Frail/Disabled } \\
\hline 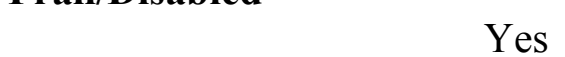 & $116(9.9 \%)$ \\
\hline No & $910(77.4 \%)$ \\
\hline \multicolumn{2}{|l|}{ Have Medicaid } \\
\hline Yes & $276(23.5 \%)$ \\
\hline No & $359(30.5 \%)$ \\
\hline \multicolumn{2}{|l|}{ Have Medicare } \\
\hline Yes & $130(11.1 \%)$ \\
\hline No & $843(71.7 \%)$ \\
\hline \multicolumn{2}{|l|}{ History of Depression } \\
\hline 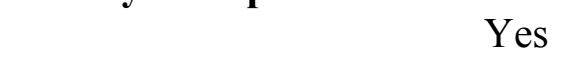 & $89(7.6 \%)$ \\
\hline No & $1,055(89.7 \%)$ \\
\hline \multicolumn{2}{|l|}{$\begin{array}{l}\text { Number of Chronic } \\
\text { Conditions }\end{array}$} \\
\hline None & $184(15.6 \%)$ \\
\hline One Condition & $332(28.2 \%)$ \\
\hline Two Conditions & $290(24.7 \%)$ \\
\hline Three or more Conditions & $338(28.7 \%)$ \\
\hline \multicolumn{2}{|l|}{ Self-Rated Health Status } \\
\hline Poor & $8(0.7 \%)$ \\
\hline Fair & $140(11.9 \%)$ \\
\hline Good & $499(42.4 \%)$ \\
\hline Very Good & $345(29.3 \%)$ \\
\hline Excellent & $150(12.8 \%)$ \\
\hline
\end{tabular}

${ }^{\text {a }}$ Percentage do not add upto $100 \%$ because of missing data 
Table 4.2 Change in Outcome Measures after Participating in EnhanceFitness: Baseline, 4-, 8-, 12-months (N = 1,176)

\begin{tabular}{|c|c|c|c|c|c|c|c|c|c|}
\hline $\begin{array}{c}\text { Functional } \\
\text { Performance } \\
\text { Measures }\end{array}$ & $\mathbf{n}$ & $\begin{array}{l}\text { Baseline } \\
M \pm \text { SD }\end{array}$ & $\begin{array}{l}\text { 4-mont } \\
\mathrm{M} \pm \mathrm{SD}\end{array}$ & $\begin{array}{l}\text { hs } \\
(\Delta 1)\end{array}$ & $\begin{aligned} & \text { 8-mon } \\
\mathrm{M} & \pm \mathrm{SD}\end{aligned}$ & $\begin{array}{l}\text { hs } \\
(\Delta 2)\end{array}$ & $\begin{array}{l}\text { 12-mon } \\
\mathrm{M} \pm \mathrm{SD}\end{array}$ & $\begin{array}{l}\text { ths } \\
(\Delta 3)\end{array}$ & p-value ${ }^{a}$ \\
\hline \multicolumn{10}{|c|}{ Chair Stands in 30 seconds } \\
\hline $\begin{array}{c}\text { Total } \\
\text { Arm Curls in } 30 \text { secon }\end{array}$ & 1,116 & $12.5 \pm 4.4$ & $14.2 \pm 5.1$ & $(1.7)$ & $14.1 \pm 5.0$ & $(1.6)$ & $14.5 \pm 5.4$ & $(2.0)$ & $<.001$ \\
\hline 8-foot $\boldsymbol{U p}-\mathbf{G o}^{\boldsymbol{b}}{ }^{\text {Total }}$ & 1,107 & $16.8 \pm 5.5$ & $18.7 \pm 5.9$ & $(1.9)$ & $18.8 \pm 6.1$ & $(2.0)$ & $19.2 \pm 5.9$ & $(2.4)$ & $<.001$ \\
\hline Total & 1,097 & $9.0 \pm 4.9$ & $8.5 \pm 5.3$ & $(-0.5)$ & $8.5 \pm 5.1$ & $(-0.5)$ & $8.6 \pm 5.8$ & $(-0.4)$ & $<.001$ \\
\hline
\end{tabular}

a Significance was calculated using Repeated Measures test

${ }^{\mathrm{b}}$ Improvement indicated by a reduction in time, resulting in a negative change in mean

M: Mean

SD: Standard Deviation

$\Delta \mathbf{1}$ Change in mean from baseline to 4-months $\Delta \mathbf{2}$ Change in mean from baseline to 8-months

$\Delta \mathbf{3}$ Change in mean from baseline to 12 -months 
Table 4.3 Change in Health-Status and Number of Falls after Participating in EnhanceFitness: Baseline, 4-, 8-, 12months

\begin{tabular}{|c|c|c|c|c|c|c|}
\hline $\begin{array}{l}\text { Functional } \\
\text { Performance } \\
\text { Measures } \\
\end{array}$ & $\mathbf{n}$ & $\begin{array}{c}\text { Baseline } \\
\%\end{array}$ & $\begin{array}{c}\text { 4-months } \\
\%\end{array}$ & $\begin{array}{c}\text { 8-months } \\
\%\end{array}$ & $\begin{array}{c}\text { 12-months } \\
\%\end{array}$ & p-value ${ }^{a}$ \\
\hline \multicolumn{7}{|c|}{$\begin{array}{l}\text { rated Health Status } \\
\text { Good/Very Good/Excellent) }\end{array}$} \\
\hline Total & 1,142 & $84.5 \%$ & $86.8 \%$ & $87.8 \%$ & $89.3 \%$ & $<.001$ \\
\hline \multicolumn{7}{|c|}{ Falls in last 4-months } \\
\hline Total & 1,085 & $15.1 \%$ & $9.7 \%$ & $8.0 \%$ & $6.7 \%$ & $<.001$ \\
\hline
\end{tabular}

${ }^{a}$ Significance was calculated using McNemar's Bowker test

$\%$ Percentage of participants 


\section{References}

Allen, K., \& Morey, M. C. (2010). Physical Activity and Adherence. In Improving Patient Treatment Adherence. New York, NY: Springer.

Belza, B., Shumway-Cook, A., Phelan, E., Williams, B., Snyder, S., \& LoGerfo, J. (2006). The Effects of a Community-Based Exercise Program on Function and Health in Older Adults: The EnhanceFitness Program. Journal of Applied Gerontology, 25(4), 291-306. doi:10.1177/0733464806290934

Belza, B., Susan, S., Meghan, T., \& James, L. (2010). From Research to Practice: EnhanceFitness, an Innovative Community-Based Senior Exercise Program. Topics in Geriatric Rehabilitation, 26(4), 299-309.

Bosković, K., Gava, B. P., Grajić, M., Madić, D., Obradović, B., \& Todorović, S. T. (2013). [Adapted physical activity in the prevention and therapy of osteoporosis]. Medicinski Pregled, 66(5-6), 221-4.

CDC. (2010). The Power of Prevention: Chronic disease... the public health challenge of the 21 st century. Retrieved September 19, 2014, from http://www.cdc.gov/chronicdisease/overview/pop.htm

CDC. (2011a). How much physical activity do older adults need? Retrieved September 09,2014 , from http://www.cdc.gov/physicalactivity/everyone/guidelines/olderadults.html

CDC. (2011b). Physical Activity for Everyone: The Benefits of Physical Activity. Retrieved September 29, 2014, from http://www.cdc.gov/physicalactivity/everyone/health/index.html\#ReduceCardiovasc ularDisease

CDC. (2011c). Physical Activity for Everyone: The Benefits of Physical Activity | DNPAO | CDC. Retrieved September 10, 2014, from http://www.cdc.gov/physicalactivity/everyone/health/

CDC. (2013a). NCHS Data Brief, 115. Retrieved from http://www.cdc.gov/nchs/data/databriefs/db115.htm

CDC. (2013b). Physical Activity and Health, Older Adults. Retrieved June 26, 2014, from http://www.cdc.gov/nccdphp/sgr/olderad.htm

Colberg, S. R., Sigal, R. J., Fernhall, B., Regensteiner, J. G., Blissmer, B. J., Rubin, R. R., ... Braun, B. (2010). Exercise and type 2 diabetes: the American College of Sports Medicine and the American Diabetes Association: joint position statement. Diabetes Care, 33(12), e147-67. doi:10.2337/dc10-9990 
Dogra, S., \& Stathokostas, L. (2012). Sedentary behavior and physical activity are independent predictors of successful aging in middle-aged and older adults. Journal of Aging Research, 2012. Retrieved from http://www.hindawi.com/journals/jar/2012/190654/

Fulop, T., Larbi, A., Witkowski, J., McElhaney, J., Loeb, M., Mitnitski, A., \& Pawelec, G. (2010). Aging, frailty and age-related diseases. Biogerontology, 11(5), 547-63. doi:10.1007/s10522-010-9287-2

Geller, K. S., Mendoza, I. D., Timbobolan, J., Montjoy, H. L., \& Nigg, C. R. (2012). The decisional balance sheet to promote healthy behavior among ethnically diverse older adults. Public Health Nursing, 29(3), 241-6. doi:10.1111/j.1525-1446.2011.00987.x

Glanz, K., Rimer, B. K., \& Viswanath, K. (2008). Health Behavior and Health Education: Theory, Research, and Practice (4th ed.). San Francisco, CA: JosseyBass.

Glei, D., Goldman, N., Lin, Y., \& Weinstein, M. (2011). Age-Related Changes in Biomarkers: Longitudinal Data from a Population-Based Sample. Research on Aging, 33(3), 312-326. doi:10.1177/0164027511399105

Hootman, J. M., \& Helmick, C. G. (2006). Projections of US prevalence of arthritis and associated activity limitations. Arthritis and Rheumatism, 54(1), 226-9. doi:10.1002/art.21562

Hughes, S. L., Seymour, R. B., Campbell, R. T., Whitelaw, N., \& Bazzarre, T. (2009). Best-practice physical activity programs for older adults: findings from the national impact study. American Journal of Public Health, 99(2), 362-8. doi:10.2105/AJPH.2007.131466

IBM Corp. (2012). IBM SPSS Statistics for Windows. Armonk, NY: IBM Corp.

Jones, C. J., Rikli, R. E., \& Beam, W. C. (1999). A 30-s chair-stand test as a measure of lower body strength in community-residing older adults. Research Quarterly for Exercise and Sport, 70(2), 113-9. doi:10.1080/02701367.1999.10608028

King, A. C., \& King, D. K. (2010). Physical Activity for an Aging Population. Public Health Reviews, 32, 401-426.

Kravitz, L. (1996). Age and Exercise. IDEA Today, 14(2), 28-35. Retrieved from http://www.unm.edu/ lkravitz/Article folder/age.html

Lorig, K., Stewart, A., Ritter, P., Gonzalez, V., Laurent, D., \& Lynch, J. (1996). Outcome Measures for Health Education and Other Health Care Interventions: Kate Lorig: 9780761900672 (1st ed.). Thousand Oaks, CA: SAGE Publications. 
Moore-Harrison, T. L., Johnson, M. A., Quinn, M. E., \& Cress, M. E. (2009). An evidence-based exercise program implemented in congregate-meal sites. Journal of Physical Activity \& Health, 6(2), 247-51.

National Cancer Institute. (2009). Physical Activity and Cancer - National Cancer Institute. Retrieved September 27, 2014, from http://www.cancer.gov/cancertopics/factsheet/prevention/physicalactivity

NIAMS. (2012). Questions and Answers About Gout. Retrieved June 06, 2014, from http:/www.niams.nih.gov/Health_Info/Gout/\#do

NIH. (2012). Exercise: Benefits of Exercise. Retrieved June 06, 2014, from http://nihseniorhealth.gov/exerciseforolderadults/healthbenefits/01.html

NIH Osteoporosis and Related Bone Diseases National Resource Center. (2012). Exercise for your bone health. Retrieved June 06, 2014, from http://www.niams.nih.gov/Health_Info/Bone/Bone_Health/Exercise/

Page, T. F., Batra, A., Ghouse, M. M., \& Palmer, R. C. (2014). Implementation Cost Analysis of a Community-Based Exercise Program for Seniors in South Florida. Health Promotion Practice, 15(4), 585-591. doi:10.1177/1524839913518221

Reid, K. J., Baron, K. G., Lu, B., Naylor, E., Wolfe, L., \& Zee, P. C. (2010). Aerobic exercise improves self-reported sleep and quality of life in older adults with insomnia. Sleep Medicine, 11(9), 934-40. doi:10.1016/j.sleep.2010.04.014

Rikli, R. E., \& Jones, C. J. (1999). Development and Validation of a Functional Fitness Test for Community-Residing Older Adults. Journal of Aging and Physical Activity, 7, 129-161.

Rogers, C., \& Keller, C. (2009). Roy's Adaptation Model To Promote Physical Activity Among Sedentary Older Adults. Geriatric Nursing, 30(2 Suppl), 21-26. doi:10.1016/j.gerinurse.2009.02.002.Roy

Senior Services. (2012). EnhanceFitness. Retrieved from http://www.ncoa.org/improvehealth/center-for-healthy-aging/content-library/EnhanceFitness-6-30-2011.pdf

Senior Services. (2013). Enhance Fitness. Retrieved October 02, 2014, from http://www.projectenhance.org/EnhanceFitness.aspx

Shih, M., Hootman, J. M., Kruger, J., \& Helmick, C. G. (2006). Physical activity in men and women with arthritis National Health Interview Survey, 2002. American Journal of Preventive Medicine, 30(5), 385-93. doi:10.1016/j.amepre.2005.12.005 
Stanford Patient Education Research Center. (2007). Chronic Disease Self-Management Program Codebook. Retrieved September 30, 2014, from http://patienteducation.stanford.edu/research/cdCodeBook.pdf

Tomioka, M., Sugihara, N., \& Braun, K. L. (2012). Replicating the EnhanceFitness physical activity program in Hawai' i's multicultural population, 2007-2010. Preventing Chronic Disease, 9, E74. Retrieved from http://www.cdc.gov/pcd/issues/2012/11_0155.htm

USDHHS: Healthy People. (2014). Older Adults - Healthy People 2020. Washington DC. Retrieved from http://www.healthypeople.gov/2020/topicsobjectives2020/overview.aspx?topicid=3 1

Wallace, J. I., Buchner, D. M., Grothaus, L., Leveille, S., Tyll, L., LaCroix, A. Z., \& Wagner, E. H. (1998). Implementation and effectiveness of a community-based health promotion program for older adults. The Journals of Gerontology. Series A, Biological Sciences and Medical Sciences, 53(4), M301-6.

Wilcox, S., Dowda, M., Griffin, S. F., Rheaume, C., Ory, M. G., Leviton, L., ... Mockenhaupt, R. (2006). Results of the first year of active for life: translation of 2 evidence-based physical activity programs for older adults into community settings. American Journal of Public Health, 96(7), 1201-9.

Yang, P., Ho, K., Chen, H., \& Chien, M. (2012). Exercise training improves sleep quality in middle-aged and older adults with sleep problems: a systematic review. Journal of Physiotherapy, 58(3), 157-63. doi:10.1016/S1836-9553(12)70106-6 


\section{CHAPTER 5}

\section{Manuscript Title: Physical Activity, Adherence, and Older Adults: Findings from a Community-Based Exercise Program in South Florida}

\section{Introduction}

Only one-fourth of the total U.S. adult population reported regularly physical activity in 2012 (National Center for Health Statistics, 2014b). Physical inactivity is the leading cause for developing chronic conditions at all ages (Allen \& Morey, 2010; CDC, 2014a, 2014b; A. C. King \& King, 2010; White et al., 2005). Further, the prevalence of physical inactivity as well as chronic conditions increases with age (Allen \& Morey, 2010; CDC, 2014a, 2014b; A. C. King \& King, 2010; White et al., 2005). Inactivity rates are highest among older adults (CDC, 2014a; White et al., 2005). Data from the Behavioral Risk Factor Surveillance System suggest that in 2013, approximately 50\% of older adults aged 60 or above did not participate in recommended 150 minutes or more of moderate intensity aerobic physical activity every week (CDC, 2014a). In addition, 76\% did not meet recommended levels of muscle strengthening exercises (CDC, 2014a). Importantly, physical inactivity makes older adults more vulnerable to chronic conditions and comorbidities (G Anderson, 2010; A. C. King \& King, 2010).

Abundant evidence supports the health benefits of physical activity in reducing the risk of many chronic conditions including heart disease, stroke, diabetes mellitus, arthritis, some cancers, and osteoporosis (Allen \& Morey, 2010; CDC, 2011f; A. C. King \& King, 2010; White et al., 2005). In addition, exercising helps maintain muscle and bone mass (CDC, 2011f; Ostlin, Eckermann, Mishra, Nkowane, \& Wallstam, 2006). However, adherence to physical activity programs for a minimum number of 
recommended sessions is necessary to attain these health benefits (Allen \& Morey, 2010; A. C. King \& King, 2010; White et al., 2005). Unfortunately, approximately 50\% of individuals who start an exercise program drop out within the first few weeks before any health benefits have been realized and achieved (Allen \& Morey, 2010; White et al., 2005). This percentage is alarming considering the known benefits of physical activity (Allen \& Morey, 2010; White et al., 2005).

Lack of physical activity and chronic conditions impact quality of life of older adults and increase the chances of dependence on others for daily activities later in life (G Anderson, 2010; A. C. King \& King, 2010). Further, data show that women disproportionately suffer the effects of aging and physical inactivity (CDC, 2011f, 2013a; A. C. King \& King, 2010; Ostlin et al., 2006). Results from the 2010 Medicare Current Beneficiary Survey revealed that in both non-institutionalized and institutionalized settings, more older women than men needed help bathing/showering (14.2\% vs. 9.5\%), getting in and out of chair/bed (15\% vs. $11.5 \%)$, and walking $(27.3 \%$ vs. $22.0 \%)$ (CDC, 2013a). Significant differences in morbidity and mortality rates among men and women suggest that men and women are exposed to different risk factors (A. C. King \& King, 2010; Ostlin et al., 2006). In addition, men and women face different kinds of barriers for participating and adhering to health promotion programs including programs that aim to increase activity levels (A. C. King \& King, 2010; Ostlin et al., 2006; White et al., 2005). There is abundant literature identifying factors that can motivate individuals to initiate participation in physical activity programs, but few studies explore factors that motivate individuals' to continue participation in these programs (White et al., 2005). This issue is further magnified if the interest is in identifying factors that affect older men and women 
independently (White et al., 2005). We aim to fill this gap by analyzing data for both the genders men and women separately, from an on-going physical activity program 'EnhanceFitness' (EF). The purpose of the current study was to identify factors that are associated with completion of the EF program.

\section{Methods}

\section{Setting}

The Health Foundation of South Florida established the Healthy Aging Regional Collaborative (HARC) in Fall 2008 to offer EF to older adults. Fourteen area-agencies funded by HFSF between October 1, 2008 and December 31, 2012 implemented EF in Broward, Miami-Dade, and Monroe counties in South Florida. A total of 160 workshops, lasting at least 4-months, were offered. The type of sites where EF workshops were offered included adult day care center, senior centers, clinics, hospitals, skilled nursing facilities, assisted living facilities, community centers, or senior housing.

\section{Study Participants and Recruitment}

Agencies offering the workshops recruited participants from both their existing client database and the community using a variety of methods including flyers, posters, and word of mouth. Qualified participants were adults aged 60 years old or older who were cognitively able to follow instructions. Individuals who had serious medical conditions, such as end-stage renal or heart disease that prohibited exercise, were excluded. Participants for this study were drawn from individuals who attended EF classes offered by HARC. 


\section{EF Overview}

$\mathrm{EF}$ is an evidence-based, low-cost, community-based group exercise program for older adults (Belza et al., 2006, 2010; Page et al., 2014; Senior Services, 2013; Wallace et al., 1998). EF, formerly known as 'Lifetime Fitness Program', was developed, tested, and found efficacious in 1998 (Belza et al., 2006, 2010; Moore-Harrison et al., 2009; Wallace et al., 1998). The original EF evaluation was conducted for six months in a controlled environment of a suburban senior center (Wallace et al., 1998). It consisted of a one-hour session held three times a week. EF focuses on stretching, flexibility, balance, low impact aerobics, and strength training exercises and helps older adults at all levels of fitness become more active, energized, and empowered to sustain independent lives (Belza et al., 2006, 2010; Moore-Harrison et al., 2009; Wallace et al., 1998). While the developers of EF define a complete course as three sessions per week for 4-months (Belza et al., 2006, 2010), HARC offered EF on an ongoing basis. The class structure and material was similar to original EF program. Program participation was voluntary and program was implemented by community-based agencies in real world settings of South Florida. Certified instructors led classes. Recommended class size was 15-25 participants. For classes with more than 15 participants, two instructors taught the class.

\section{Data Collection}

Participants were asked to complete a consent form, participant information, and health history form on the first day of the workshop. In addition, the functional performance of participants was tested by instructors using the Functional Fitness Test battery at baseline (T1) and every 4-months $(\mathrm{T} 2, \mathrm{~T} 3, \mathrm{~T} 4, \ldots)$ thereafter for those who continued to participate in the program for longer duration. 


\section{Measures}

Demographics: A participant information form was used to collect demographic information including gender, date of birth, address, marital status, disability, primary language, race/ethnicity, income, living situation, and insurance (Tables 5.1 and 5.2).

Health History Form: In the health history form, participants were asked about their known medical condition(s), medication(s), and allergies. In addition, participants were asked to do a self-assessment of their physical fitness level by responding to seven dichotomous questions (Figure 1). Participants were also asked to report on their weekly exercise schedule.

Functional Performance Measures: Outcome measures for the current study were collected using a fitness check form. Participants' functional performance was assessed by instructors using the Functional Fitness Test battery (FFT) developed by Rikli and Jones (Belza et al., 2006; Jones et al., 1999; Rikli \& Jones, 1999a). The original FFT was composed of seven activities and all were reported to have intraclass reliability ranging from 0.79 to 0.95 (Belza et al., 2006; Jones et al., 1999; Rikli \& Jones, 1999a). After receiving feedback from instructors regarding difficulties in implementing the sevenactivities FFT in community-based settings, Senior Services, who oversees the management, dissemination, and licensing of EF since 1999, tested and decided to keep the three FFT activities (Belza et al., 2006). This study used the same three activities. Lower body strength of participants was assessed by counting the number of full chair stands with arms folded across the chest performed in 30 seconds. To measure upper body strength, participants were asked to perform arm curls for 30 seconds with eightpound weights for men and five-pound weights for women. Agility and balance were 
assessed by recording the time taken to complete an eight-foot circuit (Belza et al., 2006;

Rikli \& Jones, 1999a).

\section{Data Extraction}

Data were extracted from an online database for the period October 1, 2008 through December 31, 2012. Data were imported into Statistical Package for the Social Sciences (SPSS) then cleaned and reverse coded as required. Data were analyzed using SPSS version 21.0 (IBM Corp, 2012) and Mplus version 6.0 (Muthén \& Muthén, 2010).

\section{Data Synthesis}

The seven physical fitness questions asked in the health history form were highly correlated. In order to avoid unnecessary collinearity, these items were analyzed using exploratory factor analysis (EFA). The analysis yielded a two-factor solution with excellent model fit $(\mathrm{RMSEA}=0.02, \mathrm{CFI}=0.99, \mathrm{SRMR}=0.016)$. The two factors represent participants' own beliefs about their fitness and fitness level. The factors were correlated at $r=0.54$, indicating approximately $25 \%$ shared variance (Figure 5.1 ).

The chronic conditions and risk factors from the health history form were consolidated into a chronic conditions and a risk factors variable respectively. For each, the numbers of items endorsed by the participant were categorized into four categories: none, one, two, and three or more (Tables 5.1 and 5.2).

Bazia et al. (2010) suggested attending 66\% of offered sessions in 4-months which is 32 of $48 \mathrm{EF}$ sessions in 4-months ( $\sim 16$ weeks) to attain program benefits (Belza et al., 2010). This was the definition of program completion used in this study. The number of sessions attended was dichotomized such that participants who attended at least 32 sessions within first 4-months following their start date were coded as 
"completers" and those who attended fewer than 32 sessions were coded as "noncompleters."

\section{Statistical Analyses}

Data were first checked for any outliers using P-P plots. After that, variables were tested for multi-collinearity. Overall participant characteristics and participant characteristics based on the gender and completion status were described using descriptive statistics (Tables 5.1 and 5.2).

\section{Predictors of Program Completion}

Logistic regression was performed to examine how socio-demographic factors, number of chronic conditions, risk factors, and other health indicators were associated with program completion. Since the purpose of the study was to determine factors associated with program completion for men and women independently, all the analyses were conducted and reported separately by gender. First, demographics and other independent variables of completers were compared to non-completers using Pearson's chi-square test (Tables 5.1 and 5.2). Two different models, one for men, and another for women, were developed using entry method logistic regression. Variables with $p$-values $\leq 0.300$ in the bivariate analysis were included in the final logistic regression model (Arya et al., 2010; Persson, Lexell, Rivano-Fischer, \& Eklund, 2014). For men, county of residence, race/ethnicity, language, number in household, education, frail/disabled, number of chronic conditions, risk factors for chronic conditions, and participants' belief about their own fitness were found to be significant in the bivariate analysis and thus included in the model (Table 5.1). Self-reported fitness level, although insignificant in the bivariate analysis, was still included in the final model because it was reported as a 
significant predictor of program completion in other studies (Allen \& Morey, 2010;

Findorff, Wyman, \& Gross, 2009). For women, age, County of residence, race/ethnicity, language, income, education, frail/disabled, insurance, falls' history, history of depression, and risk factors for chronic conditions were found to be significant predictors of completion (Table 5.2). Number of chronic conditions and self-reported fitness level, although insignificant in bivariate analysis, were still included in the final model because they were reported as a significant predictor of program completion in other studies (Allen \& Morey, 2010; Findorff et al., 2009). The models' goodness of fit was assessed using the Hosmer-Lemeshow goodness of fit test (Hosmer \& Lemeshow, 2004).

\section{Results}

\section{Sample Characteristics}

A total of 702 men and 3,829 women age 60 or above attended an EF workshop between October 1, 2008 and December 31, 2012. Of these, 202 (31.3\%) men and 924 (24.2\%) women were completers (Tables 5.1 and 5.2). Approximately $45 \%$ of men and $42 \%$ of women were $70-79$ years old with mean age of $75.8( \pm 8.6)$ years. Majority of men (46.9\%) lived in Broward County whereas majority of women (49.1\%) lived in Miami-Dade County. Approximately 58\% of men and $43 \%$ of women participants identified themselves as non-Hispanic whites. In comparison to $82.3 \%$ of men, almost three-quarters of women participants identified English as their primary language. In contrast to $60 \%$ of women, $43.0 \%$ of men identified themselves as single/ not partnered. Higher percentage of women (47.8\%) than men (34.0\%) reported to lived alone. Approximately $30 \%$ of women participants were college graduates and reported an annual income of more than $\$ 15,000$ whereas almost half of men participants were 
college graduates and $38.7 \%$ reported an annual income more than $\$ 15,000$. Most of the participants $(78.7 \%$ men and $72.7 \%$ women) were enrolled in either Medicare or Medicaid. One-third of participants were suffering from more than three chronic conditions. More than half the participants had a strong, positive belief about their own fitness and reported their fitness level to be excellent (Tables 5.1 and 5.2).

\section{Factors Associated with Program Completion}

For men, race/ethnicity, and having risk factors for chronic conditions were significantly associated with program completion in logistic regression analysis (Table 5.3). Black, non-Haitian men were less likely to complete the program when compared to white, non-Hispanic men (OR=0.41, 95\% CI: 0.18-0.91, $p=0.02)$. Participants who selfreported having at least one risk factor were more likely to complete the program compared to those who were exposed to three or more risk factors $(\mathrm{OR}=1.81,95 \% \mathrm{CI}$ : 1.05-3.13, $p=0.03$ ) (Table 5.3). The overall model was found to have good fit using the Hosmer-Lemeshow goodness-of-fit test $\left(\chi^{2}=8.15, d f=8, p\right.$-value $\left.=0.42\right)$.

Logistic regression results for women revealed that age, County of residence, race/ethnicity, history of depression, and having risk factors for chronic conditions were significantly associated with program completion (Table 5.4). Women aged 80 years or more were one and a half times more likely to complete the program compared to women aged 60-69 years $(\mathrm{OR}=1.46,95 \% \mathrm{CI}: 1.01-2.13, p=0.05)$. Compared to residents of Monroe County, residents of Miami-Dade County were twice as likely to complete the program $(\mathrm{OR}=2.13,95 \% \mathrm{CI}: 1.39-3.26, p=0.001)$. Black, non-Haitian women were less likely to complete the program when compared to white, non-Hispanics $(\mathrm{OR}=0.61,95 \%$ CI: $0.42-0.89, p=0.01)$. Those who did not report history of depression were over one and 
a half times more likely to complete the program ( $\mathrm{OR}=1.62,95 \% \mathrm{CI}: 1.04-2.51, p=0.03)$. Participants who were not exposed to any risk factor were more likely to complete the program compared to those who were exposed to three or more risk factors that could increase the chances of chronic conditions $(\mathrm{OR}=1.63,95 \% \mathrm{CI}$ : 1.13-2.34, $p=0.01)$ (Table

5.4). The overall model was found to have good fit using the Hosmer-Lemeshow goodness-of-fit test $\left(\chi^{2}=4.41, d f=8, p\right.$-value $\left.=0.82\right)$.

\section{Discussion}

The aim of this study was to identify factors associated with program completion defined as attending at least 32 sessions within first 4-months following their start date. As of today, EF is offered in 26 states at approximately 141 sites (Senior Services, 2013). However, we could find only four studies reporting on the efficacy or effectiveness of EF (Belza et al., 2006; Moore-Harrison et al., 2009; Tomioka et al., 2012; Wallace et al., 1998). In addition, three studies report on the cost-effectiveness of EF (Ackermann et al., 2008; Page et al., 2012; Tomioka et al., 2012). Although researchers reported low adherence rates among EF participants (Belza et al., 2006) and physical activity programs in general (Allen \& Morey, 2010), we could not find any study assessing factors associated with EF completion. The current manuscript is the first study, to our knowledge, to identify factors that are associated with EF completion.

Ample evidence supports the importance of attending a minimum number of sessions to attain health benefits in physical activity programs. In our previous manuscript, participants who completed the program showed significant improvement that was almost two times higher than who did not complete the program. Wallace et al. (1998) reported a completion rate of over $90 \%$ in their initial EF efficacy trial (Wallace et 
al., 1998). However, our study faces the problem of a low completion rate where only about $32 \%$ of men and $25 \%$ of women met the completer definition. The dissimilarity in completion rates may reflect study design difference. The initial EF efficacy study was a randomized controlled trial (Wallace et al., 1998); however, the current study was carried out in community-based settings. Further, although improving physical and psychosocial functioning was the focus of controlled EF trial, participants were given referrals for alcohol and tobacco abuse habits, if required (Wallace et al., 1998). In addition, participants were given nutrition tips and self-administered hazard checklist for home safety evaluations. Additionally, in original EF trial, participants' were contacted by telephone at 2, 4, and 16 weeks to improve compliance. During these calls, any problems related with compliance were identified and participants were motivated to continue the program and change behavior (Wallace et al., 1998). Limited resources prevented us from doing these, but we recommend using this methodology to improve participation completion. Alcohol use and smoking, poor dietary habits, and unsafe home environment can influence physical activity levels (Allen \& Morey, 2010; A. C. King \& King, 2010). Therefore, addressing them together in an intervention is advisable as it might motivate participants to continue participation.

Although our attrition rates were much higher than those found in the original EF trial, low completion rates have been reported in other studies aimed to increase physical activity among older women and men in community-based settings (Allen \& Morey, 2010; Findorff et al., 2009; Hawley-Hague et al., 2014; White et al., 2005). EF was offered on an ongoing basis in South Florida, and among 70\% of men that did not meet the completer definition criteria, 39\% attended more than 32 sessions in total but were 
not considered a completer because they did not complete those within 4-months from their first date of attendance. Similarly, among the $75 \%$ of women that did not meet the completer definition criteria, $52.9 \%$ attended more than 32 sessions in total but were not considered a completer because they did not complete those within first 4-months. Evaluating and comparing the effects of this attendance pattern is beyond the scope of this manuscript and will be evaluated in another manuscript. A brief survey of our program coordinators' revealed certain barriers and challenges faced by agencies and participants in implementing EF. Some of the challenges identified that could result in low completion rates of men include more female participants in classes, machismo or cultural beliefs, and perception of exercise programs as feminine. Our findings are consistent with existing literature (Ceballos, 2013). Barriers for women include lack of transportation, conflicting time of workshops, women's multiple roles and competing responsibilities, and a social environment that is not supportive of women participating in activity programs. Similar barriers have been reported by other researchers also (Allen \& Morey, 2010; A. C. King \& King, 2010; White et al., 2005). As mentioned above, contacting participants every few weeks to discuss and assist resolving their compliance issues, motivating them to continue participation, and reminding the benefits of program participation might help increasing completion rates.

Logistic regression was used to identify factors that are associated with program completion for men and women. In our study, women residents of Miami-Dade County were more likely to complete the program when compared to residents of Monroe County. A distinguishable difference between these County residents is that Monroe County residents are highly seasonal. Therefore, the difference found could be attributed 
to the fact that women participants in Monroe County left South Florida during the 4month window following their start date. No significant results related to County were found for men.

Contrary to findings of many other researchers (Allen \& Morey, 2010; A. C. King \& King, 2010; White et al., 2005) our results indicated that women aged 80 years or above were one and a half times more likely to complete the program when compared with women aged 60-69 years. On further analyses, we found that in comparison to those between ages 60-79 years, women aged 80 and above in our group held strong positive beliefs about their own fitness. The belief variable in the current study was a latent variable and computed using results of EFA (Figure 5.1). A direct positive relationship between beliefs about fitness and participation in an exercise program has been well documented (Ehrlich-Jones et al., 2011; Sarkisian, Prohaska, Wong, Hirsch, \& Mangione, 2005). However, the lack of use of an instrument that would have objectively measured participants' beliefs in our study prevented us from doing rigorous analysis. More detailed research is required to validate this finding. In addition, since participation in EF was voluntary, women who were healthy enough at $80+$ to participate in an exercise program were probably healthier than average overall or perceived themselves to be healthier as mentioned above.

Race and ethnicity may present their own set of barriers to program completion (Allen \& Morey, 2010; Findorff et al., 2009; A. C. King \& King, 2010). In our study, women and men who identified themselves as black or African American were less likely to complete the program compared to their white counterparts. Similar results have been reported by other researchers who found that African American older adults are less 
likely to be physically active and report low compliance levels with health promotion programs and preventive services (Allen \& Morey, 2010; Crespo, 2000; A. C. King \& King, 2010). Data from the National Center for Health Statistics also suggests that Black or African American older adults are less likely to be physically active (National Center for Health Statistics, 2014b). Removing barriers such as perceived discrimination, enhancing social support, tailoring the interventions to the gender specific needs, and recruiting culturally competent instructors might improve adherence rates for black participants (Allen \& Morey, 2010; A. C. King \& King, 2010).

History of depression was inversely related to program completion for women in the current study. This finding is supported by previous research that shows women suffering from depression are less likely to participate in social activities and maintain regular schedules (Findorff et al., 2009; Lin et al., 2004). Depression affects men and women in different ways. Not only are women more prone to depression, the literature also suggests that causes of depression and patterns of symptoms are different in women (Findorff et al., 2009; Lin et al., 2004). Factors that uniquely affect women could range from alterations in reproductive hormones (such as those experienced during menopause) to societal pressures to response to stress (Allen \& Morey, 2010; Findorff et al., 2009; A. C. King \& King, 2010; Lin et al., 2004). Learning and acknowledging these differences in intervention development might help to improve exercise completion rates among women. Same gender medical assistants have also been reported to increase the use of preventive services (Wong, 2008). Using the same rationale, female instructors might increase participation and adherence rate for women. 
This study investigated the relationship between exposure to risk factors of chronic conditions and completion with physical activity program. In the current study, women without risk factors were almost one and a half times more likely to complete the program. For women, the absence of risk factors may be associated with a perception of being in good general health and thereby women participants were more likely to attend sessions regularly, compared to women in poor general health (Allen \& Morey, 2010; Ehrlich-Jones et al., 2011; Sarkisian et al., 2005). In contrast, men who had one risk factor were more likely to complete the program. Men perceive themselves to be healthier and therefore, are less likely to participate in prevention programs (Nies \& McEwen, 2010). Therefore, having a risk factor might have encouraged men in the current study to complete the program.

\section{Limitations}

Since findings are from a program offered in South Florida only, the study findings have limited generalizability. In addition, absence of data on one or more of the included predictor variables in the final model predicting completion resulted in exclusion of 2,419 participants from logistic regression analyses. Participants in the current study were not randomly selected but rather volunteered because they thought they might benefit from the program. Therefore, selection bias could be a problem. Lastly, as the focus of HARC was implementation of EF in community-based settings, certain variables that might have allowed rigorous analyses such as participants' belief were not collected using validated instruments. However, these findings now open opportunities for future research. 


\section{Conclusion}

The current study demonstrates needs for programs that can motivate participants to continue participation in prevention programs. A few challenges that are inevitable when implementing programs at wider scale, such as low completion rates especially and missing data are highlighted. The HARC initiative is an example of Phase 4 Translational Research. It demonstrates the capacity of a local organization to implement evidencebased health promotion programs at such a large scale.

Future researchers can use the results and suggestions given in this study when designing interventions for men and women or replicating the existing ones to meet the specific needs of target population. Contacting participants by telephone every few weeks to discuss their compliance issues and making some alterations that do not alter the content of the original program may allow for better adaptation of programs as well as improved adherence and thus completion rates. A successful example of such alteration is replication of EF in Hawaii (Tomioka et al., 2012). Using available tools, implementers of the program made few alterations to meet the needs of the local population, such as using Hawaiian music for the warm-up and renaming a few exercises to relate them to the daily activities of the participants. Using the same rationale, we suggest that EF implementation would benefit from similar adaptations notably, the use of culturally competent instructors at locations with non-white participants. The use of clue words that resonate with participants and reinforce the benefits of participation would not alter the content of program; however, they might help in increasing participants' interest and motivating them for continued attendance. 
The potential exists to develop policies that enforce engaging and increasing physical activity levels among older adults. Chronic conditions are correlated with aging and affect overall quality of life of older adults (G Anderson, 2010; CDC, 2014b; A. C. King \& King, 2010). Chronic conditions not only place burden on the individual suffering, but also on already fragmented health care system (Gerard Anderson \& Horvath, 2004; Garrett \& Martini, 2007; A. C. King \& King, 2010; Schneider et al., 2009). An increase in the number of chronic conditions results in an increase in utilization of health care services (G Anderson, 2010; Gerard Anderson \& Horvath, 2004; CDC, 2014b; Garrett \& Martini, 2007; Schneider et al., 2009). According to the Robert Wood Johnson Foundations' 2010 report, $84 \%$ of all health care spending was for the $50 \%$ of the population who have one or more chronic medical conditions (G Anderson, 2010; CDC, 2014b). Schneider et al. (2009) reported that the annual Medicare payment amounts for a beneficiary with one chronic condition is $\$ 7,172$ (Schneider et al., 2009). This amount increases to $\$ 14,931$ for those with two conditions and $\$ 32,498$ for those with three or more conditions (Schneider et al., 2009). Physical activity programs such as $\mathrm{EF}$ that are found to be effective can help combat the issue of chronic conditions by reducing the chances of developing risk factors. For instance, regular physical activity helps to increase metabolic rates and burn fat, which, reduces the chances for developing obesity, a risk factor for many chronic conditions including hypertension, diabetes, and heart disease (Allen \& Morey, 2010; CDC, 2011f; A. C. King \& King, 2010; White et al., 2005). Regular activity improves muscle strength and endurance that helps to relieve symptoms of many chronic conditions including back pain and arthritis (Allen \& Morey, 2010; CDC, 2011f; A. C. King \& King, 2010; White et al., 2005). Not only do EF 
participants show significant improvement in physical activity levels (Belza et al., 2006, 2010; Moore-Harrison et al., 2009; Wallace et al., 1998), EF has the potential to reduce healthcare costs among those who complete the recommended number of sessions. Ackermann et al. (2008) found that EF users spent $\$ 1,929$ less on health care annually. Similar results have been reported by other researchers also (Belza et al., 2010; Sugihara et al., 2011). Page et al. (2014) estimated the monthly cost of implementing EF in community settings to be $\$ 873$ per month for agencies who had been offering the program for at least one year. Assuming 15 completers in each 4-month time period yields a per completer cost of $\$ 232.80$, (Page et al., 2014) well below the cost-savings documented in Ackermann et al. (2008).

EF is offered in 26 states, (Senior Services, 2013) but there is a considerable gap to fund these programs. Since EF is found to be effective in improving the health of participants and have the potential to reduce healthcare costs, there should be policies supporting the implementation of EF on a continued basis. In addition, Medicare reimbursement should be provided for agencies that offer EF, as has been done with other programs such as diabetes self-management training program targeting older adults. 
Table 5.1 Sample characteristics and Comparison of Older Men who attended $\geq 32$ sessions with those who attended $<32$ sessions within 4-months following their start date, $(n=702)$

\begin{tabular}{|c|c|c|c|c|}
\hline Variable & $\begin{array}{c}\text { All eligible } \\
\text { participants } \\
n=702\end{array}$ & $\begin{array}{c}\text { Completer } \\
(\geq 32 \text { sessions }) \\
n=220\end{array}$ & $\begin{array}{c}\text { Non- } \\
\text { Completer } \\
(<32 \text { sessions }) \\
n=\mathbf{4 8 2} \\
\end{array}$ & $p$-value ${ }^{a}$ \\
\hline & n (\%) & n (\%) & $\mathrm{n}(\%)$ & \\
\hline \multicolumn{5}{|l|}{ Age } \\
\hline $60-69$ years & $155(22.1 \%)$ & $51(23.2 \%)^{\mathrm{c}}$ & $104(21.6 \%)$ & \multirow{3}{*}{.783} \\
\hline 70-79 years & $318(45.3 \%)$ & $101(45.9 \%)^{\mathrm{d}}$ & $217(45.0 \%)$ & \\
\hline$\geq 80$ years & $229(32.6 \%)$ & $68(30.9 \%)^{\mathrm{e}}$ & $161(33.4 \%)$ & \\
\hline \multicolumn{5}{|l|}{ County of Residence } \\
\hline Broward & $329(46.9 \%)$ & $127(57.7 \%)$ & $202(42.3 \%)$ & \multirow{3}{*}{.001} \\
\hline Miami-Dade & $248(35.3 \%)$ & $59(26.8 \%)$ & $189(39.5 \%)$ & \\
\hline Monroe & $120(17.1 \%)$ & $33(15.0 \%)$ & $87(18.2 \%)$ & \\
\hline \multicolumn{5}{|l|}{ Race/Ethnicity } \\
\hline Hispanic/ Latino & $126(17.9 \%)$ & $42(20.1 \%)$ & $84(18.8 \%)$ & \multirow{5}{*}{.001} \\
\hline $\begin{array}{l}\text { Haitian/ Other Non- } \\
\text { Hispanic Caribbean }\end{array}$ & $23(3.3 \%)$ & $3(1.4 \%)$ & $20(4.5 \%)$ & \\
\hline $\begin{array}{r}\text { White, non-Hispanic } \\
\text { Black/African }\end{array}$ & $405(57.7 \%)$ & $141(67.5 \%)$ & $264(58.9 \%)$ & \\
\hline $\begin{array}{l}\text { American, non- } \\
\text { Hispanic, non-Haitian }\end{array}$ & $82(11.7 \%)$ & $13(6.2 \%)$ & $69(15.4 \%)$ & \\
\hline Other & $21(3.0 \%)$ & $10(4.8 \%)$ & $11(2.5 \%)$ & \\
\hline \multicolumn{5}{|l|}{ Primary Language } \\
\hline English & $578(82.3 \%)$ & $179(81.4 \%)$ & $399(82.8 \%)$ & \multirow{3}{*}{.085} \\
\hline Spanish & $106(15.1 \%)$ & $39(17.7 \%)$ & $67(13.9 \%)$ & \\
\hline Other & $18(2.6 \%)$ & $2(0.9 \%)$ & $16(3.3 \%)$ & \\
\hline \multicolumn{5}{|l|}{ Marital Status } \\
\hline Single/not partnered & $302(43.0 \%)$ & $101(47.0 \%)$ & $201(43.6 \%)$ & \multirow{2}{*}{.411} \\
\hline Married/ partnered & $374(53.3 \%)$ & $114(53.0 \%)$ & $260(56.4 \%)$ & \\
\hline \multicolumn{5}{|l|}{ Number in Household } \\
\hline Living alone & $239(34.0 \%)$ & $88(40.2 \%)$ & $151(31.4 \%)$ & \multirow[b]{2}{*}{.023} \\
\hline $\begin{array}{l}\text { Living with one or } \\
\text { more other people }\end{array}$ & $461(65.7 \%)$ & $131(59.8 \%)$ & $330(68.6 \%)$ & \\
\hline \multicolumn{5}{|l|}{ Annual Income } \\
\hline$<\$ 15,000$ & $175(24.9 \%)$ & $52(36.1 \%)$ & $123(40.6 \%)$ & \multirow{2}{*}{.364} \\
\hline$\geq \$ 15,000$ & $272(38.7 \%)$ & $92(63.9 \%)$ & $180(59.4 \%)$ & \\
\hline \multicolumn{5}{|l|}{ Education } \\
\hline Less than High School & $100(14.2 \%)$ & $22(10.5 \%)$ & $78(17.1 \%)$ & \multirow{4}{*}{.034} \\
\hline High School & $93(13.2 \%)$ & $27(12.9 \%)$ & $66(14.5 \%)$ & \\
\hline Some college & $155(22.1 \%)$ & $45(21.4 \%)$ & $110(24.2 \%)$ & \\
\hline College Graduate & $317(45.2 \%)$ & $116(55.2 \%)$ & $201(44.2 \%)$ & \\
\hline
\end{tabular}




\begin{tabular}{|c|c|c|c|c|}
\hline Variable & $\begin{array}{c}\text { All eligible } \\
\text { participants } \\
n=702\end{array}$ & $\begin{array}{c}\text { Completer } \\
(\geq \mathbf{3 2} \text { sessions }) \\
n=\mathbf{2 2 0}\end{array}$ & $\begin{array}{c}\text { Non- } \\
\text { Completer } \\
(<32 \text { sessions }) \\
n=482 \\
\end{array}$ & $p$-value ${ }^{\text {a }}$ \\
\hline & n (\%) ${ }^{b}$ & n (\%) & n (\%) & \\
\hline \multicolumn{5}{|l|}{ Frail/Disabled } \\
\hline $\begin{array}{l}\text { Yes } \\
\text { No }\end{array}$ & $\begin{array}{l}89(12.7 \%) \\
533(75.9 \%)\end{array}$ & $\begin{array}{c}20(9.1 \%) \\
186(84.5 \%)\end{array}$ & $\begin{array}{c}69(14.3 \%) \\
347(72.0 \%)\end{array}$ & .001 \\
\hline \multicolumn{5}{|l|}{ Insurance } \\
\hline $\begin{array}{l}\text { Yes } \\
\text { No }\end{array}$ & $\begin{array}{c}551(78.2 \%) \\
57(8.1 \%)\end{array}$ & $\begin{array}{l}174(89.2 \%) \\
21(10.8 \%)\end{array}$ & $\begin{array}{c}377(91.3 \%) \\
36(8.7 \%)\end{array}$ & .418 \\
\hline \multicolumn{5}{|l|}{ History of falls } \\
\hline $\begin{array}{r}\text { Yes } \\
\text { No }\end{array}$ & $\begin{array}{c}78(11.1 \%) \\
588(83.8 \%)\end{array}$ & $\begin{array}{l}25(11.5 \%) \\
192(88.5 \%)\end{array}$ & $\begin{array}{c}53(11.8 \%) \\
396(88.2 \%)\end{array}$ & .915 \\
\hline \multicolumn{5}{|l|}{ History of depression } \\
\hline $\begin{array}{r}\text { Yes } \\
\text { No }\end{array}$ & $\begin{array}{c}59(8.4 \%) \\
607(86.5 \%)\end{array}$ & $\begin{array}{c}18(8.3 \%) \\
199(91.7 \%)\end{array}$ & $\begin{array}{c}41(9.1 \%) \\
408(90.9 \%)\end{array}$ & .722 \\
\hline \multicolumn{5}{|l|}{$\begin{array}{l}\text { Number of Chronic } \\
\text { Conditions }\end{array}$} \\
\hline $\begin{array}{r}\text { None } \\
\text { One Condition }\end{array}$ & $\begin{array}{l}111(15.8 \%) \\
191(27.2 \%)\end{array}$ & $\begin{array}{l}32(14.7 \%) \\
80(36.9 \%)\end{array}$ & $\begin{array}{l}79(17.6 \%) \\
111(24.7 \%)\end{array}$ & \multirow[b]{2}{*}{.008} \\
\hline $\begin{array}{r}\text { Two Conditions } \\
\text { Three or more } \\
\text { Conditions }\end{array}$ & $198(28.2 \%)$ & $\begin{array}{l}43(19.8 \%) \\
62(28.6 \%)\end{array}$ & $136(30.3 \%)$ & \\
\hline \multicolumn{5}{|l|}{$\begin{array}{l}\text { Risk Factors for } \\
\text { Chronic Conditions }\end{array}$} \\
\hline None & $142(20.2 \%)$ & $51(23.5 \%)$ & $91(20.3 \%)$ & \multirow{4}{*}{.102} \\
\hline One Risk Factor & $175(24.9 \%)$ & $60(27.6 \%)$ & $115(25.6 \%)$ & \\
\hline Two Risk Factors & $113(16.1 \%)$ & $43(19.8 \%)$ & $70(15.6 \%)$ & \\
\hline $\begin{array}{r}\text { Three or more Risk } \\
\text { Factors }\end{array}$ & $236(33.6 \%)$ & $63(29.0 \%)$ & $173(38.5 \%)$ & \\
\hline \multicolumn{5}{|l|}{$\begin{array}{l}\text { Participant's belief } \\
\text { about their own fitness }\end{array}$} \\
\hline Low/No Belief & $161(22.9 \%)$ & $45(21.2 \%)$ & $116(27.2 \%)$ & \multirow{2}{*}{.103} \\
\hline \multicolumn{4}{|l|}{ Self-Reported Fitness } & \\
\hline Very Poor & $43(6.1 \%)$ & $13(6.1 \%)$ & $30(7.0 \%)$ & \\
\hline Moderate & $155(22.1 \%)$ & $45(21.1 \%)$ & $110(25.7 \%)$ & .364 \\
\hline Excellent & $443(63.1 \%)$ & $155(72.8 \%)$ & $288(67.3 \%)$ & \\
\hline
\end{tabular}

${ }^{a} p$-values were obtained from chi-square tests

b \%age do not add upto $100 \%$ because of missing data

${ }^{\mathrm{c}}$ Within age group percentage is $32.9 \%$

${ }^{\mathrm{d}}$ Within age group percentage is $31.8 \%$

${ }^{\mathrm{e}}$ Within age group percentage is $29.7 \%$ 
Completer: HARC participant who attended 32 or more sessions within first 4-months following their start date 
Table 5.2 Sample characteristics and Comparison of Older Women who attended $\geq$ 32 sessions with those who attended $<32$ sessions within 4-months following their start date, $(n=3,829)$

\begin{tabular}{|c|c|c|c|c|}
\hline Variable & $\begin{array}{c}\text { All eligible } \\
\text { participants } \\
\mathbf{n}=\mathbf{3 , 8 2 9}\end{array}$ & $\begin{array}{c}\text { Completer } \\
(\geq 32 \text { sessions }) \\
n=924\end{array}$ & $\begin{array}{c}\text { Non- } \\
\text { Completer } \\
(<32 \text { sessions }) \\
n=\mathbf{2 , 9 0 5} \\
\end{array}$ & $p$-value ${ }^{a}$ \\
\hline & $n(\%)$ & n (\%) & n (\%) & \\
\hline \multicolumn{5}{|l|}{ Age } \\
\hline 60-69 years & $1,030(26.9 \%)$ & $206(22.3 \%)^{\mathrm{c}}$ & $824(28.4 \%)$ & \multirow{3}{*}{.001} \\
\hline $70-79$ years & $1,593(41.6 \%)$ & $389(42.1 \%)^{\mathrm{d}}$ & $1,204(41.4 \%)$ & \\
\hline$\geq 80$ years & $1,206(31.5 \%)$ & $329(35.6 \%)^{\mathrm{e}}$ & $877(30.2 \%)$ & \\
\hline \multicolumn{5}{|l|}{ County of Residence } \\
\hline Broward & $1,353(35.3 \%)$ & $336(36.5 \%)$ & $1,017(35.4 \%)$ & \multirow{3}{*}{.024} \\
\hline Miami-Dade & $1,879(49.1 \%)$ & $474(51.5 \%)$ & $1,405(49.0 \%)$ & \\
\hline Monroe & $558(14.6 \%)$ & $110(12.0 \%)$ & $448(15.6 \%)$ & \\
\hline \multicolumn{5}{|l|}{ Race/Ethnicity } \\
\hline Hispanic/ Latino & $961(25.1 \%)$ & $269(30.3 \%)$ & $692(25.6 \%)$ & \multirow{6}{*}{.001} \\
\hline $\begin{array}{l}\text { Haitian/ Other Non- } \\
\text { Hispanic Caribbean }\end{array}$ & $191(5.0 \%)$ & $42(4.7 \%)$ & $149(5.5 \%)$ & \\
\hline $\begin{array}{r}\text { White, non-Hispanic } \\
\text { Black/African }\end{array}$ & $1,643(42.9 \%)$ & $411(46.3 \%)$ & $1,232(45.6 \%)$ & \\
\hline American, non- & $681(17.8 \%)$ & $125(14.1 \%)$ & $556(20.6 \%)$ & \\
\hline Hispanic, non-Haitian & & & & \\
\hline Other & $113(3.0 \%)$ & $41(4.6 \%)$ & $72(2.7 \%)$ & \\
\hline \multicolumn{5}{|l|}{ Primary Language } \\
\hline English & $2,794(73.0 \%)$ & $652(70.6 \%)$ & $2,142(73.7 \%)$ & \multirow{3}{*}{.003} \\
\hline Spanish & $896(23.4 \%)$ & $249(26.9 \%)$ & $647(22.3 \%)$ & \\
\hline Other & $139(3.6 \%)$ & $23(2.5 \%)$ & $116(4.0 \%)$ & \\
\hline \multicolumn{5}{|l|}{ Marital Status } \\
\hline Single/not partnered & $2,297(60.0 \%)$ & $580(64.7 \%)$ & $1,717(62.9 \%)$ & \multirow{2}{*}{.347} \\
\hline Married/ partnered & $1,329(34.7 \%)$ & $317(35.3 \%)$ & $1,012(37.1 \%)$ & \\
\hline \multicolumn{5}{|l|}{$\begin{array}{l}\text { Number in } \\
\text { Household }\end{array}$} \\
\hline Living alone & $1,831(47.8 \%)$ & $443(48.5 \%)$ & $1,388(48.0 \%)$ & \multirow[b]{2}{*}{.823} \\
\hline $\begin{array}{l}\text { Living with one } \\
\text { or more other people }\end{array}$ & $1,972(51.5 \%)$ & $471(51.5 \%)$ & $1,501(52.0 \%)$ & \\
\hline \multicolumn{5}{|l|}{ Annual Income } \\
\hline$<\$ 15,000$ & $1,114(29.1 \%)$ & $245(45.9 \%)$ & $869(50.8 \%)$ & \multirow{2}{*}{.046} \\
\hline$\geq \$ 15,000$ & $1,130(29.5 \%)$ & $289(54.1 \%)$ & $841(49.2 \%)$ & \\
\hline \multicolumn{5}{|l|}{ Education } \\
\hline $\begin{array}{r}\text { Less than High } \\
\text { School }\end{array}$ & $600(15.7 \%)$ & $141(15.9 \%)$ & $459(17.1 \%)$ & \multirow[t]{2}{*}{.178} \\
\hline High School & $907(23.7 \%)$ & $249(28.1 \%)$ & $658(24.5 \%)$ & \\
\hline
\end{tabular}




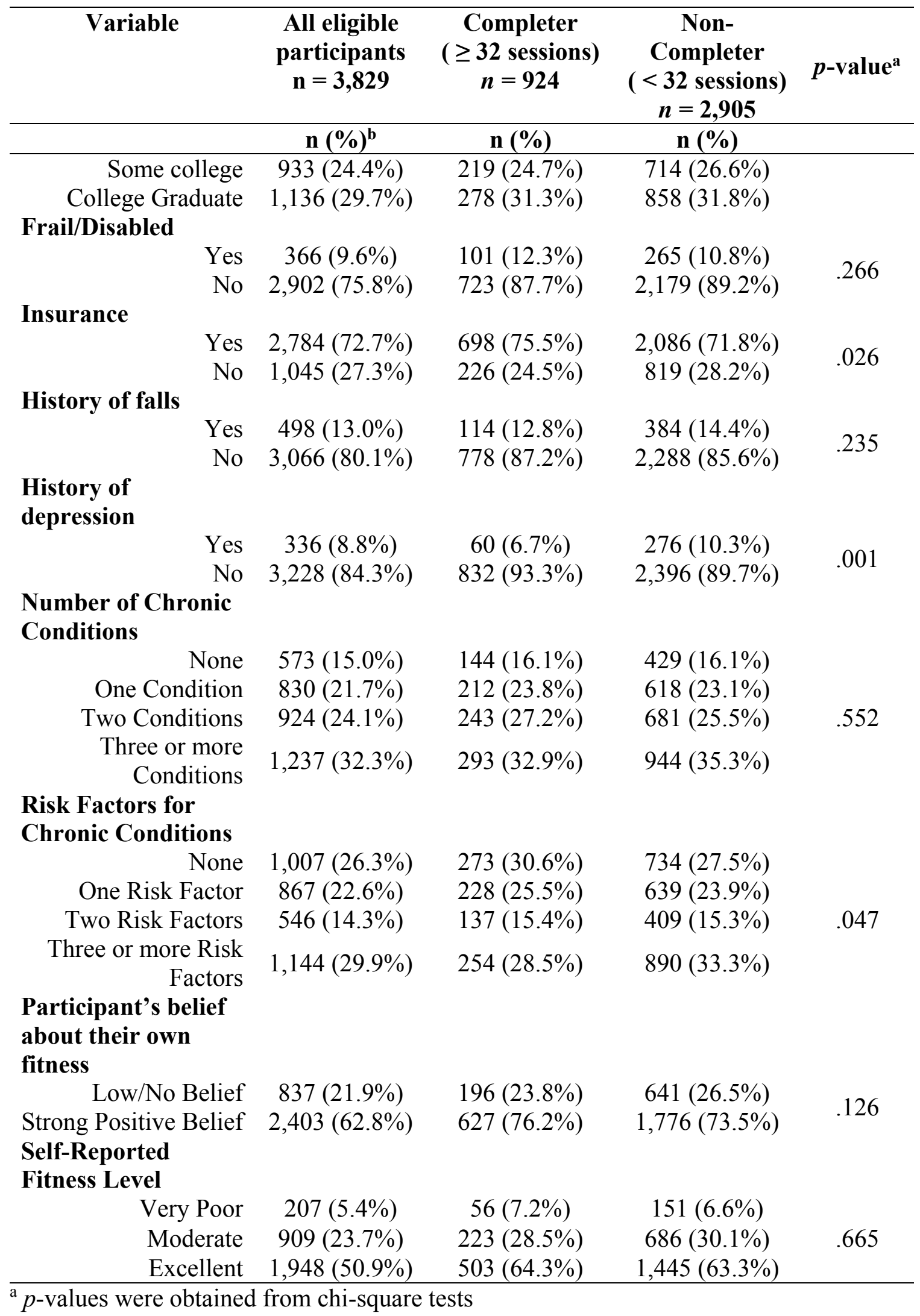


b \%age do not add upto $100 \%$ because of missing data

${ }^{\mathrm{c}}$ Within age group percentage is $20.0 \%$

${ }^{\mathrm{d}}$ Within age group percentage is $24.4 \%$

${ }^{\mathrm{e}}$ Within age group percentage is $27.3 \%$

Completer: HARC participant who attended 32 or more sessions within first 4-months following their start date 
Table 5.3 Logistic Regression Model Predicting Factors Influencing Completion of Older Men, $(\mathbf{n}=534)$

\begin{tabular}{|c|c|c|c|c|}
\hline \multirow[b]{2}{*}{ Predictor } & \multicolumn{4}{|c|}{$95 \%$ CI for OR } \\
\hline & $\begin{array}{l}\text { Odds Ratio } \\
\text { (OR) }\end{array}$ & $p$ & Lower & Upper \\
\hline \multicolumn{5}{|l|}{ County of Residence } \\
\hline Broward & 1.68 & 0.06 & 0.98 & 2.90 \\
\hline Miami-Dade & 0.975 & 0.94 & 0.50 & 1.89 \\
\hline Monroe & REF & & & \\
\hline \multicolumn{5}{|l|}{ Race/Ethnicity } \\
\hline Hispanic/ Latino & 0.73 & 0.55 & 0.26 & 2.05 \\
\hline $\begin{array}{r}\text { Haitian/ Other Non-Hispanic } \\
\text { Caribbean }\end{array}$ & 0.65 & 0.57 & 0.15 & 2.92 \\
\hline Black, non-Haitian & 0.41 & 0.02 & 0.18 & 0.91 \\
\hline Other & 2.05 & 0.16 & 0.73 & 5.72 \\
\hline White, non-Hispanic & REF & & & \\
\hline \multicolumn{5}{|l|}{ Primary Language } \\
\hline English & 1.84 & 0.51 & 0.29 & 11.42 \\
\hline Spanish & 4.16 & 0.16 & 0.55 & 31.13 \\
\hline Other & REF & & & \\
\hline \multicolumn{5}{|l|}{ Education } \\
\hline Less than High School & REF & & & \\
\hline High School & 1.13 & 0.76 & 0.52 & 2.47 \\
\hline Some college & 1.16 & 0.69 & 0.55 & 2.43 \\
\hline College Graduate & 1.65 & 0.14 & 0.84 & 3.25 \\
\hline \multicolumn{5}{|l|}{ Frail/Disabled } \\
\hline Yes & REF & & & \\
\hline No & 1.50 & 0.24 & 0.75 & 3.01 \\
\hline \multicolumn{5}{|l|}{$\begin{array}{l}\text { Number of Chronic } \\
\text { Conditions }\end{array}$} \\
\hline None & 0.71 & 0.32 & 0.36 & 1.39 \\
\hline One Condition & 1.09 & 0.74 & 0.64 & 1.86 \\
\hline Two Conditions & 0.57 & 0.05 & 0.31 & 1.00 \\
\hline Three or more Conditions & REF & & & \\
\hline \multicolumn{5}{|l|}{$\begin{array}{l}\text { Risk Factors for Chronic } \\
\text { Conditions }\end{array}$} \\
\hline None & 1.68 & 0.08 & 0.93 & 3.04 \\
\hline One Risk Factor & 1.81 & 0.03 & 1.05 & 3.13 \\
\hline Two Risk Factors & 1.62 & 0.11 & 0.90 & 2.93 \\
\hline Three or more Risk Factors & REF & & & \\
\hline
\end{tabular}


95\% CI for OR

\begin{tabular}{rlccc} 
Predictor & $\begin{array}{c}\text { Odds Ratio } \\
\text { (OR) }\end{array}$ & $\boldsymbol{p}$ & Lower & Upper \\
\hline $\begin{array}{r}\text { Participant's belief about } \\
\text { their own fitness }\end{array}$ & & & & \\
Low/No Belief & REF & & & \\
Strong Positive Belief & 1.41 & 0.13 & 0.89 & 2.22 \\
\hline $\begin{array}{rlll}\text { Self-Reported Fitness Level } \\
\text { Very Poor }\end{array}$ & REF & & & \\
Moderate & 0.72 & 0.50 & 0.28 & 1.86 \\
Excellent & 0.83 & 0.71 & 0.32 & 2.14 \\
\hline
\end{tabular}

REF: Reference Category

Completer: HARC participant who attended 32 or more sessions within first 4-months following their start date 
Table 5.4 Logistic Regression Model Predicting Factors Influencing Completion of Older Women, $(\mathbf{n}=\mathbf{1 , 5 7 8})$

95\% CI for OR

\begin{tabular}{|c|c|c|c|c|}
\hline \multirow{2}{*}{ Predictor } & \\
\hline & $\begin{array}{l}\text { Odds Ratio } \\
\text { (OR) }\end{array}$ & $p$ & Lower & Upper \\
\hline \multicolumn{5}{|l|}{ Age } \\
\hline $60-69$ years & REF & & & \\
\hline $70-79$ years & 1.33 & 0.11 & 0.94 & 1.88 \\
\hline$\geq 80$ years & 1.46 & 0.04 & 1.01 & 2.13 \\
\hline \multicolumn{5}{|l|}{ County of Residence } \\
\hline Broward & 1.33 & 0.18 & 0.88 & 2.03 \\
\hline Miami-Dade & 2.13 & 0.01 & 1.39 & 3.26 \\
\hline Monroe & REF & & & \\
\hline \multicolumn{5}{|l|}{ Race/Ethnicity } \\
\hline Hispanic/ Latino & 1.16 & 0.58 & 0.68 & 1.98 \\
\hline $\begin{array}{l}\text { Haitian/ Other Non-Hispanic } \\
\text { Caribbean }\end{array}$ & 0.78 & 0.44 & 0.43 & 1.44 \\
\hline Black, non-Haitian & 0.61 & 0.01 & 0.42 & 0.89 \\
\hline Other & 1.66 & 0.17 & 0.81 & 3.46 \\
\hline White, non-Hispanic & REF & & & \\
\hline \multicolumn{5}{|l|}{ Primary Language } \\
\hline English & REF & & & \\
\hline Spanish & 1.01 & 0.98 & 0.59 & 1.72 \\
\hline Other & 0.41 & 0.06 & 0.16 & 1.04 \\
\hline \multicolumn{5}{|l|}{ Annual Income } \\
\hline$<\$ 15,000$ & REF & & & \\
\hline$\geq \$ 15,000$ & 1.27 & 0.10 & 0.95 & 1.69 \\
\hline \multicolumn{5}{|l|}{ Education } \\
\hline Less than High School & REF & & & \\
\hline High School & 1.16 & 0.43 & 0.80 & 1.68 \\
\hline Some college & 1.11 & 0.61 & 0.74 & 1.65 \\
\hline College Graduate & 1.21 & 0.34 & 0.81 & 1.81 \\
\hline \multicolumn{5}{|l|}{ Frail/Disabled } \\
\hline Yes & REF & & & \\
\hline No & 0.92 & 0.69 & 0.61 & 1.39 \\
\hline \multicolumn{5}{|l|}{ Insurance } \\
\hline Yes & REF & & & \\
\hline No & 0.98 & 0.90 & 0.69 & 1.38 \\
\hline
\end{tabular}

Do you have history of falls

\begin{tabular}{lllll} 
Yes & REF & & & \\
No & 1.05 & 0.81 & 0.72 & 1.51 \\
\hline
\end{tabular}




\begin{tabular}{|c|c|c|c|c|}
\hline \multirow[b]{2}{*}{ Predictor } & \multicolumn{4}{|c|}{ 95\% CI for OR } \\
\hline & $\begin{array}{l}\text { Odds Ratio } \\
\text { (OR) }\end{array}$ & $p$ & Lower & Upper \\
\hline \multicolumn{5}{|l|}{$\begin{array}{l}\text { Do you have history of } \\
\text { depression }\end{array}$} \\
\hline Yes & REF & & & \\
\hline No & 1.62 & 0.03 & 1.04 & 2.51 \\
\hline \multicolumn{5}{|l|}{$\begin{array}{l}\text { Number of Chronic } \\
\text { Conditions }\end{array}$} \\
\hline None & REF & & & \\
\hline One Condition & 0.93 & 0.71 & 0.63 & 1.37 \\
\hline Two Conditions & 1.09 & 0.67 & 0.73 & 1.62 \\
\hline Three or more Conditions & 1.12 & 0.57 & 0.75 & 1.67 \\
\hline \multicolumn{5}{|l|}{$\begin{array}{l}\text { Risk Factors for Chronic } \\
\text { Conditions }\end{array}$} \\
\hline None & 1.63 & 0.01 & 1.13 & 2.34 \\
\hline One Risk Factor & 1.35 & 0.09 & 0.95 & 1.92 \\
\hline Two Risk Factors & 1.36 & 0.10 & 0.94 & 1.97 \\
\hline Three or more Risk Factors & REF & & & \\
\hline \multicolumn{5}{|l|}{ Self-Reported Fitness Level } \\
\hline Very Poor & 1.05 & 0.86 & 0.63 & 1.75 \\
\hline Moderate & 0.95 & 0.74 & 0.72 & 1.25 \\
\hline Excellent & REF & & & \\
\hline
\end{tabular}

REF: Reference Category

Completer: HARC participant who attended 32 or more sessions within first 4-months following their start date 
Figure 5.1 Exploratory Factor Analysis: Graphical Depiction of Two-Factor Solution for Correlated Fitness Questions

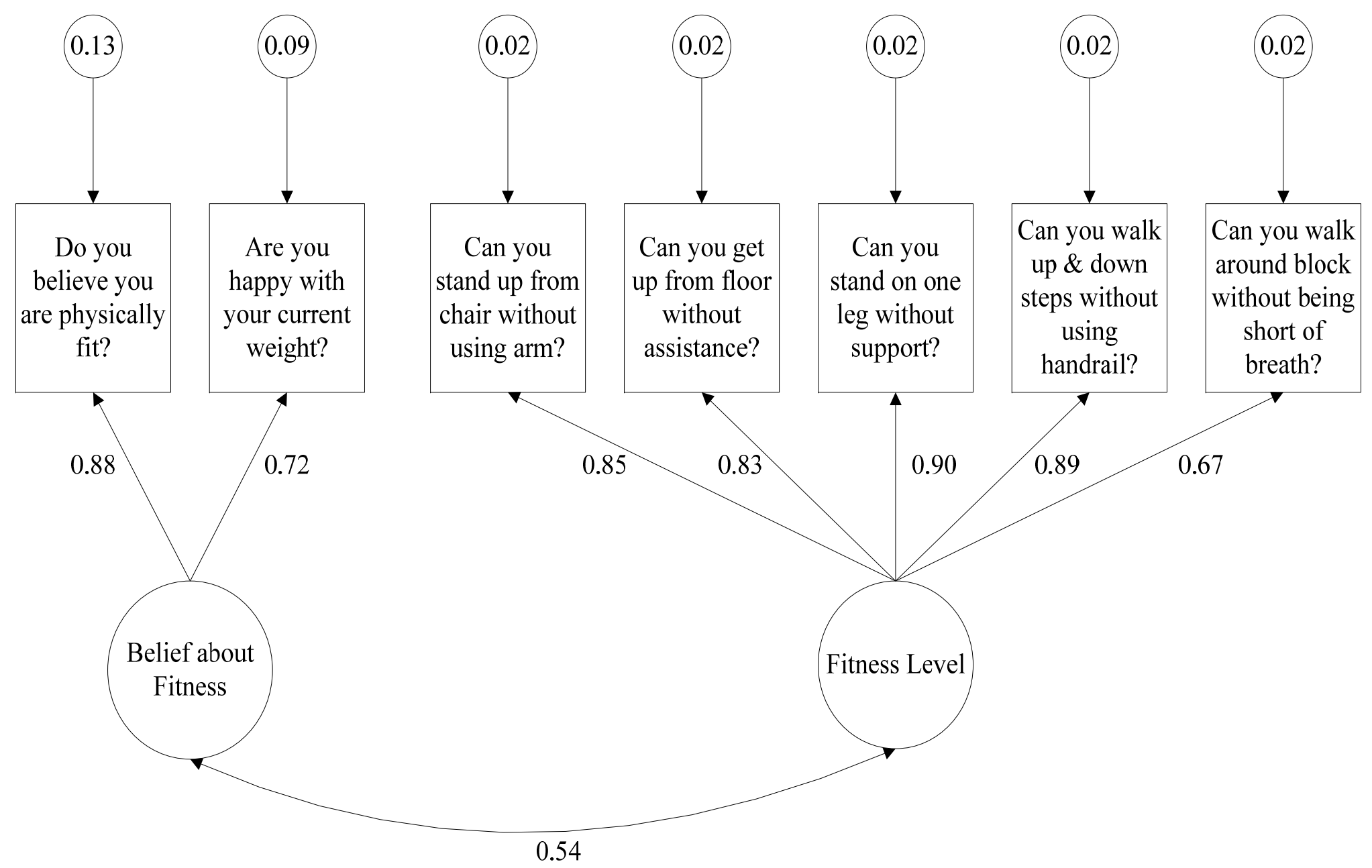




\section{References}

Ackermann, R. T., Williams, B., Nguyen, H. Q., Berke, E. M., Maciejewski, M. L., \& LoGerfo, J. P. (2008). Healthcare cost differences with participation in a community-based group physical activity benefit for medicare managed care health plan members. Journal of the American Geriatrics Society, 56(8), 1459-65. doi:10.1111/j.1532-5415.2008.01804.x

Allen, K., \& Morey, M. C. (2010). Physical Activity and Adherence. In Improving Patient Treatment Adherence. New York, NY: Springer.

Anderson, G. (2010). Chronic Care: Making the Case for Ongoing Care. Retrieved from http://www.rwjf.org/en/research-publications/find-rwjf-research/2010/01/chroniccare.html

Anderson, G., \& Horvath, J. (2004). The growing burden of chronic disease in America. Public Health Reports, 119(3), 263-70. doi:10.1016/j.phr.2004.04.005

Arya, A., Hindricks, G., Sommer, P., Huo, Y., Bollmann, A., Gaspar, T., ... Piorkowski, C. (2010). Long-term results and the predictors of outcome of catheter ablation of atrial fibrillation using steerable sheath catheter navigation after single procedure in 674 patients. Europace, 12(2), 173-80. doi:10.1093/europace/eup331

Belza, B., Shumway-Cook, A., Phelan, E., Williams, B., Snyder, S., \& LoGerfo, J. (2006). The Effects of a Community-Based Exercise Program on Function and Health in Older Adults: The EnhanceFitness Program. Journal of Applied Gerontology, 25(4), 291-306. doi:10.1177/0733464806290934

Belza, B., Susan, S., Meghan, T., \& James, L. (2010). From Research to Practice: EnhanceFitness, an Innovative Community-Based Senior Exercise Program. Topics in Geriatric Rehabilitation, 26(4), 299-309.

CDC. (2011). Physical Activity for Everyone: The Benefits of Physical Activity DNPAO | CDC. Retrieved September 10, 2014, from http://www.cdc.gov/physicalactivity/everyone/health/

CDC. (2013). Difficulty performing activities of daily living among Medicare beneficiaries, ages 65+: US, 1992-2010 (Source: MCBS). Retrieved September 19, 2014, from http://205.207.175.93/HDI/TableViewer/tableView.aspx?ReportId=522

CDC. (2014a). CDC - BRFSS - Behavioral Risk Factor Surveillance System. Retrieved February 10, 2014, from http://www.cdc.gov/brfss/index.htm

CDC. (2014b). CDC - Chronic Disease - Overview. Retrieved February 10, 2014, from http://www.cdc.gov/chronicdisease/overview/index.htm?s_cid=ostltsdyk_govd_203 
Ceballos, M. V. (2013). Machismo: A Cuturally Constructed Concept. Retrieved from http://scholarworks.calstate.edu/bitstream/handle/10211.3/105401/MiriamCEBALL OSpdfA.pdf?sequence $=1$

Crespo, C. J. (2000). Encouraging physical activity in minorities: eliminating disparities by 2010. The Physician and Sportsmedicine, 28(10), 36-51.

doi:10.3810/psm.2000.10.1230

Ehrlich-Jones, L., Lee, J., Semanik, P., Cox, C., Dunlop, D., \& Chang, R. (2011). Relationship between beliefs, motivation, and worries about physical activity and physical activity participation in persons with rheumatoid arthritis. Arthritis Care \& Research, 63(12), 1700-5. doi:10.1002/acr.20616

Findorff, M. J., Wyman, J. F., \& Gross, C. R. (2009). Predictors of long-term exercise adherence in a community-based sample of older women. Journal of Women's Health, 18(11), 1769-76. doi:10.1089/jwh.2008.1265

Garrett, N., \& Martini, E. M. (2007). The boomers are coming: a total cost of care model of the impact of population aging on the cost of chronic conditions in the United States. Disease Management, 10(2), 51-60. doi:10.1089/dis.2006.630

Hawley-Hague, H., Horne, M., Campbell, M., Demack, S., Skelton, D., \& Todd, C. (2014). Multiple Levels of Influence on Older Adults Attendance and Adherence to Community Exercise Classes. Gerontologist, 54(4), 599-610. doi:10.1093/geront/gnt075

Hosmer, D., \& Lemeshow, S. (2004). Applied Logistic Regression (2nd ed.). Hoboken, NJ: John Wiley \& Sons.

IBM Corp. (2012). IBM SPSS Statistics for Windows. Armonk, NY: IBM Corp.

Jones, C. J., Rikli, R. E., \& Beam, W. C. (1999). A 30-s chair-stand test as a measure of lower body strength in community-residing older adults. Research Quarterly for Exercise and Sport, 70(2), 113-9. doi:10.1080/02701367.1999.10608028

King, A. C., \& King, D. K. (2010). Physical Activity for an Aging Population. Public Health Reviews, 32, 401-426.

Lin, E., Katon, W., Von Korff, M., Rutter, C., Simon, G., Oliver, M., ... Young, B. (2004). Relationship of depression and diabetes self-care, medication adherence, and preventive care. Diabetes Care, 27(9), 2154-60.

Moore-Harrison, T. L., Johnson, M. A., Quinn, M. E., \& Cress, M. E. (2009). An evidence-based exercise program implemented in congregate-meal sites. Journal of Physical Activity \& Health, 6(2), 247-51. 
Muthén, L. K., \& Muthén, B. O. (2010). Mplus User's Guide. Sixth Edition. Los Angeles, CA: Muthén \& Muthén.

National Center for Health Statistics. (2014). Health, United States, 2013 (p. 511). Retrieved from http://www.cdc.gov/nchs/data/hus/hus 13.pdf

Nies, M. A., \& McEwen, M. (2010). Community/Public Health Nursing: Promoting the Health of Populations (5th ed.). St. Louis, MO: Elsevier Saunders.

Ostlin, P., Eckermann, E., Mishra, U. S., Nkowane, M., \& Wallstam, E. (2006). Gender and health promotion: a multisectoral policy approach. Health Promotion International, 21(1 Suppl), 25-35. doi:10.1093/heapro/dal048

Page, T. F., Batra, A., Ghouse, M. M., \& Palmer, R. C. (2014). Implementation Cost Analysis of a Community-Based Exercise Program for Seniors in South Florida. Health Promotion Practice, 15(4), 585-591. doi:10.1177/1524839913518221

Page, T. F., Batra, A., \& Palmer, R. (2012). Cost analysis of a community-based fall prevention program being delivered in South Florida. Family \& Community Health, 35(3), 264-70. doi:10.1097/FCH.0b013e318250be2e

Persson, E., Lexell, J., Rivano-Fischer, M., \& Eklund, M. (2014). Occupational performance and factors associated with outcomes in patients participating in a musculoskeletal pain rehabilitation programme. Journal of Rehabilitation Medicine, 46(6), 546-52. doi:10.2340/16501977-1810

Rikli, R. E., \& Jones, C. J. (1999). Development and Validation of a Functional Fitness Test for Community-Residing Older Adults. Journal of Aging and Physical Activity, 7, 129-161.

Sarkisian, C. A., Prohaska, T. R., Wong, M. D., Hirsch, S., \& Mangione, C. M. (2005). The relationship between expectations for aging and physical activity among older adults. Journal of General Internal Medicine, 20(10), 911-915. doi:10.1111/j.15251497.2005.0204.x

Schneider, K., O'Donnell, B., \& Dean, D. (2009). Prevalence of multiple chronic conditions in the United States' Medicare population. Health and Quality of Life Outcomes, 7, 82. doi:10.1186/1477-7525-7-82

Senior Services. (2013). Enhance Fitness. Retrieved October 02, 2014, from http://www.projectenhance.org/EnhanceFitness.aspx

Sugihara, N., Watanabe, M., Tomioka, M., Braun, K. L., \& Pang, L. (2011). Cost-benefit estimates of an elderly exercise program on Kaua'i. Hawaii Medical Journal, 70(6), $116-20$. 
Tomioka, M., Sugihara, N., \& Braun, K. L. (2012). Replicating the EnhanceFitness physical activity program in Hawai'i's multicultural population, 2007-2010. Preventing Chronic Disease, 9, E74. Retrieved from http://www.cdc.gov/pcd/issues/2012/11_0155.htm

Wallace, J. I., Buchner, D. M., Grothaus, L., Leveille, S., Tyll, L., LaCroix, A. Z., \& Wagner, E. H. (1998). Implementation and effectiveness of a community-based health promotion program for older adults. The Journals of Gerontology. Series A, Biological Sciences and Medical Sciences, 53(4), M301-6.

White, J. L., Ransdell, L. B., Vener, J., \& Flohr, J. A. (2005). Factors related to physical activity adherence in women: review and suggestions for future research. Women \& Health, 4l(4), 123-48. doi:10.1300/J013v41n04_07

Wong, F. L. (2008). The Manual of Intervention Strategies to Increase Mammography Rates (p. 154). Retrieved from http://www.cdc.gov/cancer/nbccedp/pdf/prumanual.pdf 


\section{СH 6}

\section{Conclusion}

The role of physical activity in combating obesity, chronic conditions, and associated comorbidities including heart diseases, hypertension, stroke, diabetes mellitus, arthritis, some cancers, and osteoporosis etcetera is well known (CDC, 2011c; Dogra \& Stathokostas, 2012; USDHHS: Healthy People, 2014). Further, regular exercise reduces the risk of depression and improves the overall psychological state of individuals (CDC, 2014c). Despite the evidence of benefits from physical activity, over half of Americans were reported to be inactive in 2012 (CDC, 2014a; USDHHS: Healthy People, 2014). The rates of inactivity are highest among older adults (A. C. King \& King, 2010; White et al., 2005). Data from the National Center for Health Statistics revealed that in 2012, only $37.5 \%$ of older adults aged 60 years and older met recommended aerobic physical activity levels and $16.1 \%$ met the muscle-strengthening guidelines to work all major muscle groups for two or more days a week (National Center for Health Statistics, 2014a).

Physical activity has been identified as one of three key modifiable behaviors that are associated with chronic conditions (AHRQ, 2002; USDHHS: Healthy People, 2014). Approximately $92 \%$ of older adults suffer from at least one chronic condition, and approximately $77 \%$ of those 65 years and above have at least two chronic conditions (National Council on Aging, 2014). Chronic conditions affect overall quality of life of older adults and are associated with higher mortality, increased disability, and functional decline over time (CDC, 2013a; Maaten et al., 2008; National Council on Aging, 2014). Structured programs could help combat the issue of physical inactivity among older 
adults (Belza et al., 2006) but 50\% of those who start participating in a program dropout within first few weeks, preventing them from gaining any health benefits achieved (Allen \& Morey, 2010; White et al., 2005).

Florida has the highest concentration (18\%) of older adults in the United States (Florida Department of Health, 2014b; U.S. Census Bureau, 2014; USDHHS, 2014a). The Health Foundation of South Florida recognized the needs of this population and established the Healthy Aging Regional Collaborative (HARC) in 2008 to reduce/eliminate the burden of preventable diseases. HARC is a five-year initiative for delivering evidence-based health promotion programs in three southeast counties of South Florida: Miami-Dade, Broward, and Monroe. This dissertation focused on EnhanceFitness (EF), one of several programs offered by HARC. EF, formerly known as 'Lifetime Fitness Program', is an evidence-based, low-cost, community-based group exercise program for older adults (Belza et al., 2006, 2010; Page et al., 2014; Senior Services, 2013; Wallace et al., 1998). It consisted of a one-hour session held three times a week and focuses on helping older adults at all levels of fitness become more active, energized, and empowered to sustain independent lives (Belza et al., 2006, 2010; MooreHarrison et al., 2009; Wallace et al., 1998). The objectives of the current study were to determine (1) short-term effectiveness of EF: Baseline to 4-months (2) long-term effectiveness of EF: Baseline to 4-, 8-, and 12-months (3) factors that are associated with program completion. In addition, we evaluated the impact of completion on EF effectiveness. 


\section{Short-term EF effectiveness results: Baseline to 4-months}

Of 1,175 eligible participants who had their 4-months follow-up fitness check done between 12 to 20 weeks, $586(49.9 \%)$ completed the program by attending 32 or more of 48 given sessions within 4-months from their first date of attendance. A paired sample t-test revealed a significant mean increase of 3.4 in the number of chair stands performed in 30-seconds for completers and 1.5 for non-completers $(p<0.001)$. The change in mean number of arm curls performed in 30-seconds was 4.1 for completers, and for non-completers it was $2.1(p<0.001)$. After participation in EF, completers took an average of 1.0 seconds less time to complete an eight-foot up-and-go activity while non-completers took 0.6 seconds less $(p<0.001)$. Overall, more participants reported to feel "Good", "Very good", or "Excellent" about their health after participating in EF for 4-months $(85.5 \%$ to $89.9 \%, p<0.001)$. A significant decrease in the number of falls from 15.2 to 11.4 at 4 -months was reported among completers $(p=0.05)$. Long-term EF effectiveness results: Baseline to 4-, 8-, and 12-months

Participants showed significant mean improvement of 1.8 in number of chair stands performed in 30 seconds from baseline to 12-months. The number of arm curls performed in 30 seconds improved on an average by 2.1 at 12 -months $(p<0.001)$. At 12 months, participants improved their eight-foot up-and-go time by decreasing, on average, by 0.4 seconds $(\mathrm{p}<0.001)$.

\section{Factors Associated with Program Completion}

For men, race/ethnicity, and having risk factors for chronic conditions were significantly associated with program completion in logistic regression analysis. For 
women age, County of residence, race/ethnicity, history of depression, and having risk factors for chronic conditions were significantly associated with program completion. The current study is the first to our knowledge to examine the effectiveness of EF in terms of completion status, determine long-term effectiveness of EF, and identify factors of completion. Results provide evidence in support of the effective translation of EF into community-based settings. Other communities that identify a need for physical activity programs for older adults to improve their quality of life and to reduce the burden on the health care system could replicate the model used by HARC. Future researchers can use the results and suggestions given in this study when designing interventions aimed to increase physical activity levels among older adults. Low adherence rates have been reported in previous studies as well as in the current study (Allen \& Morey, 2010; White et al., 2005). Discussing, identifying, and resolving solvable issues related with compliance and motivating participants to continue participation, and reminding the benefits of program participation could help combat this problem of low adherence rates. Further, when designing interventions, consideration should be given to the target population including race/ethnicity and gender of the participants. Members of certain races/ ethnicity such as African-American participants in the current study were less likely to complete the program. Removing barriers such as perceived discrimination, enhancing social support, tailoring the interventions to the needs of the specific population, and recruiting culturally competent instructors might improve adherence rates of this specific population (Allen \& Morey, 2010; A. C. King \& King, 2010). Low percentage of men participants in the EF program also warrants attention. Identified factors for low men participation includes more female participants in classes, machismo 
or cultural beliefs, and perception of exercise programs as feminine. Addressing these concerns by having separate classes for men, having male instructor, and performing exercises considered masculine could increase rates of participation for men.

Further, all participants showed significant improvement after participating in EF program for up to 12-months. However, those who attended EF sessions continuously and achieved full dose improved the most on all measures establishing evidence in support that intermittent participation is valuable, but continuous participation is required to attain maximum health benefits.

The potential exists to develop policies that enforce engaging and increasing physical activity levels among older adults. Chronic conditions are correlated with aging (G Anderson, 2010; CDC, 2014b; A. C. King \& King, 2010) and not only place burden on the individual suffering, but also on already fragmented health care system.(Gerard Anderson \& Horvath, 2004; Garrett \& Martini, 2007; A. C. King \& King, 2010; Schneider et al., 2009) An increase in the number of chronic conditions results in an increase in utilization of health care services.(G Anderson, 2010; Gerard Anderson \& Horvath, 2004; CDC, 2014b; Garrett \& Martini, 2007; Schneider et al., 2009)· According to the Robert Wood Johnson Foundations' 2010 report, $84 \%$ of all health care spending was for the $50 \%$ of the population who have one or more chronic medical conditions (G Anderson, 2010; CDC, 2014b). Schneider et al. (2009) reported that the annual Medicare payment amounts for a beneficiary with one chronic condition is $\$ 7,172$. This amount increases to $\$ 14,931$ for those with two conditions and $\$ 32,498$ for those with three or more conditions (Schneider et al., 2009). Physical activity programs such as EF that are found to be effective can help combat the issue of chronic conditions by reducing the 
chances of developing risk factors. Not only do EF participants show significant improvement in physical activity levels, EF has the potential to reduce healthcare costs among those who complete the recommended number of sessions. Ackermann et al. (2008) found that EF users spent $\$ 1,929$ less on health care annually. Page et al. (2014) estimated the monthly cost of implementing EF in community settings to be $\$ 873$ per month for agencies who had been offering the program for at least one year. Assuming 15 completers in each 4-month time period yields a per completer cost of $\$ 232.80$, (Page et al., 2014) well below the cost-savings documented in Ackermann et al. (Ackermann et al., 2008).

Since EF is found to be effective in improving the health of participants and have the potential to reduce healthcare costs, there should be policies supporting the implementation of EF on a continued basis. In addition, Medicare reimbursement should be provided for agencies that offer EF, as has been done with other programs such as diabetes self-management training program targeting older adults. 


\section{References}

Ackermann, R. T., Williams, B., Nguyen, H. Q., Berke, E. M., Maciejewski, M. L., \& LoGerfo, J. P. (2008). Healthcare cost differences with participation in a community-based group physical activity benefit for medicare managed care health plan members. Journal of the American Geriatrics Society, 56(8), 1459-65. doi:10.1111/j.1532-5415.2008.01804.x

AHRQ. (2002). Preventing Disability in the Elderly With Chronic Disease. Retrieved September 06, 2014, from http://www.ahrq.gov/legacy/research/elderdis.htm

Allen, K., \& Morey, M. C. (2010). Physical Activity and Adherence. In Improving Patient Treatment Adherence. New York, NY: Springer.

Anderson, G. (2010). Chronic Care: Making the Case for Ongoing Care. Retrieved from http://www.rwjf.org/en/research-publications/find-rwjf-research/2010/01/chroniccare.html

Anderson, G., \& Horvath, J. (2004). The growing burden of chronic disease in America. Public Health Reports, 119(3), 263-70. doi:10.1016/j.phr.2004.04.005

Belza, B., Shumway-Cook, A., Phelan, E., Williams, B., Snyder, S., \& LoGerfo, J. (2006). The Effects of a Community-Based Exercise Program on Function and Health in Older Adults: The EnhanceFitness Program. Journal of Applied Gerontology, 25(4), 291-306. doi:10.1177/0733464806290934

Belza, B., Susan, S., Meghan, T., \& James, L. (2010). From Research to Practice: EnhanceFitness, an Innovative Community-Based Senior Exercise Program. Topics in Geriatric Rehabilitation, 26(4), 299-309.

CDC. (2011). How much physical activity do older adults need? Retrieved September 09, 2014, from http://www.cdc.gov/physicalactivity/everyone/guidelines/olderadults.html

CDC. (2013). Difficulty performing activities of daily living among Medicare beneficiaries, ages 65+: US, 1992-2010 (Source: MCBS). Retrieved September 19, 2014, from http://205.207.175.93/HDI/TableViewer/tableView.aspx?ReportId=522

CDC. (2014a). CDC - BRFSS - Behavioral Risk Factor Surveillance System. Retrieved February 10, 2014, from http://www.cdc.gov/brfss/index.htm

CDC. (2014b). CDC - Chronic Disease - Overview. Retrieved February 10, 2014, from http://www.cdc.gov/chronicdisease/overview/index.htm?s_cid=ostltsdyk_govd_203 
CDC. (2014c). Physical Activity. Retrieved June 10, 2014, from http://www.cdc.gov/physicalactivity/index.html

Dogra, S., \& Stathokostas, L. (2012). Sedentary behavior and physical activity are independent predictors of successful aging in middle-aged and older adults. Journal of Aging Research, 2012. Retrieved from http://www.hindawi.com/journals/jar/2012/190654/

Florida Department of Health. (2014). Florida's Population. Retrieved October 02, 2014, from http://www.floridacharts.com/charts/AtlasIntro.aspx?ID=3

Garrett, N., \& Martini, E. M. (2007). The boomers are coming: a total cost of care model of the impact of population aging on the cost of chronic conditions in the United States. Disease Management, 10(2), 51-60. doi:10.1089/dis.2006.630

King, A. C., \& King, D. K. (2010). Physical Activity for an Aging Population. Public Health Reviews, 32, 401-426.

Maaten, S., Kephart, G., Kirkland, S., \& Andreou, P. (2008). Chronic disease risk factors associated with health service use in the elderly. BMC Health Services Research, 8 , 237-245. doi:10.1186/1472-6963-8-237

Moore-Harrison, T. L., Johnson, M. A., Quinn, M. E., \& Cress, M. E. (2009). An evidence-based exercise program implemented in congregate-meal sites. Journal of Physical Activity \& Health, 6(2), 247-51.

National Center for Health Statistics. (2014). FastStats - Homepage. Retrieved September 24, 2014, from http://www.cdc.gov/nchs/fastats/

National Council on Aging. (2014). Chronic Disease Self-Management: Fact Sheet. Retrieved October 03, 2014, from http://www.ahrq.gov/legacy/research/elderdis.htm

Page, T. F., Batra, A., Ghouse, M. M., \& Palmer, R. C. (2014). Implementation Cost Analysis of a Community-Based Exercise Program for Seniors in South Florida. Health Promotion Practice, 15(4), 585-591. doi:10.1177/1524839913518221

Schneider, K., O'Donnell, B., \& Dean, D. (2009). Prevalence of multiple chronic conditions in the United States' Medicare population. Health and Quality of Life Outcomes, 7, 82. doi:10.1186/1477-7525-7-82

Senior Services. (2013). Enhance Fitness. Retrieved October 02, 2014, from http://www.projectenhance.org/EnhanceFitness.aspx

U.S. Census Bureau. (2014). Sixty-Five Plus in the United States. Retrieved September 09, 2014, from https://www.census.gov/population/socdemo/statbriefs/agebrief.html 
USDHHS. (2014). Profile of Older Americans: 2013. Retrieved from http://www.aoa.gov/Aging_Statistics/Profile/Index.aspx

USDHHS: Healthy People. (2014). Older Adults - Healthy People 2020. Washington DC. Retrieved from http://www.healthypeople.gov/2020/topicsobjectives2020/overview.aspx?topicid=3 1

Wallace, J. I., Buchner, D. M., Grothaus, L., Leveille, S., Tyll, L., LaCroix, A. Z., \& Wagner, E. H. (1998). Implementation and effectiveness of a community-based health promotion program for older adults. The Journals of Gerontology. Series A, Biological Sciences and Medical Sciences, 53(4), M301-6.

White, J. L., Ransdell, L. B., Vener, J., \& Flohr, J. A. (2005). Factors related to physical activity adherence in women: review and suggestions for future research. Women \& Health, 41(4), 123-48. doi:10.1300/J013v41n04_07 
VITA

\section{ANAMICA BATRA}

2002-2006

Baba Farid University, Punjab, India Bachelor of Dental Surgery

2006

Best scientific paper presentation at Dental Conference, India

2008-2009

Florida International University, Miami, Florida

Master of Public Health

Research Assistant

Department of Biology

Florida International University

Miami, Florida

2011-Present

Florida International University, Miami, Florida

Doctoral Candidate

Research Associate

Department of Public Health

Florida International University

Miami, Florida

2011

Masters Student Award (HM) funded by the Retirement Research Foundation

2013

2014

University Graduate School Provost Award (Nominee)

Dissertation Year Fellowship awarded by University Graduate School, FIU

2014

Susan B. Anthony Aetna Award for Excellence in Research on Older Women

\section{PUBLICATIONS AND PRESENTATIONS}

Palmer, R. C., Samson R., S., Batra, A., Triantis, M., Mullan, I.D. (2011). Breast Cancer Screening Practices of Safety Net Clinics: Results of a Needs Assessment Study. BMC

Women's Health. 11(1): 9-16.

Batra, A., Melchior, M., Seff, L., Palmer, R.C. Evaluation of a Community-Based Falls Prevention Program in South Florida. Presented at: American Public Health Association 139th Annual Meeting and Expo; 2011 Oct. 29-Nov. 2; Washington, D.C.

Batra, A., Melchior, M., Seff, L., Palmer, R.C. Effectiveness of the Enhance Fitness Program in the Healthy Aging Regional Collaborative of South Florida. Presented at: 
American Public Health Association 139th Annual Meeting and Expo; 2011 Oct. 29Nov. 2; Washington, D.C.

Batra, A., Melchior, M., Seff, L., Newman, F., Palmer, R.C. (2012). Evaluation of a Community-Based Falls Prevention Program in South Florida. Preventing Chronic Disease. 9:110057. DOI: http://dx.doi.org/10.5888/pcd9.110057

Batra, A., Melchior, M., Seff, L., Palmer, R.C. Demographic Factors Influencing the Completion of a Falls Prevention Program. Presented at American Public Health Association 140th Annual Meeting and Expo; 2012 Oct. 27-31; San Francisco, CA.

Shedadeh, N., McCoy, H. V., Rubens, M., Batra, A., Renfrew, R., Winter, K. (2012). The Impact of Ethnic Identity on Changes in High Risk HIV Behaviors in Sexually Active Migrant Workers. Journal of Immigrant and Minority Health. 14(1): 100-106.

Page, T.F., Batra, A., Palmer, R.C. (2012). Cost Analysis of a Community-Based Fall Prevention Program Being Delivered in South Florida. Fam Community Health. 35(3):264-270.

Batra, A., Page, T.F., Melchior, M., Seff, L., Vieira, E.R., Palmer, R.C. (2013). Factors that influence the completion of falls prevention program. Health Education Research. 28(6):1067-1079.

Batra, A., Seff, L., Palmer, R.C. Effects of a community-based physical activity program in older adults: Analysis of Longitudinal Data from Healthy Aging Regional Collaborative, South Florida. Presented at American Public Health Association 141st Annual Meeting and Expo; 2013 Nov. 2-6; Boston, MA

Batra, A. Evaluation of a Community-Based Falls Prevention Program in South Florida. Presented at FIU 2013 Scholarly Forum; 2013 March 25-29; Miami, FL.

Page, T.F., Batra, A., Ghouse, M., Palmer, R.C. (2014). Implementation Cost Analysis of a Community-Based Exercise Program for Seniors in South Florida. Health Promotion Practice. DOI: 10.1177/1524839913518221

Batra, A. (2014). Using LinkedIn. APHA Student Assembly Winter 2014 Newsletter.

Batra, A., Bhatt, C., Anderson, C.L., Palmer, R.C. 'EnhanceFitness' an Evidence-Based Physical Activity. Program: Factors Influencing the Participation of Older Women. Presented at APHA 142nd Annual Meeting \& Expo; Nov. 15-19, 2014; New Orleans, LA

Batra, A., Anderson, C.L. Bhatt, C., Palmer, R.C. Translating Evidence-Based Programs into Community-Based Settings: The Role of Fidelity Observations. Presented at APHA 142nd Annual Meeting and Expo; Nov. 15-19, 2014; New Orleans, LA 